UNIVERSIDADE DE SÃO PAULO

FACULDADE DE FILOSOFIA, LETRAS E CIÊNCIAS HUMANAS

DEPARTAMENTO DE FILOSOFIA

PROGRAMA DE PÓS-GRADUAÇÃO

Explorações Filosóficas da Não-Localidade em Física Quântica:

Desdobramentos do argumento de EPR

Walquiria Godoy 
UNIVERSIDADE DE SÃO PAULO

FACULDADE DE FILOSOFIA, LETRAS E CIÊNCIAS HUMANAS

DEPARTAMENTO DE FILOSOFIA

PROGRAMA DE PÓS-GRADUAÇÃO

\section{Explorações Filosóficas da Não-Localidade em Física Quântica: Desdobramentos do argumento de EPR}

Walquiria Godoy

Dissertação apresentada no Programa de PósGraduação em Filosofia do Departamento de Filosofia da Faculdade de Filosofia, Letras e Ciências Humanas da Universidade de São Paulo, para obtenção do título de Mestre em Filosofia.

Área de Concentração: Filosofia da Ciência

Orientador: Osvaldo Frota Pessoa Junior

São Paulo

2018 
Autorizo a reprodução e divulgação total ou parcial deste trabalho, por qualquer meio convencional ou eletrônico, para fins de estudo e pesquisa, desde que citada a fonte.

Catalogação na Publicação

Serviço de Biblioteca e Documentação

Faculdade de Filosofia, Letras e Ciências Humanas da Universidade de São Paulo

Godoy, Walquiria

GG589e Explorações filosóficas da não-localidade em física quântica:desdobramentos/Walquiria Godoy; orientador Osvaldo Pessoa Jr.. - São Paulo, 2018. $89 \mathrm{f}$.

Dissertação (Mestrado) - Faculdade de Filosofia, Letras e Ciências Humanas da Universidade de São Paulo. Departamento de Filosofia. Área de concentração: Filosofia.

1. Filosofia da Ciência. 2. Física Quântica. I. Pessoa Jr., Osvaldo, orient. II. Título. 
Dedico:

A minha mãe Zélia e ao meu pai Edilson por me proporcionarem uma educação que formou, com êxito, meu ímpeto em construir o meu futuro.

Aos meus familiares que me ensinaram a viver com alegria o presente.

Aos meus muitos amigos incentivadores e inspiradores que tornaram a busca pelo conhecimento o sentido da minha vida.

Agradeço:

Ao professor Osvaldo pela excelentíssima orientação que deu origem a uma cordial amizade e profunda estima de minha parte. Um professor incrível e ser humano admirável.

Aos membros da banca, Olival Freire Júnior, Reinaldo Melo e Souza, e Patrícia Kauark pela presença, disposição e pelos enriquecedores debates e orientações.

Ao professor Silvio Seno Chibeni pelos cuidadosos e valiosos apontamentos e pelas horas a mim dedicadas, que muito contribuíram para a estruturação desta obra e para uma melhor compreensão da problemática filosófica envolvida. 


\section{Resumo}

GODOY, W. Explorações Filosóficas da Não-Localidade em Física Quântica: Desdobramentos do argumento de EPR. 2018. Dissertação (mestrado) - Faculdade de Filosofia, Letras e Ciências Humanas, Universidade de São Paulo, São Paulo, 2018.

Este é um estudo filosófico e histórico do argumento de EPR (1935), que defende que a mecânica quântica é incompleta, e tem sido alvo de intensos debates e críticas desde então. Examino a estrutura lógica do argumento, seguindo comentadores como McGrath, Chibeni e Wessels, e acompanho os primeiros debates envolvendo Einstein, Bohr, Schrödinger, Furry e Bohm. Estudando as primeiras tentativas de testar experimentalmente os chamados estados "entrelaçados", aponto para as semelhanças entre a análise feita por Bohm \& Aharonov (1957) do experimento de Wu \& Shaknov (1950), para a polarização de raios gama, e a desigualdade de Bell (1964). O debate sobre incompletude se transformou com o trabalho de Bell, que obteve um dilema segundo o qual deve-se abandonar ou o realismo (uma tese filosófica) ou a localidade (uma tese física), ou seja, descartar teorias realistas locais. A partir deste dilema, e de um dilema derivado do trabalho de EPR, derivo um argumento a favor da nãolocalidade independente da tese do realismo. 


\begin{abstract}
GODOY, W. Philosophical Explorations of Non-Locality in Quantum Physics: Developments of the EPR Argument. 2018. Dissertation (Master's) - Faculdade de Filosofia, Letras e Ciências Humanas, Universidade de São Paulo, São Paulo, 2018.
\end{abstract}

This is a philosophical and historical study of the EPR argument (1935), that concluded that quantum mechanics is incomplete, and which has been the focus of intense debate and criticisms since then. I examine the logical structure of the argument, following commentators such as McGrath, Chibeni, and Wessels, and follow the first debates involving Einstein, Bohr, Schrödinger, Furry, and Bohm. Studying the first attempts to experimentally test the so-called "entangled" states, I point out the similarities between the analysis done by Bohm \& Aharonov (1957) of the experiment of Wu \& Shaknov (1950), involving gamma ray polarization, and the Bell inequality (1964). The debate about incompleteness was transformed by the work of Bell, Who obtained a dilemma according to which one should abandon either realism (a philosophical thesis) or locality (a physical thesis), i.e. discard local realist theories. From this dilemma, and a dilemma obtained from the EPR paper, I derive an argument in favor of non-locality that is independent of the thesis of realism. 


\section{Sumário}

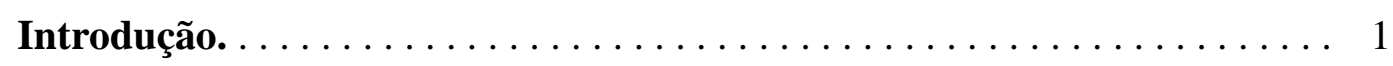

Capítulo I - Debates sobre o Argumento de EPR

1. A Mecânica Quântica ...................... 3

2. O Argumento de EPR ................... 6

3. Os Pilares do Argumento ................. 9

4. O Princípio de Incerteza no Argumento. . . . . . . . . . 11

5. A Crítica de Chibeni ..................... 13

6. A Análise de McGrath. . . . . . . . . . . . . . 17

7. A Análise de Wessels. ..................... 21

8. A Resposta de Bohr. ...................... 28

9. A Versão de Bohm. . . . . . . . . . . . . . . . . 35

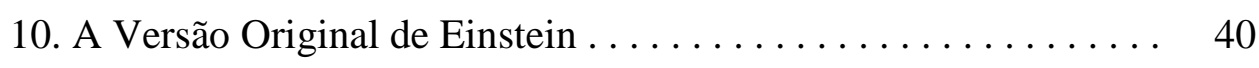

11. O Realismo de Einstein. .................. 43

Capítulo II - A Teoria Quântica de Polarização como Forma de Testar o Argumento

1. A Proposta de Furry e Schrödinger. . . . . . . . . . . . . . . 49

2. A Teoria Quântica de Polarização. ............... 53

3. Como Testar o Argumento de EPR............... 57

Capítulo III - O Teorema de Bell e a Não-Localidade

1. Teorias de Variáveis Ocultas e Provas de Impossibilidade. . . . . 64

2. A TVO Contextual de David Bohm............... 65

3. O Teorema de Bell .................. 70

4. O Dilema de Bell. . . . . . . . . . . . . . . . 75

5. Argumento da Não-Localidade e o Dilema do Instrumentalista. . 77

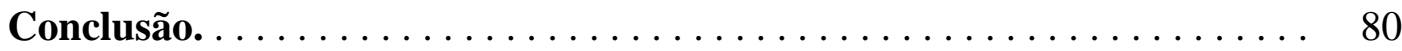

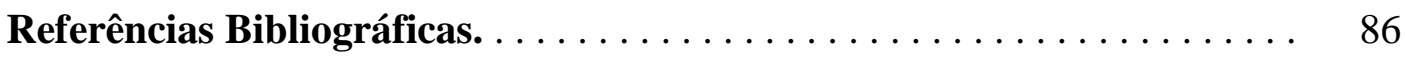




\section{Introdução}

Um par de partículas quânticas interagentes, quando separadas espacialmente, mantém um tipo de correlação expressa na forma do estado singleto da função de onda do sistema global. Se a primeira partícula é submetida à medição de uma grandeza física, por exemplo, a posição ou o momento, e resulta em um valor determinado, o estado da partícula passa a ser descrito por uma autofunção correspondente a este autovalor. Na situação em que essa correlação é negativa, se a segunda partícula for submetida à medição da mesma grandeza, fornecerá sempre o resultado oposto à primeira partícula. Entretanto, a mecânica quântica não pode prever qual será o resultado das medições antes de fazer pelo menos uma delas.

O formalismo da mecânica quântica descreve a situação ditando que a função de onda do sistema global sofre uma "redução" após a primeira medição. Se uma realidade for atribuída para esta função de onda, então ter-se-ia que admitir que a redução descreve um colapso aleatório não-local. A segunda partícula sofreria um colapso para o autoestado oposto ao da primeira partícula, aparentemente sem estar sujeita a medições.

A coisa se complica ainda mais em uma situação que envolve a possibilidade de medição de duas grandezas quânticas incompatíveis (isto é, representadas por operadores não comutativos) na primeira partícula. O princípio de incerteza quântico afirma que não é possível determinar com precisão exata os valores de duas grandezas cujos operadores não comutam, entretanto, em um cenário contrafactual podemos escolher medir, na primeira partícula, uma determinada grandeza, e em um outro cenário contrafactual poderíamos medir o correspondente observável incompatível. Porém, tal escolha não deveria afetar instantaneamente a realidade em um local distante, como a Lua. Poderíamos assim inferir, por meio da correlação da função de onda global, a existência de dois valores bem definidos para duas grandezas incompatíveis para a segunda partícula, sem provocar qualquer distúrbio de medição na segunda partícula.

As implicações científicas e filosóficas acerca desta problemática são arrasadoras. Por um lado, seria a teoria quântica incompleta? Haveria a possibilidade de completá-la? Como poderíamos sustentar dentro da mecânica quântica o conceito de "localidade", que é fundamental na teoria da relatividade? Por outro lado, um 
importante teorema vinculado a seus testes experimentais evidencia a incompatibilidade e supremacia da teoria quântica em relação a teorias de variáveis ocultas locais que pudessem vir a completar a teoria quântica. Seria então o mundo quântico não-local? Como solucionar os profundos paradoxos oriundos do abandono da localidade, do determinismo e da causalidade? Este é um intenso debate que esteve presente ao longo do século XX e que culmina em teses epistemológicas e metodológicas que transitam entre dois polos: o realismo científico e o antirrealismo científico.

O capítulo I do presente trabalho versará sobre a estrutura lógica e conceitual do argumento de Einstein, Podolsky \& Rosen (EPR 1935), que defende que a teoria quântica é incompleta. Examino os primeiros debates e algumas versões importantes do argumento, como a versão original de Einstein e a de David Bohm. Além disso, apresento como o realismo de Einstein o influenciou em sua crítica à teoria quântica.

O capítulo II se debruçará brevemente sobre as primeiras tentativas de entender o que é o "entrelaçamento quântico", distinguindo este estado de misturas fatoráveis. Examino também os primeiros testes experimentais significativos que foram capazes de proporcionar alguma resposta à problemática da incompletude, oriunda do argumento de EPR.

Por fim o capítulo III dedicar-se-á ao principal desfecho teórico do tema, apresentando o teorema de Bell, que tornou possível a obtenção de testes experimentais mais evidentes para estudar o entrelaçamento. Apresento também uma discussão sobre as consequências filosóficas e conceituais emergentes da derivação lógica de um dilema entre uma tese filosófica (o realismo) e um princípio físico (a localidade).

Problemáticas como a apresentada nesta dissertação, que envolvem o debate lógico e conceitual presente nas teorias físicas e resultam em discussões sobre teses filosóficas, não devem ser jamais abandonadas, pois envolvem uma discussão sobre os objetivos da ciência e, consequentemente, acaba por influenciar os rumos do desenvolvimento científico. A ciência é um mero instrumento de descrição de fenômenos, com o objetivo único e utilitarista de promover o desenvolvimento do campo tecnológico, ou é um procedimento milenar que pretende desvendar a realidade e os mistérios da existência? 


\section{Capítulo I}

\section{Debates sobre o Argumento de EPR}

\section{A Mecânica Quântica}

A mecânica quântica foi desenvolvida em torno de 1926, a partir do trabalho seminal de Werner Heisenberg, e independentemente por Erwin Schrödinger. Ela é a teoria física que descreve os processos atômicos, medidos em laboratório, permitindonos compreender a natureza da matéria e da radiação. No entanto, a questão sobre a compreensão dos fenômenos quânticos esbarra em uma série de objeções quando são consideradas perspectivas filosóficas realistas.

O primeiro desconforto surge logo nas origens da teoria, com o aspecto físico quantizado da energia, sendo que esta era entendida, até o começo do século XX, como uma grandeza contínua. Após a teoria clássica fracassar ao descrever o espectro de radiação de corpo negro, tanto na versão de Wien quanto na de Rayleigh (que gerava a “catástrofe do ultravioleta"), Max Planck fez uma interpolação entre as duas leis e em outubro de 1900 obteve uma nova lei de radiação consistente com as medições experimentais. Para explicar essa lei, fez uso dos métodos estatísticos de Boltzmann, e conseguiu apresentar sua nova explicação teórica, no dia 14 de dezembro, em uma reunião da Sociedade Alemã de Física, em seu artigo "Sobre a Teoria da Lei de Distribuição de Energia no Espectro Normal". A quantização da energia dos osciladores presentes no corpo negro foi incorporada nas posteriores teorias que viriam a compor a "antiga teoria quântica"; como a quantização da radiação eletromagnética feita por Einstein (1905) e a quantização dos níveis atômicos feita por Niels Bohr (1913), além de ser o aspecto que viria a dar nome à teoria.

Outro ponto problemático que surgiu com a antiga teoria quântica foi a chamada "dualidade onda-partícula", debatida entre os físicos e envolvendo o aspecto corpuscular da luz apresentado no artigo de Einstein, e que foi confirmando-se em 1916 por Robert Millikan. Louis de Broglie, um historiador e irmão do físico experimental francês Maurice de Broglie, propôs em 1924 a existência de ondas de matéria, de forma que o comportamento dual da radiação também seria aplicável à matéria.

Surgiu então, em 1925, a chave para a nova mecânica quântica: Werner Heisenberg percebeu que as grandezas que descrevem o mundo atômico não comutam: 
$\boldsymbol{A} \boldsymbol{B} \neq \boldsymbol{B} \boldsymbol{A}$. Com Max Born, Pascual Jordan e Heisenberg desenvolve-se então a mecânica matricial, a primeira versão da teoria quântica.

Bastou Wolfgang Pauli aplicar, com grande dificuldade, a nova teoria para a descrição do átomo de hidrogênio, que uma nova abordagem, bem mais fácil de fazer os cálculos, foi desenvolvida de maneira independente por Erwin Schrödinger, no início de 1926. Nesta mecânica ondulatória, os estados dos sistemas atômicos são representados por funções matemáticas, chamadas de funções de onda. Born interpretou o quadrado da função de onda como fornecendo a probabilidade de detectar uma partícula em uma certa região. Mas qual seria o significado desta probabilidade? As partículas préexistiriam às medições? O que significa a função de onda do ponto de vista ontológico? Estas questões de cunho filosófico e conceitual serão trabalhadas ao longo do Cap. I desta dissertação.

Uma descrição matemática mais rigorosa da teoria quântica foi elaborada por John von Neumann, em 1932, representando estados quânticos em um espaço vetorial complexo (espaço de Hilbert). A evolução temporal de um sistema é descrita por uma equação dinâmica, como a equação de Schrödinger, válida para sistemas fechados, isto é, a cada instante o estado de um sistema quântico pode ser representado por um único vetor no espaço de Hilbert correspondente, e essa equação dinâmica rege essa evolução temporal. Além disso, há o princípio de superposição que afirma: dados dois estados permissíveis para um sistema quântico (ou seja, um estado que pode ser preparado no sistema), então qualquer combinação linear deles também é um estado permissível.

A regra de Born mencionada acima estipula as probabilidades de se obterem os resultados para medições de quaisquer observáveis. Nesse mesmo contexto, o processo de medição envolve também o postulado da projeção, que indica que o estado de um sistema após a medição sofrerá uma "redução" para o autoestado correspondendo ao autovalor obtido como resultado da medição. Notemos que o postulado da projeção, formalizado por von Neumann, tem aplicação limitada, já que não vale quando o sistema quântico é destruído, ou em medições chamadas de " $2 \circ$ tipo", como por exemplo, a medição de energia de um átomo. Ele foi incorporado nas interpretações

\footnotetext{
${ }^{1}$ São chamadas medições de $1^{\circ}$ tipo aquelas que, imediatamente após serem realizadas, podem ser repetidas mantendo o resultado obtido, sendo também chamadas "repetíveis". Medições de $2^{\circ}$ tipo não são repetíveis, pois o estado final é diferente do autoestado correspondente ao resultado, sendo também chamadas "previsíveis", pois existe um estado do sistema que leva a tal resultado (Landau \& Peierls 1931, apud. Pessoa 2006, pp. 303-4).
} 
ortodoxas, apesar de nunca ter sido mencionado por Niels Bohr, articulador da interpretação da complementaridade.

Outro conceito fundamental é o princípio de incerteza, desenvolvido por Werner Heisenberg em 1927, que impõe uma limitação na exatidão com que grandezas conjugadas, como posição e momento, podem ser atribuídas a um sistema quântico. Este princípio é gerador de diversos conflitos de interpretação. Ele está envolvido, por exemplo, em discussões relacionadas ao aspecto probabilístico da teoria, que difere do probabilismo envolvido na Mecânica Estatística Clássica, e que, de acordo com Heisenberg e Bohr, é fundamental na mecânica quântica de tal forma que o determinismo deveria ser abandonado. Além disso, o princípio de incerteza possui um papel fundamental no argumento de incompletude da teoria quântica proposto por Einstein, Podolsky e Rosen (EPR) em 1935, conforme veremos na seção I.4. Veremos também na seção I.8 que o princípio de incerteza foi objeto de intensos debates entre Einstein e Bohr no Congresso de Solvay de 1927, e como a exploração, por meio de experimentos mentais, desse princípio levou Bohr a reafirmar a interpretação da complementaridade e a completude da teoria quântica.

Todas essas considerações filosóficas, presentes em torno da teoria quântica e da relação entre o sistema quântico e o aparelho de medição, promovem um efeito cascata de conceitos e problemas filosóficos, que surgem a partir de novas situações físicas e novos experimentos mentais, que, por sua vez, dão origem a novas formas de compreender a natureza. No contexto deste trabalho, que tomará por eixo principal o argumento de EPR, e analisará seus desdobramentos, veremos como a "não-localidade"2 surge dessas explorações filosóficas da teoria quântica, desembocando nos aspectos conceituais e nas comprovações experimentais relacionadas ao Teorema de Bell.

O presente capítulo versará sobre a estrutura lógico-conceitual do argumento de EPR, que defende que a teoria quântica é incompleta, examinando os primeiros debates e algumas versões importantes do argumento, como a versão original de Einstein e a de David Bohm. Além disso, apresentaremos como o realismo de Einstein o influenciou em sua crítica à teoria quântica, e examinaremos questões filosóficas envolvendo realismo, antirrealismo e teoria quântica.

\footnotetext{
${ }^{2}$ De acordo com a nova reforma ortográfica, não é aconselhado o uso do hífen após o prefixo "não". No entanto, prefiro adotar o uso do hífen nas palavras relacionadas à "não-localidade", já que se trata de um conceito importante dentro da discussão.
} 


\section{O Argumento de EPR}

"A descrição da realidade física fornecida pela mecânica quântica pode ser considerada completa?" Este é o título dado ao artigo de 1935 publicado por Albert Einstein, Boris Podolsky e Nathan Rosen (conhecido como "EPR”). A conclusão do artigo vem a ser uma resposta negativa a essa questão.

Duas condições fundamentais para o estabelecimento do argumento de incompletude foram utilizadas. A primeira foi chamada por EPR de condição de completude: para que uma teoria seja considerada completa, "todo elemento da realidade física precisa ter um correspondente na teoria física” (EPR 1981, p. 90; 1935, p. 777 b). ${ }^{3}$ A segunda condição estabelecida foi o critério de realidade física, "Se, sem de modo algum perturbar um sistema, pudermos prever com certeza (ou seja, com probabilidade igual à unidade) o valor de uma quantidade física, então existe um elemento de realidade física correspondente a essa quantidade física" (EPR 1981, p. 91; 1935, p. 777 b). Voltaremos a examinar essas condições nas seções seguintes.

Outro pilar a ser usado para a argumentação está na base do formalismo quântico, no caso, o princípio de incerteza $a^{4}$, segundo o qual em um sistema quântico não é possível prever o valor exato para duas grandezas físicas cujos operadores não comutam entre si. Muitos dos grandes debates e análises do argumento são direcionados às diversas interpretações desse princípio.

A chamada interpretação ortodoxa, ou interpretação de Copenhagen, adota uma postura filosófica antirrealista ou instrumentalista, segundo a qual os elementos matemáticos utilizados na teoria não se referem à objetos inobserváveis, mas são meros instrumentos teóricos necessários à estrutura da teoria para que a estruturação da teoria chegue a enunciados sobre elementos observáveis ${ }^{5}$. Por outro lado, qualquer interpretação que estabeleça a existência real de grandezas inobserváveis é entendida como uma postura realista, o que pode ser chamado de realismo dos inobserváveis.

\footnotetext{
${ }^{3}$ Para auxiliar o leitor em relação às referências das citações, são referenciadas a edição original e a tradução, sendo que "a" e "b" indicam a coluna da página onde a citação se encontra.

${ }^{4}$ A palavra "incerteza", que dá nome ao princípio, sugere a existência de valores bem definidos que são desconhecidos, o que está associado à interpretação dos coletivos (ensembles). Muitos preferem o termo "princípio de indeterminação", que seria um termo mais apropriado à postura instrumentalista da interpretação ortodoxa. Na presente dissertação, porém, usarei "incerteza" em um sentido mais genérico, acompanhando a tradição histórica.

5 Nesse sentido, vale lembrar que o uso costumeiro da palavra "observável" está associado a esta interpretação antirrealista, que legitima como reais apenas grandezas observáveis. EPR utilizam a palavra "physical quantities", que mantemos nas citações como "quantidades" (seguindo a tradução de 1981), mas que no texto chamaremos de "grandezas".
} 
Baseando-se no princípio de incerteza, EPR estabelecem duas asserções sobre completude da teoria e realidade simultânea dessas duas grandezas físicas:

Disso [princípio de incerteza] se segue que ou (1) a descrição da realidade fornecida pela função de onda, não é completa, ou (2) quando os operadores correspondentes a duas quantidades físicas não comutam, essas quantidades não podem ter realidades simultâneas. (EPR 1981, p. 92; 1935, p. 778 b)

Notemos que os autores interpretam o princípio de incerteza de uma certa maneira, de acordo com essas duas asserções, que estão conectadas por um "ou exclusivo". Por um lado, se (1) for falsa, (2) será uma asserção verdadeira, indicando que a mecânica quântica, incluindo o princípio de incerteza, seria uma teoria completa, pois, nesse caso, as duas quantidades cujos operadores não comutam não têm realidade física simultânea. Por outro lado, se (1) for verdadeira, (2) deverá ser falsa; o princípio de incerteza impede a previsão de dois valores de observáveis incompatíveis, mas na realidade eles existiriam (neste caso), e, portanto a teoria quântica seria incompleta.

Veremos que o argumento de EPR não envolve uma medição que tenha se realizado de fato. Seria possível medir o momento de uma partícula, e seria possível medir sua posição, mas para o argumento funcionar, nenhuma dessas medições deve ser realizada. Diz-se então que o argumento de EPR se baseia em duas situações "contrafactuais", ou seja, medições que não são realizadas de fato.

Esse argumento contrafactual aborda um "sistema combinado I + II", por exemplo, duas partículas, cujo estado é descrito na mecânica quântica pela seguinte função de onda:

$$
\psi\left(\mathrm{x}_{1}, \mathrm{x}_{2}\right)=\sum_{\mathrm{n}=1}^{\infty} \psi_{\mathrm{n}}\left(\mathrm{x}_{2}\right) \mathrm{u}_{\mathrm{n}}\left(\mathrm{x}_{1}\right)
$$

onde $\mathrm{x}_{1}$ corresponde às variáveis que descrevem o primeiro sistema e $\mathrm{x}_{2}$ às variáveis que descrevem o segundo sistema. Ao apresentar esta fórmula em sua Eq. 7, EPR (1981, p. 93; 1935, p. 779 a) salientam se tratar do estado apenas do primeiro sistema. Assim, $\mathrm{u}_{\mathrm{n}}\left(\mathrm{x}_{1}\right)$ são as autofunções do sistema I correspondentes a um observável A, e $\psi_{\mathrm{n}}\left(\mathrm{x}_{2}\right)$ são apenas os coeficientes da série de funções ortogonais $\mathrm{u}_{\mathrm{n}}\left(\mathrm{x}_{1}\right)$.

Se o observável A é medido sobre o primeiro sistema, obtendo-se um valor $\mathrm{a}_{\mathrm{k}}$, considerando o sistema global, a função de onda acima se reduziria a apenas um dos termos da somatória, a saber, $\psi_{\mathrm{k}}\left(\mathrm{x}_{2}\right) \mathrm{u}_{\mathrm{k}}\left(\mathrm{x}_{1}\right)$, sendo $\mathrm{u}_{\mathrm{k}}\left(\mathrm{x}_{1}\right)$ o estado do primeiro sistema e $\psi_{\mathrm{k}}\left(\mathrm{x}_{2}\right)$ o estado do segundo sistema. Por outro lado, se um outro observável B é medido 
neste mesmo sistema, com correspondentes autovalores $b_{s}$ e autofunções $v_{s}\left(x_{1}\right)$, a maneira apropriada de escrever a função de onda combinada seria:

$$
\Psi\left(\mathrm{x}_{1}, \mathrm{x}_{2}\right)=\sum_{\mathrm{s}=1}^{\infty} \varphi_{\mathrm{s}}\left(\mathrm{x}_{2}\right) v_{\mathrm{s}}\left(\mathrm{x}_{1}\right)
$$

Novamente, EPR indicam que este é o estado apenas do primeiro sistema, de maneira que $\varphi_{\mathrm{s}}\left(\mathrm{x}_{2}\right)$ são os novos coeficientes da superposição. Se o observável B é medido e se obtiver o valor $b_{r}$, após a medição o estado global se reduziria a apenas um dos termos da somatória, no caso, $\varphi_{\mathrm{r}}\left(\mathrm{x}_{2}\right) v_{\mathrm{r}}\left(\mathrm{x}_{1}\right)$, sendo $v_{\mathrm{r}}\left(\mathrm{x}_{1}\right)$ o estado do primeiro sistema e $\varphi_{\mathrm{r}}\left(\mathrm{x}_{2}\right)$ o estado do segundo sistema.

Dessa forma, seria possível obter, por meio de duas medições diferentes, dois estados diferentes para o segundo sistema. Nesse momento EPR utilizam o princípio da localidade nos seguintes termos:

[...] como no momento da medição os dois sistemas não mais estão interagindo, não pode ocorrer nenhuma mudança real no segundo sistema como decorrência de qualquer coisa que se faça no primeiro. (EPR 1981, p. $94 ; 1935$, p. 779 b)

A pretensão do experimento contrafactual é dizer que, devido a essa localidade, "é possível atribuir duas funções de onda diferentes (no nosso exemplo $\psi_{\mathrm{k}}$ e $\varphi_{\mathrm{r}}$ ) à mesma realidade (o segundo sistema após a interação com o primeiro)" (EPR 1981, p. 94; 1935, p. 779 b).

No caso de essas duas funções de onda serem autofunções de dois observáveis incompatíveis - EPR citam como exemplo a posição $(\mathrm{Q})$ e o momento $(\mathrm{P})$-, na mecânica quântica essas duas quantidades não poderiam ter realidades simultâneas.

EPR, concluindo o argumento, retomam o critério de realidade física, evidenciando a capacidade que ambas as medições têm de "prever com certeza, e sem perturbar de modo algum o sistema, tanto o valor da quantidade $\mathrm{P}$ (ou seja, $\mathrm{p}_{\mathrm{k}}$ ), quanto o valor da quantidade Q (isto é, $\mathrm{q}_{\mathrm{r}}$ )" (EPR 1981, p. 95; 1935, p. 780 a), por meio das duas autofunções que podem descrever o sistema II de acordo com a escolha da medição no sistema I, e que, portanto, “duas quantidades físicas com operadores não comutativos podem ter realidades simultâneas" (EPR 1981, p. 96; 1935, p. 780 b). Eles retomam o princípio de incerteza que, conforme explicitamos anteriormente, em seus termos se traduz em duas asserções: 
[...] ou 1) a descrição da realidade fornecida pela função de onda, não é completa, ou 2) quando os operadores correspondentes a duas quantidades físicas não comutam, essas quantidades não podem ter realidades simultâneas. (EPR 1981, p. 95; 1935, p. 780 b)

Para concluir o argumento, EPR supõem a completude da função de onda ${ }^{6}$, isto é, a negação de (1), que implica a afirmação de (2), ou seja, a afirmação da impossibilidade de existência de duas quantidades físicas que não comutam. Porém, com o argumento desenvolvido por meio do experimento contrafactual, chegam à conclusão de que duas quantidades físicas, com operadores não comutativos, podem ter realidades simultâneas. Isso implica, entretanto, a negação de (2). Dessa forma, supor a completude implicaria obter afirmações contraditórias, a existência e não existência de dois elementos de realidade cujos observáveis são incompatíveis. Com isso, EPR afirmam que somos forçados a admitir a incompletude da mecânica quântica. A forma como EPR apresentam a conclusão do argumento é, de fato, um pouco circunvoluta, como veremos mais adiante ${ }^{7}$.

\section{Os Pilares do Argumento}

Uma análise sistemática do argumento de incompletude de EPR auxilia a perceber os detalhes da questão levantada e entender as objeções feitas por alguns físicos a esse respeito. Nessa abordagem será utilizada a notação presente no volume II de Conceitos de Física Quântica de Osvaldo Pessoa Jr. (2006).

$\mathrm{Na}$ discussão inicial do argumento de EPR, na seção I.2, a condição de completude já foi apresentada, e a denotaremos por $\mathbf{C}$, assim como o critério de realidade, que será denotado por $\mathbf{R}$. Além dessas duas condições, o argumento utiliza o princípio de localidade, LOC, segundo o qual "não pode ocorrer nenhuma mudança

\footnotetext{
${ }^{6}$ A assunção da completude da função de onda na estrutura do argumento é questionada em sua efetividade e necessidade por Chibeni (1997, 2005), McGrath (1978) e Wessels (1981), conforme apresentaremos nas seções I.5, I.6 e I.7.

${ }^{7} \mathrm{Na}$ segunda metade do século XX, uma vasta bibliografia sobre a análise lógica do argumento de EPR se desenvolveu e retomou o tema há décadas adormecido. Abordaremos uma análise mais atual com as publicações de Silvio Chibeni de 1997 e 2005, e retomaremos duas análises lógicas mais complexas, de James McGrath (1978) e de Linda Wessels (1981). Robert Deltete e Reed Guy produziram, em 1991, um artigo que também debate a análise lógica e sistemática do argumento e usam como referências as reconstruções lógicas dos artigos de McGrath e Wessels. Tal artigo foi utilizado como referência em Chibeni (2005), de forma que não será abordado em detalhes, mas concorda em diversos aspectos com os pontos principais levantados nas análises lógicas aqui apresentadas nas seções I.5, I.6 e I.7.
} 
real no segundo sistema como decorrência de qualquer coisa que se faça no primeiro" (EPR 1981, p. 94; 1935, p. 779).

Verifica-se a aceitação do formalismo da mecânica quântica, MQ, e o postulado da projeção, PP (mencionado na seção I.1), lembrando-se que se trata de duas partículas correlacionadas e, portanto, que a aplicação do postulado parece sugerir (numa perspectiva realista) um efeito não-local, na medida em que a função de onda associada a uma das partículas se altera instantaneamente com uma medição na outra partícula.

Por fim, percebe-se o caráter contrafactual, CF, do argumento, ou seja, a proposta envolve apenas a possibilidade de realizar duas medições diferentes na mesma partícula (digamos a "primeira" partícula), obtendo assim resultados bem definidos para a primeira partícula e, consequentemente, determinando os valores da segunda partícula. No entanto, não há como fazer essas medições simultaneamente, assim o caráter contrafactual é intrínseco ao argumento. Reforçando isso, notamos que se uma das medições for de fato feita, o argumento já não se segue, indicando que o argumento se sustenta na contrafactualidade.

Esquematicamente temos a seguinte estrutura para a construção do argumento da incompletude da mecânica quântica:

$$
\text { (MQ (incluindo PP), LOC, R, CF) } \Rightarrow \text { não C(MQ) }
$$

$\mathrm{Na}$ abordagem feita pelo filósofo da física inglês Michael Redhead sobre o paradoxo de $E P R^{8}$, ele exprime, entre outras considerações, o que chamou de dilema de Einstein: "se aceitarmos o formalismo $F$ da Mecânica Quântica [MQ] como correto em um nível puramente observacional/instrumental, então ou precisamos abandonar $L$ [LOC], o princípio de localidade, ou precisamos admitir a incompletude de $F$ [ C(MQ)]" (Redhead 1987, p. 76). O “ou” em questão não deve ser entendido como o “ou exclusivo". Na transformação da Eq. 3 para o dilema de Einstein, pressupõe-se a veracidade de $\mathbf{R}$ e $\mathbf{C F}$.

No mesmo ano de publicação do artigo de EPR, Bohr publicou uma resposta à questão levantada. Uma de suas críticas foi baseada na "ambiguidade" do critério de elemento de realidade $\mathbf{R}$ usado por EPR, no ponto em que afirma "sem de modo algum perturbar um sistema”. Bohr considerou que a escolha em medir a posição ou o

\footnotetext{
${ }^{8} \mathrm{O}$ argumento ficou conhecido como "paradoxo de EPR", pois reflete o caráter paradoxal da existência e não existência de dois elementos de realidade física, caso a quântica seja completa. A citação mais antiga na qual se foi possível encontrar o uso deste termo foi no livro de David Bohm (1951, p. 611).
} 
momento de uma das partículas correlacionadas envolveria, obviamente, arranjos experimentais diferentes, o que caracteriza "uma influência sobre as próprias condições que definem os tipos possíveis de previsões relativas ao comportamento futuro do sistema" (Bohr 1981, p. 103; 1935, p. 700 a). A condição, presente em R, de não perturbar o sistema de modo algum não seria satisfeita no argumento de EPR, o que invalidaria o argumento 9 .

\section{O Princípio de Incerteza no Argumento}

Um elemento importante presente no argumento de EPR é o peso que o princípio de incerteza assume dentro de sua estrutura. Ele é apresentado da seguinte forma:

Desse modo, não é possível prever um valor definido para a coordenada de uma partícula no estado dado pela equação (2) [autoestado de momento], podendo-se obtê-lo apenas por uma medição direta. Depois da determinação da coordenada, a partícula não mais permanece no estado da equação (2). $\mathrm{Na}$ mecânica quântica, a conclusão usual é que quando se conhece a quantidade de movimento de uma partícula, sua coordenada não tem realidade física. (EPR 1981, p. 92; 1935, p. 778 b)

Apenas para relembrarmos, esse princípio é fundamental para que, conforme notamos na seção I.2, EPR estabeleçam as duas asserções que dão início à prova e cuja apresentação vem logo após a citação acima.

Disso [princípio de incerteza] se segue que ou (1) a descrição da realidade fornecida pela função de onda, não é completa, ou (2) quando os operadores correspondentes a duas quantidades físicas não comutam, essas quantidades não podem ter realidades simultâneas. (EPR 1981, p. 92; 1935, p. 778 b)

Isto é, por meio do princípio de incerteza se obtém o principal dilema do argumento, segundo o qual ou a mecânica quântica não é completa, ou não há realidade simultânea para dois observáveis incompatíveis. Vale a pena examinarmos a formulação dada a este princípio.

Há pelo menos três versões do princípio de incerteza, no que tange a ele ser formulado de maneira mais realista ou instrumentalista. Utilizando observáveis de spin

\footnotetext{
9 A visão de Bohr é reconstruída por alguns autores por meio da diferença entre os conceitos de localidade, associada à inexistência de influência da medição de uma partícula sobre a outra, e separabilidade, em que as propriedades de uma partícula são independentes da outra, sendo que Bohr aceitaria a primeira característica do fenômeno e rejeitaria a segunda (Pessoa 2006, p. 211-13). Retomaremos a resposta de Bohr na seção I.8.
} 
da direção x e z (para simplificar o enunciado), podemos considerar inicialmente uma versão instrumentalista:

Pr-Incert-instr: Se um observável $S_{\mathrm{x}}$ for medido (o que leva a um resultado bem definido), então não se pode prever com certeza o resultado de uma medição do observável incompatível $\mathrm{S}_{\mathrm{z}}$.

A versão instrumentalista sustenta-se sobre uma medição feita do primeiro observável, o que leva à impossibilidade de previsão do resultado da medição do segundo observável. Esta versão não se compromete com a existência desses valores bem determinados antes de qualquer medição.

Uma segunda versão do princípio de incerteza expressa o enunciado anterior falando em valores possuídos, isto é, elementos de realidade. A conexão entre os enunciados se dá pela suposição de que, após a medição de um observável, o sistema passa para o autoestado associado a este, o que pressupõe o postulado da projeção. Assim, temos a versão realista fraca do princípio de incerteza:

Pr-Incert-fraco: Se a grandeza física $S_{\mathrm{x}}$ tiver valor bem definido, então não se pode prever com certeza o resultado de uma medição da grandeza física incompatível $S_{z}$.

Nesta versão, não importa como o valor bem definido do primeiro observável foi preparado: pode ter sido por medição direta, indireta, filtragem, evolução unitária, etc. O consequente do enunciado é idêntico ao da versão instrumentalista: ambas seguem para a impossibilidade de previsão do resultado do observável incompatível, e não para a impossibilidade de sua existência (como na versão seguinte, forte). A versão fraca é expressa no seguinte enunciado de $\operatorname{EPR}(1981$, p. 92; 1935, p. 778 b): “não é possível prever um valor definido para a coordenada [posição] de uma partícula no estado dado pela equação (2) [um autoestado de momento]".

Prosseguido com a abordagem do princípio de incerteza no artigo, EPR apresentam uma versão mais forte, necessária para que seu argumento seja bem sucedido: "quando se conhece a quantidade de movimento de uma partícula, sua coordenada não tem realidade física" (EPR 1981, p. 92; 1935, p. 778 b). Isso corresponde a uma versão forte do princípio de incerteza:

Pr-Incert-forte: Se a grandeza física $S_{\mathrm{x}}$ tiver valor bem definido, então a grandeza física incompatível $S_{z}$ não tem realidade física. 
É interessante perceber que o argumento de EPR só funciona com a versão forte do princípio de incerteza, pois esta é a única que se refere a valores possuídos no consequente do enunciado, isto é, à existência de elementos de realidade, sem envolver medições - que é a situação requerida dentro do argumento por não serem feitas medições no sistema II. O argumento não funcionaria com a versão instrumentalista, pois como ela envolve apenas a previsão do resultado de medições, tanto no antecedente quanto no consequente do condicional, não é possível extrair dessa sentença a existência de elementos de realidade antes da medição. $\mathrm{O}$ argumento tampouco funcionaria com a versão fraca, pois esta também envolve apenas a previsão do resultado de medições no consequente do condicional.

\section{A Crítica de Chibeni}

A forma como o argumento de EPR aparece no artigo foi analisada no livro Aspectos da Descrição Física da Realidade, tese de doutorado de Silvio Chibeni $(1997)^{10}$. A estrutura lógica do argumento é apresentada com o uso do cálculo proposicional, como se segue (Chibeni 1997, p. 40):

C: a descrição quântica da realidade é completa;

RS: quantidades físicas incompatíveis (i.e., cujos operadores não comutam) podem ter realidade simultânea;

$\mathrm{MQ}(\mathrm{AB})$ : a $\mathrm{MQ}$ fornece valores precisos e simultâneos para as quantidades incompatíveis A e B. [...]

$\begin{array}{lll}\text { 1. } & (\mathrm{RS} \& \mathrm{C}) \rightarrow \mathrm{MQ}(\mathrm{AB}) & \text { [definição de completude] } \\ \text { 2. } & \neg \mathrm{MQ}(\mathrm{AB}) & {[\mathrm{MQ}]} \\ \text { 3. } & \neg(\mathrm{RS} \& \mathrm{C}) & {[1 \text { e } 2]} \\ \text { 4. } & \neg \mathrm{C} \vee \neg \mathrm{RS} & {[3]} \\ \text { 5. } & \mathrm{C} \rightarrow \mathrm{RS} \quad[\text { critério de realidade aplicado aos sistemas correlacionados] } \\ \text { 6. } & \mathrm{C} \rightarrow \neg \mathrm{RS} & {[4]} \\ \text { 7. } & \mathrm{C} \rightarrow(\mathrm{RS} \& \neg \mathrm{RS}) & {[5 \text { e 6] }} \\ \text { 8. } & \neg \mathrm{C} & {[7]}\end{array}$

A partir daí, Chibeni desenvolve a argumentação de que Podolsky teria estendido a discussão de forma desnecessária, por conta de dois pontos: (i) por ter usado o condicional C $\rightarrow$ RS, e (ii) por ter adotado a chamada "doutrina da perturbação".

\footnotetext{
${ }^{10}$ Uma análise mais detalhada do argumento e estendida a uma variante mais forte que não faz referência ao arranjo experimental, e que escapa à crítica de Bohr, pode ser encontrada em Chibeni (2005). Na seção I.8 abordaremos a resposta de Bohr e retomaremos brevemente a variante mais forte apresentada por Chibeni.
} 
$\mathrm{O}$ condicional $\mathrm{C} \rightarrow \mathrm{RS}$ é introduzido como um estratagema para gerar uma contradição, mas o que realmente importa para seu argumento geral é RS, ou seja, a tese da existência simultânea de dois elementos de realidade associados a observáveis incompatíveis. Essa conclusão se segue do argumento (envolvendo o experimento contrafactual de duas partículas correlacionadas separadas espacialmente) sem assumir a tese da completude $\mathrm{C}$, de que "a descrição quântica da realidade é completa". Assim, a demonstração de RS levaria, junto com o passo 3, diretamente à conclusão de incompletude. Dessa forma, o argumento de EPR seria válido sem a necessidade de se estabelecer o condicional $\mathrm{C} \rightarrow \mathrm{RS}$, o que Podolsky supôs como um artifício lógico para estruturar seu argumento.

Chibeni (1997, p. 42) menciona que esse condicional é anunciado três vezes por Podolsky como sendo o passo crucial do argumento, no início do artigo e ao final, quando afirma que tal prova acaba de ser dada. No entanto, tal condicional $C \rightarrow R S$ não deve ser confundido com o enunciado do dilema derivado do princípio de incerteza, que citamos anteriormente na seção I.2 (na versão de EPR, 1981, p. 95; 1935, p. 780 b):

Então, ou (1) a descrição da realidade fornecida pela função de onda na mecânica quântica não é completa, ou (2) essas duas quantidades [descritas por operadores não-comutativos] não podem ter realidade simultânea. (EPR 1981, p. 90; 1935, p. 777 b)

O condicional na verdade se segue imediatamente a este trecho do resumo do artigo:

Considerações acerca do problema de fazer previsões concernentes a um sistema com base em medições executadas em outro sistema, que interagiu previamente com o primeiro, leva ao resultado de que se (1) é falso, então (2) também é falso. Assim, é se levado a concluir que a descrição da realidade fornecida pela função de onda não é completa. (EPR 1981, p. 90; 1935 , p. 777 b)

Dessa forma fica claro que Podolsky de fato pretende demonstrar o condicional C $\rightarrow$ RS, e não demonstrar diretamente RS. Mas Chibeni (1997, p. 42) aponta que é impossível localizar no artigo o ponto em que o antecedente $\mathrm{C}$ aparece. Este salienta que a validade lógica do argumento não é afetada, mas não é clara a justificativa de Podolsky para assumir a demonstração do condicional como sendo o ponto crucial do argumento.

Conforme nota Chibeni, o único momento, entre o anúncio de que $\mathrm{C}$ seria assumida para a obtenção de RS e a declaração de que tal resultado já havia sido alcançado, em que a palavra "assumimos" aparece, é no seguinte parágrafo: 
Voltando agora ao caso geral contemplado nas Eqs. 7 e 8, assumimos que $\psi_{\mathrm{k}}$ e $\varphi_{\mathrm{r}}$ são de fato autofunções de operadores que não comutam, $\mathrm{P}$ e $\mathrm{Q}$, correspondendo aos autovalores $\mathrm{p}_{\mathrm{k}}$ e $\mathrm{q}_{\mathrm{r}}$, respectivamente. (Apud Chibeni 1997, p. 44; EPR 1935, p. 780 a)

Segundo Chibeni (p. 45), "essa proposição revela-se estranha”, pois "o que está sendo 'assumido' é um resultado quântico bem conhecido". Entendemos que ele se refira ao resultado envolvendo os operadores de posição e momento, e à consequência do formalismo quântico de que se um sistema está em um autoestado de um operador, a medição do observável correspondente fornece como resultado um autovalor bem definido. No próprio artigo de EPR, segundo Chibeni, esse resultado quântico é provado justamente antes dessa suposta assunção.

É interessante notar que, na visão de Chibeni, o que está sendo assumido é que a MQ fornece uma descrição correta da realidade, pois há duas entidades teóricas $\psi_{\mathrm{k}}$ e $\varphi_{\mathrm{r}}$ correspondendo a dois elementos de realidade $p_{k}$ e $q_{r}$. Neste sentido, Chibeni (p. 45) aponta também que essa confusão pode ter conexão com o fato de Einstein adotar como condição de completude uma correspondência biunívoca entre os "estados reais" e as funções de onda, e afirma ainda que essa condição de completude difere da condição de completude adotada por Podolsky no artigo. A Fig. 1 apresenta um diagrama ilustrativo dos conceitos de completude e correção de teorias.

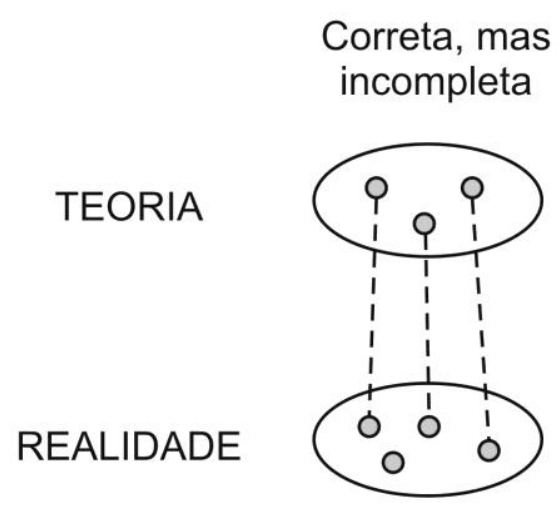

(a)

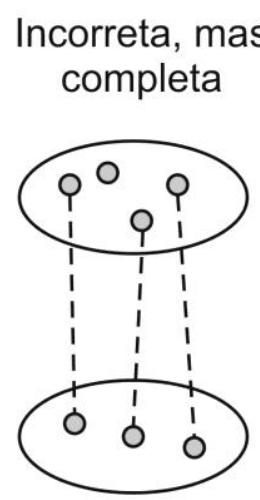

(b)

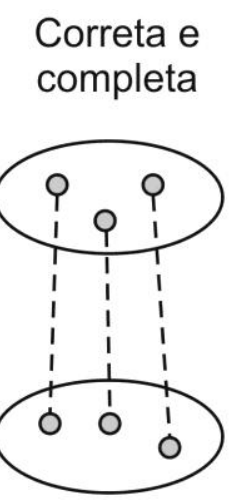

(.c)
Incorreta e incompleta

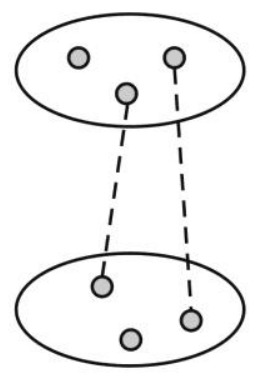

(d)

Figura 1: Diagramas de completude e correção de teorias.

Segundo a condição necessária de completude de uma teoria, presente no artigo, "todo elemento de realidade física precisa ter um correspondente na teoria física" (EPR 1981, p. 90; 1935, p. 777 b). Dessa forma, uma teoria completa poderia ser também 
incorreta, conforme a Fig. 1(b), ou correta, conforme a Fig. 1(c). A concepção biunívoca de completude atribuída a Einstein seria representada pela Fig. 1(c).

Nesse sentido, segundo Chibeni, a assunção de completude não é efetivamente utilizada, mas sim a assunção de que a teoria quântica é correta. Segundo Chibeni (1997, p. 45), uma descrição correta da realidade "é mais ou menos o 'inverso' da completude", simetria esta que é ilustrada nas Figs. 1(a) e 1(b).

É possível verificar o uso do condicional $\mathrm{C} \rightarrow \mathrm{RS}$ na conclusão do artigo:

Partindo da suposição de que a função de onda fornece uma descrição completa da realidade física, chegamos à conclusão de que duas quantidades físicas com operadores não-comutativos podem ter realidades simultâneas. Dessa maneira, a negação de (1) implica a negação da única outra alternativa, (2). Somos assim forçados a concluir que a descrição quântica da realidade física através das funções de onda não é completa. (EPR 1981, p. 95-96; 1935, p. 780 b)

De acordo com Chibeni, portanto, Podolsky concluiu com o condicional, mas sem assumir efetivamente o antecedente ao longo do argumento, mas apenas a correção da teoria quântica. A condição de completude é usada somente após a derivação de RS, seguindo a linha (4) da derivação apresentada por Chibeni.

Quanto à adoção da doutrina da perturbação no artigo, Chibeni indica que Podolsky apela para a interpretação ortodoxa ao afirmar que, para pares de quantidades físicas incompatíveis, "o conhecimento preciso de uma impossibilita o conhecimento preciso da outra", e que a tentativa de determinar uma delas empiricamente "alterará o estado da outra" (Chibeni 1997, 41; EPR 1981, p. 92; 1935, p. 778 b). Para Chibeni, essa doutrina é desnecessária para o argumento; além disso, Chibeni afirma que adotar a doutrina da perturbação no argumento de incompletude forma uma "mistura bizarra", pois o objetivo do argumento de incompletude é demonstrar que a MQ não fornece certos valores de elementos da realidade física, já a doutrina da perturbação afirma que tais valores não podem ser obtidos empiricamente (Chibeni 1997, p. 42).

Mais uma dificuldade é apontada por Chibeni dentro do artigo de EPR e relaciona-se à predição e medição simultânea de dois observáveis incompatíveis numa mesma partícula:

De fato, nossa conclusão não seria alcançada se insistíssemos em que duas ou mais quantidades físicas só poderiam ser encaradas como elementos simultâneos de realidade quando pudessem ser simultaneamente medidas ou previstas. Segundo esta perspectiva, como apenas uma das quantidades $P$ e $Q$, mas não as duas simultaneamente, pode ser prevista, elas não são simultaneamente reais. (EPR 1981, p. 96; 1935, p. 780 b) 
Esta observação aparece no penúltimo parágrafo do artigo de EPR, e indica que Podolsky estava ciente desse problema (Chibeni 1997, p. 45), mas ele utiliza a hipótese de localidade para argumentar contra a viabilidade deste critério mais forte de realidade:

Isso [negar que $P$ e $Q$ tenham realidades simultâneas] faz as realidades de $P$ e $Q$ dependerem do processo de medida executado no primeiro sistema, o qual não perturba de modo algum o segundo. Nenhuma definição razoável de realidade pode permitir tal coisa. (EPR 1981, p. 96; 1935, p. 780 b)

\section{A Análise de McGrath}

James H. McGrath analisou detalhadamente o artigo de EPR, exprimindo-o também por meio do cálculo proposicional. Ele dividiu o argumento em três etapas. Das Etapas I e II derivam-se logicamente dois teoremas que servem de suporte para a Etapa III. É importante notar que a descrição lógica de McGrath segue de maneira detalhada a estrutura do argumento presente no artigo de EPR, conforme ficará claro na análise que segue.

A Etapa I, como o próprio McGrath classifica, é uma prova categórica do Teorema denotado por I.10, que pode ser traduzido por:

Não é o caso que haja um elemento de realidade correspondendo ao observável $\mathcal{P}$ e um elemento de realidade correspondendo ao observável $\mathcal{Q}$ quando os operadores $\hat{P}$ e $\widehat{Q}$ não comutam, ou não é o caso que a teoria quântica forneça uma descrição completa da realidade física. (McGrath 1978, p. 560.)

Notemos que este teorema nada mais é do que o teorema que se segue do princípio de incerteza que foi mencionado na seção I.1.

Disso [princípio de incerteza] se segue que ou 1) a descrição da realidade fornecida pela função de onda, não é completa, ou 2) quando os operadores correspondentes a duas quantidades físicas não comutam, essas quantidades não podem ter realidades simultâneas. (EPR 1981, p. 92; 1935, p 778 b)

A Etapa II é apresentada por McGrath também como prova categórica do Teorema II.21, que é lido nos seguintes termos:

Se a teoria fornece uma descrição completa da realidade física, então há um elemento de realidade correspondendo ao observável $\mathcal{P}$ do Sistema II e um elemento de realidade correspondendo ao observável $\mathcal{Q}$ do Sistema II e os operadores $\hat{P}$ e $\hat{Q}$ não comutam. (McGrath 1978, p. 561) 
Notemos também que este teorema corresponde ao condicional lógico a ser provado insistentemente no artigo de EPR e que, segundo Chibeni, é desnecessário.

A Etapa III se utiliza desses dois teoremas para iniciar uma prova da não completude, caracterizada como a reductio ad absurdum.

McGrath, muito detalhadamente, descreve por meio do cálculo proposicional uma série de regras não lógicas, isto é, que se fundamentam em outras fontes de conhecimento. A Etapa I, por exemplo, repousa sobre um axioma físico, relacionado à equação de autovalor da física quântica, na qual um operador aplicado a uma autofunção é igual ao autovalor do operador vezes a própria autofunção, e quatro regras não lógicas baseadas na condição de completude ( $\mathrm{RC}$ - a teoria deve conter uma contrapartida para cada elemento de realidade); no critério de elemento de realidade “invertido" ( $\mathrm{Z}$ - se há contrapartida de um elemento de realidade na teoria então é possível prever o seu valor ${ }^{11}$ ); no princípio de incerteza parte I (X - impossibilidade de estabelecer duas equações de autovalor para dois observáveis incompatíveis em um autoestado $\Psi$ ); e no princípio de incerteza parte II (Y - impossibilidade de prever o valor de um observável se a sua equação de autovalor não é válida para $\Psi){ }^{12}$

A Fig. 2 mostra a Etapa I apresentada por McGrath por meio do cálculo proposicional, no qual há uma contradição entre a possibilidade de previsão (devido à existência de uma contrapartida na teoria) e a impossibilidade de previsão (devido ao princípio de incerteza), levando assim a um reductio ad absurdum, e ao teorema:

$$
\sim\left(\mathrm{R}^{\mathrm{p}} \cdot \mathrm{R}^{\mathrm{q}} \cdot * \hat{\mathrm{P}} \widehat{\mathrm{Q}}\right) \vee \sim \mathrm{C}
$$

Aqui, $\mathrm{R}^{\mathrm{p}} \cdot \mathrm{R}^{\mathrm{q}} \cdot *^{\hat{P}} \widehat{\mathrm{Q}}$ representa os elementos de realidade para os operadores não comutativos $\widehat{\mathrm{P}}$ e $\widehat{\mathrm{Q}}$, e $\mathrm{C}$ representa a completude.

\footnotetext{
${ }^{11}$ A seção I.7 apresentará mais detalhadamente esta regra não lógica (Z) ao abordar a análise de Linda Wessels.

${ }^{12}$ McGrath (1978, pp. 561-62). A notação RC, Z, X e Y é a usada pelo autor.
} 


\section{Stage I}

\begin{tabular}{r|ll}
$\mathrm{i}$ & $\hat{P}\{\operatorname{Cor}\} \mathscr{P} \cdot \hat{Q}\{\operatorname{Cor}\} \mathscr{Q} \cdot \hat{P} \psi=p \psi$ & \\
1 & $\left(R^{\mathscr{P}} \cdot R^{\mathscr{Q}} \cdot *^{\hat{P} Q}\right) \cdot C$ & Hypothesis \\
2 & $C P^{R^{\mathscr{P}}}$ & $1, \mathrm{RC}$ \\
3 & $\diamond P p$ & $2, \mathrm{Z}$ \\
4 & $C P^{R \mathscr{Q}}$ & $1, \mathrm{RC}$ \\
5 & $\diamond P_{q}$ & $4, \mathrm{Z}$ \\
6 & $\diamond P p \cdot \diamond P q$ & 3,5, conjunction \\
& & introduction \\
7 & $\sim(\hat{Q} \psi=q \psi)$ & $i, 1, \mathrm{X}$ \\
8 & $\sim \diamond P q$ & $7, \mathrm{Y}$ \\
9 & $\sim\left[\left(R^{\mathscr{P}} \cdot R^{\mathscr{Q}} \cdot *^{p \hat{Q}}\right) \cdot C\right]$ & 5,8, reductio ad absurdum \\
10 & $\sim\left(R^{p} \cdot R^{q} \cdot *^{P \hat{Q}}\right) \vee \sim C$ & 9, de Morgan's Law
\end{tabular}

Figura 2: Etapa I do argumento de EPR escrita por meio do cálculo proposicional (McGrath 1978, p. 562).

A Etapa II é uma derivação lógica do teorema II.21 que já foi anunciado acima, e no qual a completude implica realidade simultânea da posição e do momento do sistema II, sendo $\widehat{P}$ e $\widehat{Q}$ observáveis incompatíveis.

$$
\mathrm{C} \supset \mathrm{R}_{\mathrm{SII}}^{\mathcal{P}} \cdot \mathrm{R}_{\mathrm{SII}}^{\mathrm{Q}} \cdot * \widehat{\mathrm{P}} \widehat{\mathrm{Q}}
$$

(Teorema II.21)

Essa etapa é mais longa que a primeira, envolve cinco axiomas que são abreviações formais da física da interação de sistemas quânticos e sete regras não lógicas: $\Phi$ representa o sistema combinado (CM); $\Phi$ é não fatorável (B); a equação de autovalor prevê o resultado da medição $(\mathrm{M})$; há processo de redução de estado depois de uma medição (RWP); princípio de localidade (I); previsão sem distúrbio (W); e o critério de elemento de realidade $(\mathrm{CR}){ }^{13}$

A Fig. 3 mostra o cálculo proposicional, apresentado por McGrath, para a Etapa II do argumento.

\footnotetext{
${ }^{13}$ McGrath (1978, pp. 564-66). A notação CM, B, M, RWP, I, W, CR é a usada pelo autor.
} 


\begin{tabular}{|c|c|c|}
\hline 1 & \multirow{2}{*}{\multicolumn{2}{|c|}{$\mid \begin{array}{l}u\{\operatorname{Rep}\} S^{\mathrm{I}} t=0 \cdot v\{\operatorname{Rep}\} S^{\mathrm{I}} t=0 \cdot \hat{A}\{\operatorname{Cor}\} \mathscr{A}^{\mathrm{I}} \cdot \hat{B}\{\operatorname{Cor}\} \mathscr{B}^{\mathrm{I}} \cdot \hat{B} v_{s}=b_{s} v_{s} \\
\quad \hat{A} u_{n}=a_{n} u_{n} \\
S^{\mathrm{I}}\{\text { Iso }\} S^{\mathrm{II}}\end{array}$}} \\
\hline ii & & \\
\hline iii & \multicolumn{2}{|c|}{$\psi\{\operatorname{Rep}\} S^{\mathrm{II}} t=0 \cdot \varphi\{\operatorname{Rep}\} S^{\mathrm{II}} t=0 \cdot \hat{P}\{\operatorname{Cor}\} \mathscr{P O I}^{\mathrm{I}} \hat{Q}\{\operatorname{Cor}\} \mathscr{2}^{\mathrm{I}} \cdot *^{\beta Q}$} \\
\hline iv & \multicolumn{2}{|c|}{$O \Psi_{t=0}=\Psi_{t=t>T}$} \\
\hline $\mathrm{v}$ & \multicolumn{2}{|l|}{$\diamond M_{S I}^{\mathscr{A}} \cdot \diamond M_{S I}^{\mathscr{S}}$} \\
\hline 1 & $C$ & Hypothesis \\
\hline 2 & $\Psi\{\operatorname{Rep}\} S^{I+I I}$ & i, iii, iv, $\mathrm{CM}$ \\
\hline 3 & $\Psi=\sum_{n} \psi_{n} u_{n}\{\operatorname{Rep}\} S^{\mathrm{I}+\mathrm{II}}$ & $2, \mathrm{~B}$ \\
\hline 4 & $\diamond M_{S I}^{\mathscr{A}}$ & $v$, conjunction elimination \\
\hline 5 & $M_{S I}^{\mathscr{A}} \rightarrow a_{n}$ & $\mathrm{i}, 4, \mathrm{M}$ \\
\hline 6 & $\diamond\left(\psi_{k}\{\operatorname{Rep}\} S^{\mathrm{II}}\right)$ & i, $2,3,4,5$, RWP \\
\hline 7 & $\Psi=\sum_{s} \varphi_{s} v_{s}\{\operatorname{Rep}\} S^{\mathrm{I}+\mathrm{II}}$ & $2, \mathrm{~B}$ \\
\hline 8 & $\diamond M_{\mathrm{sI}}^{g}$ & $\vee$, conjunction elimination \\
\hline 9 & $M_{s 1}^{\mathscr{B}} \rightarrow b_{q}$ & $\mathrm{i}, 8, \mathrm{M}$ \\
\hline 10 & $\diamond\left(\varphi_{r}\{\operatorname{Rep}\} S^{I I}\right)$ & i, $2,7,8,9$, RWP \\
\hline 11 & $\diamond\left(\psi_{k}\{\operatorname{Rep}\} S^{\text {II }}\right) \cdot \diamond\left(\varphi_{r}\{\operatorname{Rep}\} S^{\text {II }}\right)$ & 6,10 , conjunction introduction \\
\hline 12 & $M_{\text {SI }}\{\mathrm{ND}\} S^{I I}$ & ii, I \\
\hline 13 & $\diamond P_{p S I I} \cdot P_{p S I I}\{\mathrm{ND}\} S^{\mathrm{II}}$ & $3,12, \mathrm{w}$ \\
\hline 14 & $R_{3 \mathrm{II}}^{\mathscr{P}}\{\operatorname{Cor}\} \mathscr{P}$ & 13, CR \\
\hline 15 & $\Delta P_{q S I I} \cdot P_{q S I I}\{\mathrm{ND}\} S^{\mathrm{II}}$ & $7,12, \mathrm{w}$ \\
\hline 16 & $R_{\text {SII }}^{\mathcal{Q}}\{\operatorname{Cor}\} \mathscr{Q}$ & $15, \mathrm{CR}$ \\
\hline 17 & $C P_{S I I}^{\text {RI }}$ & $1,14, \mathbf{R C}$ \\
\hline 18 & $C P_{\text {SII }}^{R g}$ & $1,16, \mathrm{RC}$ \\
\hline 19 & $C P_{s I I}^{R Q P} \cdot C P_{s I I}^{R 2}$ & 17,18 , conjunction introduction \\
\hline 20 & $R_{s \mathrm{II}}^{\mathscr{g}} \cdot R_{s \mathrm{II}}^{\mathscr{Q}} \cdot *^{P} \hat{Q}$ & iii, 14,16 , conjunction introduction \\
\hline 21 & $C \supset\left(R_{S I I}^{g} \cdot R_{S I I}^{\mathscr{R}} \cdot *^{\hat{P} \hat{Q}}\right)$ & $1-20$, implication introduction \\
\hline
\end{tabular}

Figura 3: Etapa II do argumento de EPR escrita por meio do cálculo proposicional (McGrath 1978, p. 563).

Notemos que, conforme já mencionado, a Etapa II é uma prova do teorema que indica que completude implica em realidade simultânea de dois observáveis incompatíveis. Segundo Chibeni, essa implicação é um condicional desnecessário a ser provado por Podolsky, e na realidade ele acaba provando diretamente o consequente do condicional, isto é, a realidade simultânea.

Observando atentamente a análise de McGrath, percebemos que a assunção de completude corresponde à regra não lógica notada por $\mathrm{RC}$, presente já na derivação do teorema I.10, da Etapa I. Essa regra aparece na Etapa II apenas nas proposições 17 e 18, que são usadas na derivação da proposição 19 , no entanto, nenhuma dessas proposições $(17,18$ e 19) são utilizadas para derivar a proposição 20 , que corresponde à realidade 
simultânea. Dessa forma, podemos concluir que a realidade simultânea é derivada sem a passagem pela assunção de completude (RC), e que, portanto, esta última é desnecessária. Assim, o teorema II.21, no qual a hipótese de completude implica em uma realidade simultânea, também se torna desnecessário, uma vez que a prova realizada é referente diretamente ao consequente do condicional.

A Etapa III é simples, não utiliza axiomas nem regras não lógicas, apenas estabelece um reductio ad absurdum utilizando os dois teoremas derivados, I.10 e II.21. Uma vez que, tanto na crítica de Chibeni quanto na análise de McGrath, notamos que a assunção de completude é desnecessária e que se prova diretamente a realidade simultânea, a Etapa III continuaria válida, mesmo sem o uso do teorema II.21, pois utilizando a derivação da realidade simultânea na Etapa II, a incompletude se seguiria do passo 4 da Etapa III. A Fig. 4 mostra a apresentação de McGrath da Etapa III do argumento de EPR.

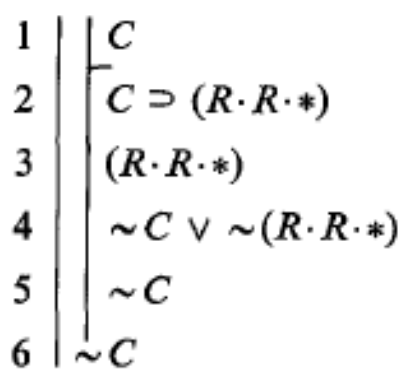

\section{Stage III}

$\quad$ Hypothesis
Theorem, II.21
1, 2, modus ponens
Theorem, I.10
3, 4, modus tollendo ponens
1-5 reductio ad absurdum

Figura 4: Etapa III do argumento de EPR escrita por meio do cálculo proposicional (McGrath 1978, p. 566).

\section{A Análise de Wessels}

Linda Wessels, em 1981, utilizando o artigo de McGrath (1978) como uma de suas referências, também desenvolveu uma profunda e complexa análise lógica do argumento de EPR, de maneira a verificar sua possível validade e consistência.

Wessels dividiu o argumento em apenas dois subargumentos. O primeiro, assim como em McGrath, culminaria em um dilema entre a incompletude e a não realidade simultânea: $(\sim C \vee \sim R S)$. O termo $\sim R S$, que usamos na discussão de Chibeni, é escrito 
por Wessels como $(A)(B)\left(O(A, B) \rightarrow \sim(R(A) \& R(B))^{14}\right.$, e chamado por ela de "sentença de Heisenberg", $H$, e consiste na afirmação de não existência simultânea de dois valores para grandezas físicas representadas por observáveis incompatíveis, que deriva do princípio de incerteza ${ }^{15}$.

No segundo subargumento, a assunção de completude da mecânica quântica implicaria a negação da sentença de Heisenberg, $(C \rightarrow \sim H)$. Portanto, essa negação $\sim H$ corresponde à afirmação da realidade simultânea $R S$; que aparece no condicional lógico que Silvio Chibeni (1997) aponta como desnecessário, ou seja, $(C \rightarrow R S)$. Neste segundo subargumento, Wessels, assim como Chibeni, concorda que a assunção de completude é desnecessária, e que de fato EPR derivam no segundo subargumento a negação direta da sentença de Heisenberg $(\sim H)$, ou seja, a afirmação da realidade simultânea $(R S)$. Ainda assim, e da mesma forma que Chibeni, Wessels conclui que o argumento é válido; entretanto, ela aponta algumas ambiguidades.

Antes de discutir essas ambiguidades, vale a pena explorar um ponto interessante relacionado à derivação do primeiro subargumento. Wessels identifica como premissa remanescente do primeiro subargumento o que identificamos em McGrath como sendo a regra não lógica Z, presente no estágio I de sua análise e correspondendo, conforme a seção I.6, ao critério de elemento de realidade invertido. Wessels o apresenta da seguinte forma:

$$
\mathscr{D}:(A)(T(A) \rightarrow P(A))
$$

Na simbologia adotada por Wessels (1981, p. 4), $\mathscr{D}$ afirma que, para todo observável $A$, se a grandeza física $A$ é um elemento da teoria $(T(A))$, então um valor definido da grandeza $A$ é previsível pela teoria $(P(A))$. No caso de McGrath, essa é a regra não lógica Z. Ambos parecem equivaler à afirmação do artigo de EPR que diz:

Se $\psi$ é uma autofunção do operador $A$, isto é, se $\psi^{\prime} \equiv A \psi=a \psi$, onde $a$ é um número, então a quantidade física $A$ tem, com certeza, o valor $a$ sempre que a partícula esteja no estado dado por $\psi$. De acordo com nosso critério de realidade, para uma partícula no estado $\psi[\ldots]$ existe um elemento de

\footnotetext{
${ }^{14}$ Nesta expressão, $O(A, B)$ identifica que os observáveis $A$ e $B$ são incompatíveis, e $R(A)$ diz que a grandeza física $A$ é um elemento de realidade física. A notação " $(A)$ ", usada por Wessels, representa a quantificação " $(\forall A)$ ”.

${ }^{15}$ Wessels define a "sentença de Heisenberg" (H) fundamentada no artigo original dele de 1927 sobre o princípio de incerteza, alegando o fato curioso de que lá ele afirma a completude da teoria quântica e infere desta, unida à relação de incerteza, "que nenhum sistema pode ter, simultaneamente, valores de duas grandezas físicas se essas grandezas forem representadas em quântica por operadores não comutativos" (Wessels 1981, p. 5).
} 
realidade física correspondente à quantidade física $A$. (EPR 1981, p. 91; 1935, p. 778a)

Esta sentença afirma basicamente a referida regra não lógica $\mathrm{Z}$ de McGrath:

se a teoria contém uma contrapartida de um elemento de realidade, no caso a autofunção $\psi$, então a possibilidade de previsão do valor do observável, correspondente ao elemento de realidade, é assegurada. (McGrath 1978, p. $561)^{16}$

Wessels (1981, p. 5) afirma, entretanto, que essa premissa remanescente $\mathscr{D}$ aparece apenas implicitamente, mas que ela claramente é usada no argumento. De fato, podemos desmembrar a argumentação da seguinte maneira:

$$
\begin{gathered}
\mathscr{C}: R(A) \rightarrow T(A) \\
\mathscr{\mathscr { D } : T ( A ) \rightarrow P ( A )} \\
R(A) \rightarrow P(A)
\end{gathered}
$$

Isto é, assumindo a completude, um elemento de realidade, $R(A)$, implica um elemento da teoria, $T(A)$; mas pela premissa remanescente, $\mathscr{D}$, apontada por Wessels, um elemento da teoria, $T(A)$, assegura sua previsibilidade, $P(A)$; então se há um elemento de realidade, $R(A)$, isso implica na sua previsibilidade, $P(A)$.

Em sua análise lógica, Wessels identifica duas premissas não quânticas principais, a condição de completude de EPR ( $\mathscr{C}$ ), no primeiro subargumento, e critério de realidade de EPR ( $\mathscr{R})$, no segundo subargumento:

Condição de Completude de EPR. Se uma teoria física é completa, então "todo elemento de realidade física deve conter uma contrapartida na teoria física" (Wessels 1981, p. 4, citando EPR)

Critério de Realidade de EPR. "se, sem de modo algum perturbar o sistema, nós pudermos prever com certeza o valor de uma quantidade física, então existe um elemento de realidade física correspondente a esta quantidade física" (Wessels 1981, p. 5, citando EPR)

Wessels aponta então uma primeira ambiguidade na condição de completude. Ela se pergunta:

Para ser considerada completa, uma teoria deve prever o valor da quantidade A possuída pelo sistema $S$, ou é o suficiente apenas prever que o sistema tem algum valor? Se se deseja o valor, a teoria deve prever que o sistema tem tal valor ou simplesmente que medindo $A$ em $S$ este é o valor que será encontrado? (Wessels 1981, p. 8)

\footnotetext{
${ }^{16}$ McGrath faz referência à página $778 b$ do artigo original de EPR (1935).
} 
O questionamento de Wessels é basicamente se "prever com certeza o valor" significa prever o valor possuído previamente ou significa prever um valor qualquer, bem definido (que poderia não pré-existir à medição). Conforme aponta Wessels, a questão de se podemos inferir da mecânica quântica alguma coisa sobre o valor possuído na ausência de uma medição é um tema de muita discordância na interpretação do formalismo quântico. Além disso, Wessels menciona também a problemática da previsão simultânea de dois observáveis, que provocaria a negação da sentença de Heisenberg; por outro lado, se essa previsão não for simultânea, então não haverá contradição dentro do argumento. Sua tentativa então é estabelecer formulações mais precisas do argumento que sejam capazes de dissolver essas ambiguidades. Para isso ela se utiliza da lógica modal. A Fig. 5 apresenta a estrutura básica dos dois subargumentos.

\begin{tabular}{|c|c|}
\hline Subargument 1 & Subargument 2 \\
\hline For all $i: \mathscr{C} i$ & For all $i: \mathscr{R} i$ \\
\hline$Q M i$ & $E P R i$ \\
\hline$\overline{\sim C} \vee H$ & Opm \\
\hline
\end{tabular}

Figura 5: Estrutura lógica dos dois subargumentos de EPR segundo Linda Wessels (1981, p.15).

É possível verificar que, nesta análise, a estrutura principal do argumento é simples, o primeiro subargumento envolve apenas a condição de completude $(\mathscr{C})$ e o princípio de incerteza derivado da mecânica quântica $(Q M)$. O segundo subargumento envolve apenas o critério de realidade física $(\mathscr{R})$ e a realidade simultânea de dois observáveis incompatíveis $(O p m)$, no caso a posição e o momento, derivada no argumento contrafactual $(E P R)$.

Para construir sua análise lógica, Wessels (1981, p. 14) considera várias versões do argumento, onde utiliza versões indexadas por $i=1,2,3,4$ (sendo que $i$ aparece na Fig. 5), que diferem quanto à previsibilidade da teoria. $P 1(A)$ implica que a mecânica quântica pode prever que $S$ tem algum valor (não especificado), para o observável $A$ no tempo $t$. $P 2(A, r)$ implica que a mecânica quântica prevê que $S$ tem valor $r$ para $A$ no tempo $t$. $P 3(A, r)$ implica que se uma medição for feita sobre $S$ no tempo $t$, o valor $r$ será encontrado. $P 4(A, r)$ implica que a mecânica quântica prevê que se uma medição de $A$ 
fosse feita sobre $S$ no tempo $t$, o valor $r$ seria encontrado. Notemos que apenas $P 3$ e $P 4$ envolvem medições e que, além disso, apenas $P 4$ envolve um cenário contrafactual.

Wessels aplica cada possibilidade gerada pelos índices $i$ às duas premissas do argumento, quais sejam, a condição de completude $(\mathscr{C} i$ ) e o critério de realidade física ( $\mathscr{R} i$ ), gerando quatro possibilidades de interpretação para cada uma delas. Além disso, ela gera, ainda por meio dos mesmos índices, quatro possibilidades de interpretação da não previsibilidade de dois observáveis incompatíveis que surge da mecânica quântica $(Q M i)$ por meio do princípio de incerteza, e mais quatro possibilidades de interpretação da possível previsão de dois observáveis incompatíveis (EPRi).

Ao analisar o primeiro subargumento, sua conclusão para a premissa remanescente $Q M$ é de que apenas as versões $Q M 3$ e $Q M 4$ se seguem da mecânica quântica na perspectiva da interpretação de Copenhagen, pois esta sempre se refere à não previsibilidade de valores medidos, e não de valores possuídos. Ao analisar a condição de completude e o caráter não determinístico da teoria quântica, Wessels finalmente chega a um dos pontos principais de sua análise, o fato de que a condição de completude parece implicar que apenas teorias sobre sistemas determinísticos podem ser completas, pois a previsibilidade teórica implica considerações sobre influências físicas do passado e presente em um sistema $S$. No entanto, a mecânica quântica é claramente uma teoria que viola o determinismo, pois trata o colapso do sistema para um estado definido como sendo aleatório e dependente de uma medição. Dessa forma, a condição de completude usada parece não ser um critério apropriado.

Wessels conclui então que não é razoável exigir que uma teoria seja capaz de prever características de $S$ com base nas influências físicas temporalmente anteriores de $S$, quando nem mesmo a própria natureza é capaz de determinar essas características de maneira única. Com isso ela explica que as versões $\mathscr{C} 2, \mathscr{C} 3$ e $\mathscr{C} 4$, satisfazem justamente esse requerimento, se o sistema for não determinístico, pois essas três versões envolvem a previsão de um valor $r$ (um elemento da teoria correspondente a um elemento da realidade) determinado em três condições: sem medição, com medição e em um cenário contrafactual.

Até esse momento, portanto, apenas $\mathscr{C} 1$ seria apropriada para uma teoria de um sistema não determinístico, pois esta condição está associada ao que Wessels chama de sistema fracamente determinado, isto é, um sistema que apenas determina se há ou não há algum valor para um observável A no tempo t, mas não determina exatamente qual valor. Aqui Wessels se pergunta o que aconteceria "se um sistema quântico for não 
apenas não determinístico, mas também falhar em ser fracamente determinado?" (Wessels 1981, p. 18). Nessas condições então, nenhuma das versões $\mathscr{C} i$ seriam adequadas e "se os sistemas quânticos não são fracamente determinados, nem mesmo $\mathscr{C} 1$ é justificável, e não há versão correta [sound] do primeiro subargumento" (Wessels 1981, p. 19).

Ao analisar as versões do critério de realidade, $\mathscr{R} i$, no segundo subargumento, Wessels verifica que, segundo a base mínima da interpretação de Copenhagen da mecânica quântica, "quando a mecânica quântica atribui probabilidade um para o valor $r$ do observável $A$ para o sistema $S$ na situação $\sigma$, esta é uma previsão com certeza de que se $S$ for (fosse) medido para $A$ em $\sigma$, o valor $r$ será (seria) encontrado" (Wessels 1981, p. 13). Ou seja, as previsões quânticas são sempre referentes ao resultado de uma medição, seja ela condicional ou contrafactual. Dessa forma, as versões do critério de realidade $\mathscr{R} 3$ e $\mathscr{R} 4$ não são aceitáveis, na interpretação ortodoxa, para inferir as propriedades possuídas por um sistema quântico, e portanto, não podem inferir a existência de elementos de realidade antes da medição.

Restariam então as versões $\mathscr{R} 1$ e $\mathscr{R} 2{ }^{\prime}{ }^{17}$ mas ainda assim, o caráter não determinista dos sistemas quânticos geraria problemas. Wessels admite:

Nós concluímos que se os sistemas quânticos não são fracamente determinados, então nenhuma dessas versões de critério de realidade podem ser adotadas; se os sistemas quânticos são fracamente determinados (embora não determinísticos) então $\mathscr{R} 1$ e $\mathscr{R} 2$ ', e somente estas, são justificáveis. (Wessels 1981, p. 20)

Ao concluir sua análise, Wessels verifica, para cada um dos dois subargumentos, se as premissas se seguem da mecânica quântica e se são apropriadas. No primeiro subargumento, se os sistemas quânticos forem fracamente determinados, as únicas versões interpretativas para o princípio de incerteza que se seguem da interpretação de Copenhagen são $Q M 3$ e $Q M 4$; entretanto, a única condição de completude válida para um sistema de determinação fraca é $\mathscr{C} 1$. Dessa forma, nenhuma combinação entre as premissas possíveis dentro da interpretação de Copenhagen é válida, já que se mesclariam as diferentes interpretações de previsão quântica indexadas por $i$.

Da mesma forma, no segundo subargumento, apenas EPR3 e EPR4 se seguem diretamente da mecânica quântica, pois correspondem à possibilidade de previsão de

\footnotetext{
${ }^{17} \mathrm{Em} \mathscr{R} 2$ ', o apóstrofe usado na parte superior da representação indica uma versão mais fraca, definida por Wessels (1981) na p. 20: "Nesse infere-se não que na situação $\sigma$ o sistema $S$ tem o valor particular previsto para $A$ em alguma situação $S$-equivalente a $\sigma$, mas simplesmente que $S$ tem algum valor (não especificado) em $\sigma$ quando um valor para $A$ é previsto em uma situação $S$-equivalente a $\sigma$ ".
} 
dois observáveis incompatíveis envolvendo medições condicionais ou contrafactuais. Porém, as únicas versões do critério de realidade válidas para justificar a existência dos elementos de realidade são $\mathscr{R} 1$ e $\mathscr{R} 2$ ', o que tampouco combina o mesmo índice interpretativo. Wessels conclui, como diagnóstico preliminar, que "o argumento de EPR deve ser julgado não correto" (Wessels 1981, p. 21).

No entanto, Wessels afirma que a conclusão acima pode ser evitada se considerarmos que EPR se basearam em outras assunções interpretativas, que eles teriam considerado óbvias demais para mencionar. Wessels (1981, p. 23) sugere o uso de uma premissa implícita, $I^{*}$, que indica a assunção de uma leitura da mecânica quântica que "requer propriedades possuídas pelos sistemas na ausência de medição". Com isso, é possível encontrar duas versões válidas para o primeiro subargumento e quatro para o segundo subargumento.

Wessels pretende então encontrar qual das versões geradas após assumir que $I^{*}$ estava na mente de EPR. Ela acredita que as premissas $\mathscr{C} 2$, que diz que se há um elemento de realidade, a teoria deve prever o valor $r$ sem envolver medição; e $\mathscr{R} 2$, que também implica que se for possível prever $r$ na ausência de uma medição, há um elemento de realidade; capturariam a pretendida condição de completude e critério de realidade por EPR, além de $I^{*}$ ter sido assumido tacitamente. Mesmo assim, Wessels conclui que não é possível encontrar versão válida combinando $\mathscr{C} 2$ e $Q M 3$ ou $Q M 4$, além de admitir que não está segura de que historicamente as versões $Q M 3$ e $Q M 4$ sejam aquelas derivadas diretamente da teoria.

Mesmo assim, Wessels prossegue sua análise para o segundo subargumento afirmando que $I^{*}$ não é aceitável do ponto de vista da interpretação de Copenhagen, e que seguindo com a intenção de repousar o argumento sobre premissas não controversas, a negação de $I^{*}$ bloquearia o segundo subargumento, pois sem ela, $\mathscr{R} 2$ não poderia ser combinado com EPR3 e EPR4 para resultar na negação da sentença de Heisenberg.

Assim, a conclusão de Wessels é que mesmo quando as premissas suprimidas são consideradas, não há versão correta do primeiro subargumento. Entretanto, Wessels coloca que o desafio mais sério deste argumento à interpretação padrão da mecânica quântica está justamente no segundo subargumento, com a negação da sentença de Heisenberg. Ela afirma ainda que, dependendo do suporte de suposições adotado, a negação da sentença de Heisenberg pode ser justificada. 
Segundo a autora, a primeira suposição a ser aceita deve ser que os sistemas quânticos sejam fracamente determinados $(W D)$, isto é, o sistema apenas determina se há ou não há algum valor para um observável $A$ no tempo $t$, mas não determina exatamente qual valor, pois caso contrário, não haveria versão aceitável do critério de realidade, pois não seria possível determinar com certeza o valor do observável $A$ no tempo $t$, que é uma exigência do critério de elemento de realidade. Aceitando então $W D$, as versões $\mathscr{R} 1$ e $\mathscr{R}$ 2' são justificáveis e são aquelas que não incluem medição no enunciado sobre a previsibilidade. Ainda assim, para combiná-las com as versões de $E P R$ que seguem diretamente da mecânica quântica, EPR3 e EPR4, é necessário que a suposição $I^{*}$ seja aceita, pois sem ela, a possibilidade de previsão dos dois observáveis incompatíveis que é obtida da situação experimental contrafactual do argumento não poderá concluir que esses valores sejam possuídos na ausência da medição.

Dessa forma, Wessels inclui mais duas premissas necessárias à negação da sentença de Heisenberg, $\sim H$ (isto é, essa negação é a afirmação da existência simultânea de dois valores para observáveis incompatíveis): WD (que os sistemas quânticos sejam fracamente determinados) e $I^{*}$ (que as propriedades quânticas sejam possuídas pelos sistemas na ausência de medição), afirmando que "se uma interpretação é proposta em que a sentença de Heisenberg seja verdadeira, então pelo menos $W D$ ou $I^{*}$ deve ser assumida como falsa" (Wessels 1981, p. 26-27), isto é, qualquer interpretação adequada deve negar pelo menos uma das premissas $W D, I^{*}$ ou $H$, sendo esta uma condição necessária.

\section{A Resposta de Bohr}

No mesmo ano da publicação do artigo de EPR, Niels Bohr publicou sua resposta também no Physical Review, sob o mesmo título "Can Quantum-Mechanical Description of Physical Reality be Considered Complete?”. No artigo, Bohr argumenta que há uma ambiguidade no critério de realidade física utilizado por EPR, e propõe solucionar o problema da incompletude por meio do conceito de complementaridade.

Sobre o critério de realidade formulado por EPR e já apresentado na seção I.1, Bohr identifica uma ambiguidade essencial no que diz respeito à expressão "sem de modo algum perturbar o sistema". Bohr (1981, p. 97; 1935 p. 696 a) inicia reconhecendo que o experimento em mecânica quântica proposto por EPR "é interessante", indicando uma semelhança com a Mecânica Clássica, no sentido de que, 
em ambas, é possível prever o valor de qualquer variável de um sistema mecânico a partir de medições executadas em outro sistema.

Porém, Bohr irá apontar que há uma diferença importante entre medições em sistemas clássicos e quânticos, pois em experimentos quânticos há uma impossibilidade de controlar e analisar mais detalhadamente as reações entre o objeto e o instrumento de medição. Esta é uma propriedade essencial de qualquer arranjo adequado ao estudo do quantum de ação, que possui "um aspecto de individualidade completamente estranho à física clássica” (Bohr 1981, p. 100; 1935, p. 697 b).

Bohr passa boa parte do artigo exemplificando essa característica no experimento da dupla fenda e definindo o conceito de complementaridade de arranjos experimentais, antes de voltar em seu argumento principal. EPR supuseram que, em um par de partículas em um estado entrelaçado, a medição feita em uma das partículas não perturba a outra partícula. Bohr dirá que há uma ambiguidade na expressão usada por EPR de "sem de modo algum perturbar um sistema":

É claro que, num caso como o que se acabou de considerar, não há terreno para qualquer perturbação mecânica sobre o sistema, durante o último e crítico estágio do processo de medida. Mas mesmo nesse estágio existe essencialmente a questão de uma influência sobre as próprias condições que definem os tipos possíveis de previsões relativas ao comportamento futuro do sistema. (Bohr 1981, p. 103-4; 1935, p. 700 a; citado também em Bohr 1949, p. 234)

Aparentemente Bohr, ao se deparar com a ausência de um distúrbio mecânico na previsão das grandezas físicas do segundo sistema no argumento de EPR, parece abrir mão da perturbação física e partir para uma explicação um tanto metacientífica. Segundo Chibeni (2005, p. 11), a resposta de Bohr ao EPR "mostra que ele sentiu a insuficiência da sua argumentação anterior, baseada na interpretação do distúrbio da medição. Ele se propôs a aprofundar a crítica dos padrões realistas da física clássica, e a desviar o debate para a arena linguística”. Dessa forma, segundo Bohr, a medição da posição da primeira partícula permitiria a previsão da posição da segunda, mas não do seu momento; a medição do momento da primeira partícula permitiria prever o momento da segunda, mas não a sua posição. Assim, haveria uma espécie de influência sobre a outra partícula e sobre as condições de previsão de suas grandezas físicas, e é por meio dessa ambiguidade no critério de elemento de realidade que Bohr pretende refutar EPR.

Examinemos agora aspectos do argumento de Bohr com mais detalhe. O físico dinamarquês salientou que a mecânica quântica se baseia num formalismo matemático 
coerente que cobre automaticamente qualquer processo de medição, mesmo o proposto por EPR, e afirmou que a aparente contradição apresentada pelo argumento de incompletude apenas "põe a nu uma inadequação essencial da perspectiva costumeira da filosofia natural em fornecer uma descrição racional dos fenômenos físicos do tipo que estamos interessados na mecânica quântica” (Bohr 1981, p. 98; 1935, pp. 696-7).

Bohr salientou a correção das deduções matemáticas da teoria quântica, destacando a derivação do princípio de incerteza a partir do seu formalismo. Assim, enfatizou "o fato de não ser jamais possível, na descrição do estado de um sistema mecânico, atribuir valores definitivos a duas variáveis canonicamente conjugadas" (Bohr 1981, p. 98; 1935, p. 696b). É este ponto que EPR procuram atacar em seu argumento da incompletude.

Explorando o princípio de complementaridade, Bohr examina diferentes versões do experimento da fenda simples e dupla, ilustrando a distinção entre fenômenos clássicos e quânticos no que diz respeito ao problema da medição; a aplicação do formalismo matemático quântico, que contradiz a costumeira filosofia natural e a descrição racional; e como essas duas perspectivas se relacionam com a ambiguidade apontada por ele no critério de realidade física. Os primeiros três experimentos a serem examinados podem ser considerados um resumo do debate entre Bohr e Einstein no Congresso de Solvay de 1927.

No primeiro arranjo experimental examinado, Bohr (1981, p. 99; 1935, p. 697a) considera uma partícula que atravessa uma fenda num diafragma (Fig. 6).

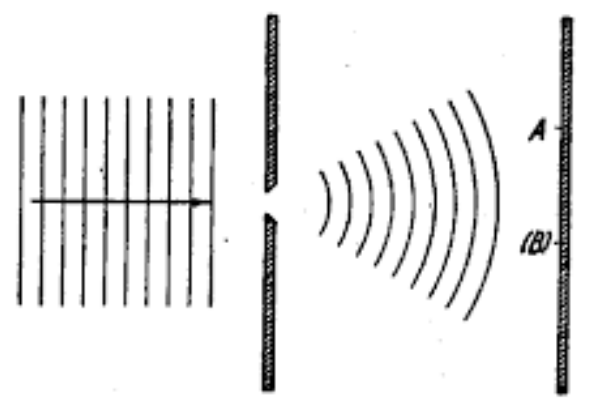

Figura 6: Diagrama do primeiro arranjo experimental, de fenda simples (Bohr 1949, p. 212).

Após a partícula passar pela fenda, o fenômeno da difração implicará uma incerteza na quantidade de movimento da partícula (na direção paralela ao diafragma que contém a fenda), incerteza esta que será tanto maior quanto menor for a largura da 
fenda, pois a largura da fenda determina a incerteza $\Delta q$ da posição da partícula ao passar por ela. Pelo princípio de incerteza:

$$
\Delta p \Delta q \sim h
$$

Segundo Bohr, a incerteza $\Delta p$ da partícula está relacionada à troca de quantidade de movimento com o diafragma. A discussão então proposta por Bohr é o quanto essa interação com o aparato de medição deve ser levada em consideração na descrição do fenômeno.

Bohr supõe então um segundo arranjo experimental com dois diafragmas, o primeiro com uma fenda, no qual a partícula - ou o elétron - sofre difração, e o segundo com diversas fendas paralelas (entre si e com a fenda do primeiro diafragma), no qual a partícula sofreria interferência, e uma chapa fotográfica em seguida (Fig. 7).
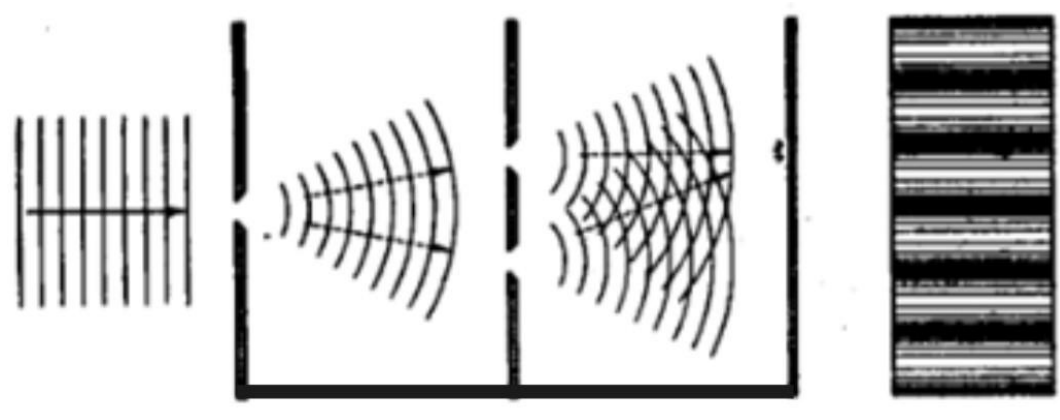

Figura 7: Diagrama do segundo arranjo experimental, com dois diafragmas, chapa fotográfica e suporte fixo (adaptado de Bohr 1949, p. 216). No texto, Bohr (1981, p.99; 1935, p. 697b) considera que o segundo diafragma possa conter "diversas fendas paralelas", não apenas as duas mostradas na figura.

Todo o conjunto dos dois diafragmas e da chapa fotográfica está rigidamente fixado a um suporte comum que define o referencial espacial, de maneira que a quantidade de movimento trocada com o diafragma será transferida ao suporte comum. Dessa forma, não há maneira de considerar essa reação do aparato experimental na previsão do resultado final, ou seja, na previsão sobre a posição da impressão da partícula sobre a chapa fotográfica.

O ponto que Bohr pretende implementar com esse arranjo experimental é a impossibilidade de uma análise mais detalhada das reações da partícula no instrumento de medição, o que garante a formação de franjas de interferência.

Bohr então propõe um terceiro arranjo experimental, no qual o primeiro diafragma não está conectado pelo suporte comum aos outros componentes do 
experimento (Fig. 8). Considere uma partícula que chegue à chapa fotográfica. Conhecendo o momento inicial da partícula (na direção paralela ao diafragma) e do primeiro diafragma, e medindo a quantidade de movimento final deste primeiro diafragma, seria possível inferir a quantidade de movimento da partícula após sua passagem pela primeira fenda, e portanto inferir por qual fenda ela passou, antes de atingir a chapa fotográfica.

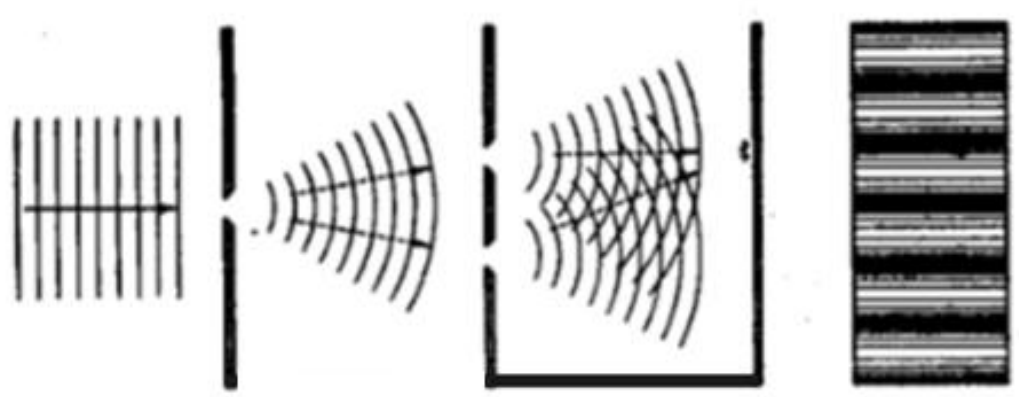

Figura 8: Diagrama do terceiro arranjo experimental, com dois diafragmas, chapa fotográfica e sem suporte fixo para o primeiro diafragma (adaptado de Bohr 1949, p. 216). Ao se determinar a quantidade de movimento do primeiro diafragma, o padrão de interferência é destruído.

Porém, "na situação adequada ao controle da quantidade de movimento do primeiro diafragma, este corpo não pode ser mais empregado com o propósito de ser um instrumento de medida [...] deve, da mesma maneira que a partícula que atravessa a fenda, ser tratado como um objeto de investigação, no sentido de que as relações quânticas de incerteza relativas à posição e à quantidade de movimento precisam ser explicitamente levadas em consideração" (Bohr 1981, p. 101; 1935, p. 698 a-b).

Assim, se o momento inicial do primeiro diafragma é preparado com precisão, sua posição será mal definida, e "pode-se mostrar" que "a menor incerteza sobre a posição do primeiro diafragma compatível com um tal conhecimento [de sua quantidade de movimento] implicará a destruição total de qualquer efeito de interferência” (idem). O ponto é que o primeiro diafragma estaria inicialmente numa superposição de posições bem definidas (já que sua quantidade de movimento foi preparada com exatidão), com uma incerteza $\Delta q$, e essa superposição de posições seria transferida para o padrão espacial de interferência na chapa fotográfica, resultando na "destruição total de qualquer efeito de interferência" (Bohr 1981, p. 101; 1935, p. 698b).

A situação desses dois últimos arranjos experimentais, na visão de Bohr, não reflete uma descrição incompleta da teoria quântica, que teria que sacrificar um dos elementos de realidade. Pelo contrário, na teoria quântica há uma “impossibilidade [...] 
de controlar com precisão a reação do objeto sobre os instrumentos de medida" (p. 102). Não se trata apenas de "uma ignorância acerca dos valores de certas quantidades físicas, mas com a impossibilidade de definir tais quantidades de modo inequívoco" (idem). Isso leva a procedimentos experimentais essencialmente diferentes adequados à medição de cada observável, e a escolha entre um ou outro aspecto da descrição do fenômeno é uma indicação da complementaridade entre essas descrições. No segundo experimento tem-se um fenômeno ondulatório (com franjas), e no terceiro um fenômeno corpuscular (com trajetórias bem definidas).

Para aplicar essas observações ao experimento utilizado no artigo de EPR, Bohr elabora um quarto arranjo experimental composto por um diafragma com duas fendas paralelas através das quais passam duas partículas independentes uma da outra.

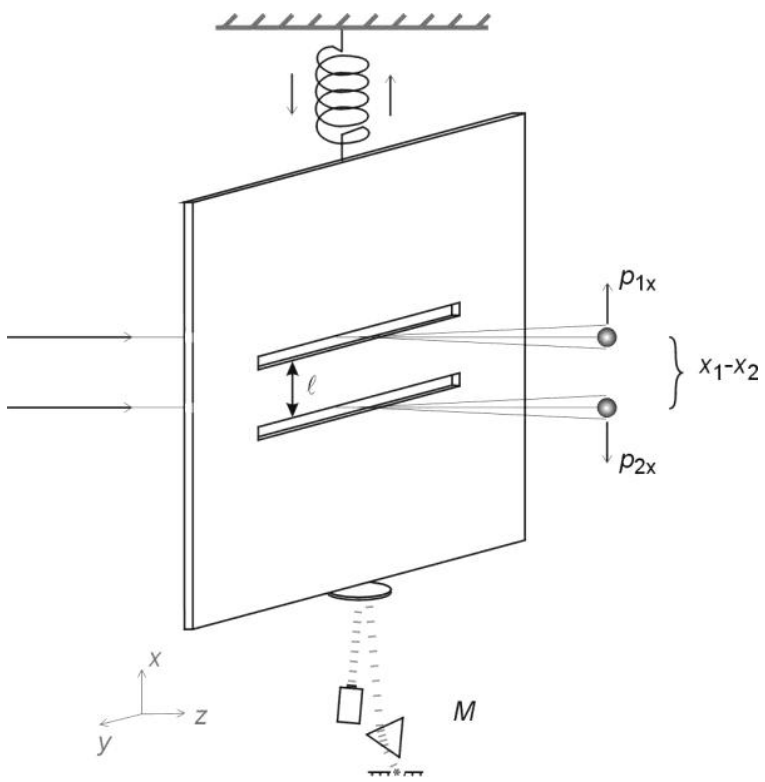

Figura 9: Quarto arranjo experimental descrito por Bohr. Esta seria a realização física para preparar o estado entrelaçado de EPR. A quantidade de movimento do diafragma é monitorado experimentalmente, sendo nula no início (preparação) e no final (pós-seleção). Neste caso, a soma dos momentos das partículas é zero. Por outro lado, pelo princípio de incerteza aplicado ao diafragma, a posição inicial das fendas é desconhecida, assim como das partículas. Mas a diferença de posições é fixada pela separação entre as fendas, logo após a passagem das partículas. Figura obtida de Pessoa (2006, p. 209).

Ao medir a quantidade de movimento do diafragma antes e depois da passagem das partículas, é possível determinar a soma das quantidades de movimento na direção perpendicular as fendas, além de ser conhecida a diferença entre as coordenadas das partículas, conforme as equações abaixo, permanecendo indeterminados os valores individuais dessas grandezas. 


$$
\begin{gathered}
P_{1 y}+P_{2 y}=A \\
X_{1 y}-X_{2 y}=B
\end{gathered}
$$

Com essas relações é fácil perceber que com uma medição subsequente da posição ou do momento de uma das partículas é possível, sem interferir na outra partícula, determinar respectivamente a posição ou o momento desta. Escolher qual observável medir, segundo a perspectiva de Bohr, é apenas uma “discriminação entre procedimentos experimentais, que permitem o uso inequívoco de conceitos clássicos complementares" (Bohr 1981, p. 103; 1935, p. 699b).

Neste último arranjo experimental, ao medir a posição de uma das partículas, mede-se a posição do diafragma rígido, mas ocorre uma perturbação incontrolável no momento do diafragma, o que impossibilita a previsão do momento da outra partícula. Por outro lado, ao medir o momento de uma das partículas, não há como determinar a posição do diafragma e, portanto, a posição da outra partícula (Bohr, 1981, p. 103; 1935, p. 700a).

Seria aí que reside a ambiguidade no uso do termo "sem de modo algum perturbar o sistema”. Nesse caso, conforme observa Bohr, obviamente não há perturbação mecânica sobre a partícula que não está sendo medida, no entanto, existe uma "influência sobre as próprias condições que definem os tipos possíveis de previsões relativas ao comportamento futuro do sistema". Para Bohr, essas condições fazem parte da descrição de qualquer fenômeno e a argumentação de EPR não justifica sua conclusão pela incompletude. Nas medições quânticas há uma interação incontrolável entre os objetos e os instrumentos de medição, levando à exclusão mútua de dois procedimentos experimentais que permitem a definição simultânea de quantidades físicas complementares.

Bohr aponta para uma distinção fundamental entre as descrições clássicas e quânticas dos fenômenos físicos, em que, na física clássica, a distinção entre objeto e instrumentos de medição não implica nenhuma diferença no caráter da descrição do fenômeno, ao passo que na teoria quântica essa relação entre objeto e instrumento de medição é fundamental para a descrição do fenômeno, e suas raízes, segundo Bohr, estão no uso indispensável de conceitos clássicos na interpretação das medições.

Percebemos então que, na visão de Bohr, há uma ambiguidade no critério de elemento de realidade física, pois apesar de não haver "perturbação mecânica" na partícula não medida, haverá "uma influência sobre as próprias condições que definem 
o sistema”, refletindo na impossibilidade de atribuir valor para a grandeza conjugada da partícula não medida. Para Bohr, em um experimento a nível quântico, a interação entre o instrumento de medição e o objeto provoca reações incontroláveis que nos obrigam a discriminar entre diferentes procedimentos experimentais, que permitem o uso inequívoco desses conceitos clássicos (como posição e momento) e reforçam a interpretação da complementaridade, reafirmando a teoria quântica como teoria completa.

Silvio Chibeni (2005) apresentou uma variante mais forte do argumento de EPR que, segundo ele, não poderia ser neutralizada pelas manobras filosóficas de Bohr. Chibeni (2005, p. 13) afirma que "no sistema de EPR, a redução de estado de um objeto remoto em relação ao local de medição deve ser entendida epistemicamente - isto é, como um mero acréscimo ao nosso conhecimento sobre o objeto, desacompanhado de qualquer alteração física”. Assim, uma única medição feita sobre um dos objetos de um sistema correlacionado possibilitaria a previsão do resultado de uma medição da mesma grandeza feita sobre o outro objeto distante, mas como esse valor não estaria contido no estado de descrição do objeto antes da medição, a teoria seria incompleta e a teoria quântica não estaria habilitada para descrever completamente as propriedades individuais dos objetos. A atribuição teórica da probabilidade $1 / 2$ para este resultado bem definido deveria ser entendida como uma probabilidade clássica ou epistêmica.

Chibeni faz referência ao argumento original de Einstein, que é mais simples e tem a vantagem de chegar à conclusão de incompletude sem qualquer referência a arranjos experimentais mutuamente excludentes, nem a grandezas incompatíveis (ver seção I.10, a seguir). Além disso, Chibeni defende que não se faz uso de contrafactuais. Como o contexto experimental é único o tempo todo, esta variante escaparia da crítica de Bohr, e "não deixa espaço para acusações de transgressão de supostas regras para o uso não ambíguo de termos referentes a propriedades reais dos objetos" (Chibeni 2005, p. 13).

\section{A Versão de Bohm}

David Bohm, em 1951 publicou um livro chamado Quantum Theory, que contém uma abordagem interessante do paradoxo de EPR (que, curiosamente, chama de “ERP”). Bohm (p. 611) comenta que a crítica de EPR “de fato, mostrou-se injustificada", citando o artigo de Bohr (1935) e de Furry (1936). Isso é curioso, pois 
um ano depois ele faria uma análise diferente do problema, em seu artigo sobre a interpretação causal (Bohm 1952). Em sua crítica a EPR, Bohm (1951, p. 611) argumenta que os autores fazem uso de assunções a respeito da natureza da matéria que parecem ser naturais, mas que implicitamente contradizem a teoria quântica. Aponta que a análise do argumento proporciona um profundo conhecimento sobre a diferença entre os conceitos clássicos e quânticos da natureza da matéria. Além disso, Bohm apresenta uma versão do argumento utilizando as propriedades de spin de partículas correlacionadas. De fato, sua versão é análoga a de EPR e não acrescenta mudanças na essência do argumento, porém tornou-se mais clara e conveniente no que diz respeito ao desenvolvimento de testes experimentais, por se tratar de grandezas discretas.

Em sua análise, Bohm indica a presença de quatro suposições dentro do argumento, duas explicitas e duas implícitas. A primeira delas é o critério de completude para uma teoria física.

(1) Todo elemento de realidade física deve ter uma contrapartida em uma teoria física completa. (Bohm 1951, p. 612)

A segunda suposição é o critério suficiente para reconhecer um elemento de realidade.

(2) Se, sem de modo algum perturbar o sistema, pudermos prever com certeza (i.e., com probabilidade igual à unidade) o valor de uma quantidade física, então existe um elemento de realidade correspondente a esta quantidade física. (Bohm 1951, p. 612)

Bohm afirma que o uso desses dois critérios repousa implicitamente sobre as seguintes suposições sobre a realidade:

(3) O mundo pode ser corretamente analisado em termos de "elementos de realidade" existentes distinta e separadamente.

(4) Qualquer um desses elementos deve ser uma contrapartida de uma quantidade matemática definida precisamente, presente em uma teoria completa. (Bohm 1951, p. 612)

Neste ponto é interessante comparar essas quatro suposições com aquelas explicitadas por McGrath. As duas primeiras são simples, já que são colocadas explicitamente por EPR. A suposição (1) de Bohm é condição de completude (RC, na notação de McGrath) e a suposição (2) é o critério de elemento de realidade $\mathrm{CR}$. A tentativa de encontrar as suposições (3) e (4) em McGrath fracassa. A suposição (3) é uma tese realista mais forte que o critério $\mathrm{CR}$, e salienta a separabilidade do universo em termos de elementos de realidade distintos e independentes. A suposição (4) exige 
apenas que a contrapartida em RC seja exata. Como são teses "implícitas”, é razoável que não sejam encontradas escritas nem em EPR, nem em McGrath.

Bohm pretende mostrar que esses critérios não deveriam ser aplicados em um nível quântico de precisão. Considerando que o objetivo de EPR era mostrar que a interpretação corrente da teoria quântica era insuficiente e que a função de onda não continha uma descrição completa da realidade física, Bohm menciona que se seu argumento estivesse correto, haveria a necessidade de se buscar uma teoria mais completa, por meio de variáveis ocultas! Sabemos que é isso que Bohm faria ao terminar a redação do livro. ${ }^{18}$

Bohm inicia sua exploração do tema supondo um sistema descrito pelo autoestado $\Psi_{a}$, no qual o observável $A$ tem um valor definido $a$. Ele considera também um observável $B$, que não comuta com $A$ e que, portanto, não existe uma função de onda para a qual $A$ e $B$ tenham valores definidos simultaneamente. Bohm afirma que, nessa situação, adotando a suposição (4), assumir que a função de onda fornece uma descrição completa da realidade leva à conclusão de que $A$ e $B$ não podem existir simultaneamente. Isso implica que, quando $B$ é medido e se obtém um valor definido, o elemento correspondente ao observável $A$ é destruído. Para Bohm, é natural supor que essa destruição é devida aos quanta transferidos do aparelho de medição para o sistema.

O experimento hipotético de EPR, porém, consegue medir um observável sem de nenhum modo perturbar o sistema! Bohm é bastante didático ao salientar este ponto central do trabalho de EPR. Esta montagem proporciona a EPR a possibilidade "de obter uma contradição entre a suposição de que a teoria quântica fornece uma descrição completa da realidade e a suposição de que seu critério de realidade deve necessariamente se aplicar a qualquer teoria completa" (Bohm 1951, p. 613). Dado que este último critério é aceito, a única alternativa razoável é que a teoria quântica não forneça uma descrição completa da realidade física.

Para analisar o experimento hipotético de EPR, conforme já indicamos, Bohm propõe uma versão diferente, mas conceitualmente equivalente e de tratamento matemático mais fácil. Ele supõe uma molécula contendo dois átomos de spin $\eta / 2$ (ou simplesmente $1 / 2$ ), em um estado de spin total zero. Pode-se dizer, seguindo Bohm, que os spins de cada átomo apontam para direções opostas. Ele supõe então que esta

\footnotetext{
${ }^{18} \mathrm{O}$ professor Ernesto Hamburger, do IFUSP, foi aluno de Bohm nas aulas de Mecânica Quântica, e conta que ele usava o Quantum theory como livro didático, mas em vários trechos dizia: "o autor deste livro está errado".
} 
molécula seja desintegrada por um processo que não modifique o momento angular total do sistema. Os dois átomos se encontrarão, portanto, separados, tendo cessada a interação entre eles, contudo o momento angular de spin combinado permanece sendo zero, pois, por hipótese, nenhum torque atuou sobre o sistema.

Após analisar um exemplo de momentos angulares correlacionados na física clássica, Bohm passa a analisar como o experimento seria descrito na teoria quântica. Nesse caso, o observador pode medir qualquer um dos três componentes, $x, y$ ou $z$ do spin da partícula 1, por exemplo, mas não mais do que um componente. De qualquer forma, seja qual for o componente medido, o mesmo componente do átomo 2 terá sempre o valor oposto, e, assim como na teoria clássica, é possível medir indiretamente qualquer componente do spin do átomo 2. Assumindo a hipótese de localidade, como as duas partículas não interagem a distância, trata-se de medir um componente arbitrário do spin do átomo 2 sem de modo algum perturbar o átomo 2.

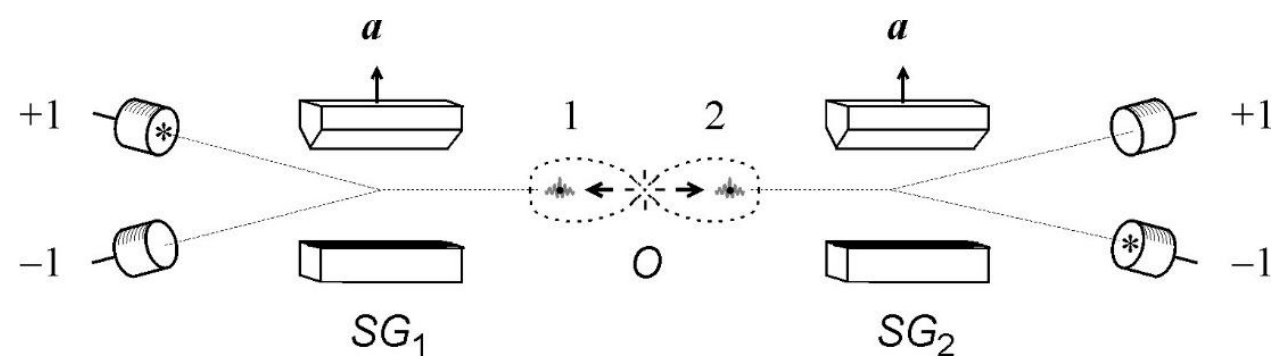

Figura 10: Estado de singleto de duas partículas de spin 1/2 (Pessoa 2006, p. 216).

Para concluir o argumento na versão de Bohm, um ponto importante é que o observador é livre para reorientar o aparato de medição em qualquer direção arbitrária enquanto os átomos estão em voo, e assim, obter um valor para qualquer componente do spin. Dessa forma, se o critério suficiente de elemento de realidade (2) de EPR é aplicável, então devem existir simultaneamente elementos de realidade no segundo átomo definidos precisamente, correspondendo aos três componentes do spin. Como a função de onda pode especificar apenas um desses componentes com precisão completa por vez, conclui-se que a função de onda não fornece uma descrição completa de todos os elementos de realidade existentes no segundo átomo (Bohm, 1951, pp. 614-15).

Esta versão do argumento, utilizando os componentes do spin dos átomos, é análoga à versão original de EPR e, portanto, conduz à mesma conclusão. A resposta de Bohm ao argumento envolve a análise das suposições implícitas (3) e (4) apontadas por ele no início. Segundo Bohm (p. 615), essas suposições podem ser entendidas como a 
hipótese de que "o mundo é de fato feito de 'elementos de realidade' que existem separadamente e são definidos precisamente" (podemos chamá-la de "hipótese da realidade separada e precisa". No entanto, sublinha Bohm, a teoria quântica implica uma concepção bastante diferente do mundo, em nível microscópico.

Após descrever matematicamente o sistema de duas partículas de spins correlacionados, Bohm retorna à discussão das suposições (3) e (4), que seriam as raízes de toda teoria clássica e podem ser entendidas como a hipótese de que a realidade é construída sobre um plano matemático, pois é exigido que "todo elemento que aparece no mundo real deva corresponder precisamente a algum termo aparecendo em um conjunto completo de equações matemáticas" (p. 619).

Para Bohm, a correspondência biunívoca (um-para-um) entre teoria matemática e elementos de realidade bem definidos existe apenas no nível clássico de precisão, ao passo que no nível quântico haveria apenas uma correspondência estatística. No entanto, Bohm pretende conciliar essa correspondência estatística com o fato de que a função de onda fornece a mais completa descrição possível do sistema. Para isso, Bohm estabelece o conceito de potencialidade, e assume que as propriedades de um dado sistema existem, num nível mais preciso, de uma forma definida imprecisamente. Em outras palavras, os observáveis quânticos de um elétron, por exemplo, não são propriedades bem definidas, mas são potencialidades, as quais são realizadas mais definidamente após a interação com um sistema clássico apropriado, no caso, o aparelho de medição (Bohm, 1951, p. 620).

Essa interpretação não viola o princípio de incerteza, pois, antes da interação com o aparelho clássico, os observáveis incompatíveis existem juntos de forma aproximadamente definida, sendo potencialidades que se opõem, e essas variáveis são potencialmente capazes de tornarem-se melhor definidas. A rigor, posição e momento "não podem ser consideradas como pertencendo apenas ao elétron; pois a realização dessas potencialidades depende tanto dos sistemas com os quais ele interage quanto dos próprios elétrons" (p. 620). Nesse sentido, a visão de Bohm acompanha a afirmação de Niels Bohr, de uma "influência sobre as próprias condições que definem os tipos possíveis de previsões relativas ao comportamento futuro do sistema".

Um aspecto notável da abordagem de Bohm a respeito do argumento de EPR é a simplificação experimental e matemática de sua versão do argumento com as componentes do spin, o que facilita a compreensão do argumento. Ele recorda que a 
função de onda completa do spin do par de partículas pode ser expressa como a combinação de dois estados possíveis, $\psi_{\mathrm{c}}=u_{+}(1) u_{-}(2)$ e $\psi_{d=} u_{-}(1) u_{+}(2)$.

$$
\psi_{\mathrm{o}}=\frac{1}{\sqrt{2}}\left(\psi_{\mathrm{c}}-\psi_{\mathrm{d}}\right)
$$

Antes da medição, há uma relação de fase bem definida entre os estados conjuntos $\psi_{\mathrm{c}}$ e $\psi_{d}$, de forma que para um dado átomo nenhuma componente do spin existe com um valor definido precisamente. Porém, assim que um dos átomos interage com um aparelho de medição, as relações de fase entre $\psi_{\mathrm{c}}$ e $\psi_{d}$ são destruídas. Em qualquer instante em que a partícula (1) desenvolver uma componente de spin definida, a função de onda da partícula (2) automaticamente tomará uma forma definida, de maneira a garantir o desenvolvimento de um valor oposto se essa partícula também interagir com um aparato de medição da mesma componente. A função de onda descreve então a propagação das potencialidades correlacionadas (Bohm, 1951, p. 621), não fornecendo uma correspondência matemática biunívoca em relação aos elementos de realidade.

Com isso, Bohm considera que a teoria quântica é menos matemática em suas bases filosóficas do que a teoria clássica, pois ela não assume que o mundo é construído de acordo com um plano matemático definido precisamente. Descarta também a possibilidade de suplementar a descrição quântica com variáveis ocultas (Bohm, 1951, p. 622).

\section{A Versão Original de Einstein}

A relação entre Einstein e a mecânica quântica é um tema que tem sido bastante estudado. No artigo publicado com Podolsky e Rosen, argumenta-se a favor da incompletude da mecânica quântica utilizando o princípio de incerteza. No entanto, em algumas correspondências de Einstein, aparecem argumentos de incompletude mais simples e fundamentais que não se utilizam do princípio de incerteza.

No primeiro capítulo do livro The Shaky Game: Einstein, Realism and the Quantum Theory, de Arthur Fine, logo no terceiro parágrafo, o autor aponta os dois principais incômodos de Einstein com a mecânica quântica. Primeiramente, Einstein não podia conceber a probabilidade exercendo uma função irredutível nos fundamentos 
físicos, e segundo, a mecânica quântica colocava em perigo o programa tradicional de física, que postula a realidade independente do observador.

Essas preocupações aparecem em algumas cartas de Einstein, a primeira destinada a Max Born em 1926, onde Einstein apresenta sua famosa frase, "Ele [Deus] não joga dados" (Born, 1971, p. 88), e a segunda presente em uma carta destinada a Schrödinger em 1950, onde ele escreve: "a maioria deles não vê que tipo de jogo instável [shaky game] eles estão jogando com a realidade" (in Przibam, 1967, p. 39, apud Fine, 1996, p. 2).

O posicionamento resistente de Einstein com relação à mecânica quântica foi, por muitos, interpretado como uma incapacidade em entendê-la em virtude de uma suposta senilidade. O próprio Einstein tinha consciência desses rumores, e em 1944 escreve a Born:

Mesmo o grande sucesso inicial da teoria quântica não me faz acreditar no jogo de dados fundamental, apesar de eu estar consciente de que nossos colegas mais jovens interpretam isto como consequência da [minha] senilidade (Fine, 1996, pp. 13-14; Born, 1971, p. 149)

Também em carta a Maurice Solovine em 1949 ele escreve:

A geração atual vê em mim ao mesmo tempo um herege e um reacionário, alguém que, por assim dizer, passou de seu tempo. (Solovine, 1956, p. 94, apud Fine, 1996, p. 14)

Einstein, na realidade, reconhecia a grandeza da teoria, no entanto, conforme ele mesmo afirmou em carta a Born em 1926, uma voz interior lhe dizia que ela [MQ] ainda não era a coisa real, ele entendia a mecânica quântica como "uma teoria correta de leis estatísticas, mas como uma concepção inadequada de processos elementares individuais" (Hermann, 1968, carta 53, apud Fine, 1996, p. 29).

É possível depreender a visão de Einstein sobre a incompletude da teoria quântica de uma carta a Schrödinger em 19 de junho de 1935, na qual ele fez uma crítica ao próprio artigo de EPR, que, redigido por Podolsky, o deixara insatisfeito por obscurecer a essência da incompletude:

Por razões de linguagem este artigo foi escrito por Podolsky depois de muita discussão. Mesmo assim ele não saiu tão bem quanto eu tinha originalmente desejado; pelo contrário, a coisa essencial foi, por assim dizer, obscurecida pelo formalismo. (Fine 1996, p. 35)

Nesta carta, Einstein cita um exemplo de incompletude mais simples, que envolve a situação com probabilidade inferior a 1 e sem a ocorrência de distúrbio da medição. Trata-se do exemplo de uma bola e duas caixas fechadas, sendo que a bola se 
encontra dentro de uma das caixas. Uma descrição incompleta da realidade seria "a probabilidade de que a bola esteja na primeira caixa é 1/2”. Uma descrição completa seria “a bola está na primeira caixa”. Dessa forma, a descrição incompleta é uma afirmação probabilística com probabilidade menor do que 1, feita em circunstâncias em que há alguma verdade a mais a ser dita, isto é, onde a medição vai simplesmente revelar algo que já está posto na realidade (Fine 1996, p. 36).

Aqui Fine aborda o problema do distúrbio medição: ou seja, o resultado medido surge com a medição ou a medição revela o que já está lá?

Para solucionar esse problema, Einstein propõe assumir um princípio de separação: "os conteúdos da segunda caixa são independentes do que acontece na primeira caixa" (Fine 1996, p. 36). Além disso, Einstein assume também uma lei de conservação em que bolas não são nem criadas nem destruídas. Assim, é possível descobrir por meio da observação na primeira caixa se a bola está ou não na segunda caixa: por exemplo, se a bola não estiver na primeira caixa, ela está na segunda. Se a teoria apenas permite afirmações probabilísticas com probabilidade menor que 1, então a teoria é incompleta.

Segundo Fine, nesta mesma carta, Einstein segue dando uma reformulação técnica do argumento de EPR apresentando a essência da noção de incompletude que teria ficado "obscurecida" na exposição de Podolsky. Ele considera um sistema de duas partículas correlacionadas por meio de uma lei de conservação do momento linear total. O princípio de separação garante que se uma propriedade vigora para uma das partículas, isso não depende de medições feitas sobre a outra partícula, quando elas se encontram separadas espacialmente. Fine (1996, p. 37) aponta que "completude é a afirmação de que se uma certa propriedade física de fato vale para uma partícula em um dado instante, então a função de estado para o sistema combinado naquele instante deve fornecer probabilidade um de que a propriedade valha (i.e., o subsistema consistindo da partícula deve ter uma função de estado que é um autoestado da propriedade em questão)".

Fine reformula o argumento da caixa de Einstein e supõe que duas partículas, $A$ e $B$, estão afastadas e que é feita uma medição onde o momento linear da partícula $A$ está em certa direção. Usando a lei de conservação seria possível inferir o momento linear da partícula $B$, a partir do resultado da medição sobre $A$, de forma que, após a medição de $A$, a partícula $B$ tem certo momento linear. Pelo princípio de separação (localidade), esta propriedade real de $B$ já deve ter realidade no momento em que se 
iniciou a medição sobre $A$, ou imediatamente antes, no caso de uma medição instantânea. Caso contrário, ter-se-ia criado o momento de $B$ pela medição em $A$, o que caracterizaria uma violação do princípio de separação.

No entanto, na teoria quântica, no momento inicial da medição sobre $A$, o estado do sistema composto não forneceu probabilidade 1 para encontrar qualquer valor de momento para $B$, pois o estado fornecido pela teoria é uma superposição não trivial dos produtos de "autoestados de momento" para os subsistemas $A$ e $B$. Assim, como a função de estado, antes da medição, fornece apenas as probabilidades dos valores de momento, então a descrição fornecida pela função de estado dada pela teoria quântica é incompleta (Fine 1996, p. 37).

Fine indica que, como nesta ilustração, o argumento estabelece a incompatibilidade entre separação e completude, e para ele, esta é a incompatibilidade que ficou obscurecida no artigo de EPR. Fine cita ainda que, muitos anos depois, Einstein (1949, p. 682) a coloca nas seguintes palavras:

[...] o paradoxo nos obriga a renunciar uma das duas seguintes afirmações:

(1) A descrição por meio da função $\psi$ é completa

(2) Os estados reais dos objetos separados espacialmente são independentes uns dos outros. (Fine 1996, p. 37).

Isso se apresenta como um dilema, o "dilema de Einstein" mencionado por Redhead (que mencionamos da seção I.3), que é renunciar a completude $\mathbf{C}(\mathrm{MQ})$ ou renunciar a localidade LOC:

$$
\neg \mathbf{C}(\mathrm{MQ}) \text { ou } \neg \mathbf{L O C}
$$

Este dilema será utilizado em uma interessante derivação de um argumento a favor da não-localidade, independente de considerações sobre o realismo no capítulo III.

\section{O Realismo de Einstein}

A versão original de Einstein para o argumento de incompletude da mecânica quântica traduz apenas uma pequena parte de sua insatisfação com a teoria. De fato, essa insatisfação possui raízes mais profundas que se encontram em sua postura filosófica e epistemológica formadas, em grande parte, durante a sua trajetória como cientista brilhante, desenvolvedor de uma das teorias conceitualmente mais 
revolucionárias da história da ciência, bem como portadora de grande sucesso empírico, a teoria da relatividade. Nesse sentido, a angústia permanente de Einstein com relação à mecânica quântica, angústia esta que o acompanhou pelo resto de sua vida, certamente não é oriunda de uma queixa senil e sem fundamento ou de uma incapacidade de aceitar quebra de paradigmas conceituais. Pelo contrário, é fruto de um realismo correto e consistente e que nos ajudará a compreender o quão pertinente foi, e continua sendo, sua crítica à teoria.

Apesar de todas as tentativas de Einstein em explicar seu ponto de vista, que era bastante razoável, muitas vezes nos deparamos apenas com sua mais famosa frase, "Ele [Deus] não joga dados” (Born, 1971, p. 88), que exprimiria seu grande incômodo com o pretenso indeterminismo da teoria quântica.

Conforme afirma Lehner, Max Born, um dos principais oponentes de Einstein quanto ao estatuto da mecânica quântica, viu o indeterminismo como a quebra fundamental entre a mecânica quântica e a física clássica, e passou a entender a crítica de Einstein como um preconceito contra a possibilidade de uma Física radicalmente indeterminista. Esta visão-padrão, que apresenta Einstein como um revolucionário que matou o espaço e o tempo absolutos, mas que agora se tornou conservador, teimosamente agarrado a suposições metafísicas antiquadas e apresentada por Lehner (2011, p. 185) como um mal-entendido, está muito aquém da totalidade e complexidade de sua avaliação da mecânica quântica, conforme afirmou Wolfgang Pauli: "o ponto de partida de Einstein é mais 'realista' do que 'determinista"' (Pauli para Born, 31 de março de 1954, Born 1971, p. 216).

Contudo, Pauli também fez sua avaliação quanto ao posicionamento de Einstein perante a teoria quântica, considerando-o como uma "tentativa ingênua e antiquada de continuar fazendo modelos mecânicos intuitivos na tradição da física do século XIX" (Lehner 2011, p. 186). Lehner aponta também que a crítica de Einstein ao positivismo lógico levou os comentadores de orientação mais filosófica a identificarem a posição dele como um "realismo epistemológico tradicional", isto é, a tese de que a ciência constitui uma imagem fiel da realidade que deve ser independente do observador (Holton, 1968, apud Lehner 2011, p. 186). Segundo Lehner, esta visão passou a ser rotulada por defensores da interpretação de Copenhagen como um realismo ingênuo, contribuindo para o mito gerado em torno da postura de Einstein em relação à nova teoria. 
De fato, em algum aspecto, uma boa teoria física para Einstein deveria estar pautada em princípios independentes do observador, porém, veremos nos próximos parágrafos que esta tese não é tão simples quanto parece, e que os critérios de Einstein para uma boa teoria física, vinculados a sua tese realista, possuem razões muito mais complexas do que a tese simplista do realismo ingênuo.

Primeiramente, o real para Einstein não é algo revelado imediatamente nas nossas experiências; pelo contrário, nossa confiança em um constructo sobre a realidade está baseada em uma correspondência deste com as nossas experiências. Lehner cita o seguinte trecho de Cartas de Dr. Albert Einstein, organizado por Herbert Louis Samuel, 1951.

O "real" não nos é dado de maneira alguma imediatamente, somente as experiências dos seres humanos nos são dadas. [...] A postulação do "real" como algo que existe independente da minha experiência é uma totalidade de construções intelectuais [...]. Nossa confiança no sistema de crença sobre a realidade repousa apenas no fato que aqueles conceitos e relações [postos como reais] estão em uma relação de correspondência com nossa experiência; este é o único fundamento para a "verdade" de nossas afirmações. (Einstein 1951, apud Lehner 2011, p. 186-7)

Lehner afirma que a visão de Einstein é de que "a verdade da ciência não está em ser uma imagem fidedigna de uma realidade independente da mente, mas no seu sucesso em contabilizar nossas experiências" (Lehner 2011, p. 187).

Artur Fine propõe que o realismo de Einstein não esteja relacionado a uma tese epistemológica sobre a relação da teoria com a realidade independente do observador, mas sim que é uma tese metodológica, sobre como deve ser a estrutura interna da ciência. Para Fine, o realismo de Einstein é "um conjunto de requisitos para uma teoria fundamental satisfatória: a teoria deve falar sobre objetos independentes de observação, deve representá-los em um quadro espaço-temporal, deve consistir de leis deterministas" (Lehner 2011, p. 187). Einstein seria um realista sobre o constructo intelectual da ciência.

Na tentativa de compreender as convicções metodológicas de Einstein e sua postura filosófica realista, Lehner apresenta o período "filosófico" de Einstein, vinculado à sua defesa da teoria da relatividade geral por meio de seus princípios metodológicos. Após ser publicada em 1915, a teoria da relatividade geral sofreu com demasiado ceticismo quanto à renúncia do espaço e do tempo absolutos. Segundo Lehner (2011, p. 184), por um lado ela ganhou espaço após a confirmação de suas previsões a respeito do desvio da luz das estrelas pela massa do Sol, em 1919, e por 
outro, ela foi criticada por sua matemática de difícil compreensão. Einstein teve então que sustentá-la defendendo sua sensatez física e epistemológica, o que o levou a dedicar seus pensamentos aos fundamentos e métodos da física. Foi, portanto, por intermédio de sua experiência bem sucedida com a teoria da relatividade geral que se deu o desenvolvimento do chamado "realismo de Einstein", que, por sua vez, sustenta o princípio metodológico central na base de sua crítica à mecânica quântica (Lehner 2011, p. 186).

É possível compreender um pouco mais a visão de Einstein por meio de um comentário dele sobre a crítica que Moritz Schlick fez em seu artigo Raum und Zeit in der gegenwärtigen Physik (Espaço e tempo na física contemporânea). Einstein primeiro contrasta as visões de Schlick e de Mach, dizendo que reais para Mach são apenas as sensações e para Schlick são as sensações e os eventos de natureza física. A partir daí e utilizando a epistemologia de Schlick, Einstein coloca que o "real" em física é o "ordenado espaço-temporalmente", e não o "dado imediatamente", afirmando que o dado imediatamente pode ser uma ilusão (Lehner 2011, p. 188). Segundo Lehner, Einstein estava diferenciando a realidade fenomênica da realidade física dos eventos ordenados espaço-temporalmente.

No caso da teoria da relatividade geral, a covariância geral das equações de campo significa que a estrutura gravito-inercial não é determinada a priori como no caso do espaço newtoniano, mas a partir de um campo evoluindo dinamicamente que interage com a matéria. Para esclarecer essa situação Einstein precisou buscar pelas propriedades de invariância das equações de campo. Dessa forma e conforme explica Lehner, as leis fundamentais só podem ser definidas em objetos invariantes, como tensores e vetores, que são definidos independente da escolha de um sistema descritivo de referência, e são, portanto, definidas objetivamente e independente do observador.

Dentro dessa perspectiva, as medições em física revelam as representações das grandezas objetivas em um sistema de coordenadas determinado, sendo, portanto, grandezas variantes, e sua realidade seria fenomênica, dependente de um observador situado em um sistema de referência.

Neste ponto, é interessante notar que Einstein não está preocupado com a distinção entre o "real" e o "não-real", mas com a distinção entre grandezas que são inerentes ao sistema físico, independente da escolha das coordenadas, e grandezas que dependem do sistema de coordenadas. Einstein afirma então que "seria imediatamente plausível requerer que a física devesse introduzir em suas leis apenas grandezas do 
primeiro tipo" (apud Lehner 2011, p. 191), mas ele admite que isso é irrealizável na prática, pois a física não pode ser feita sem um sistema de coordenadas.

Apesar da relevante discussão sobre a distinção entre realidade fenomênica e realidade objetiva, Lehner aponta que esses dois conceitos de realidade são independentes de afirmações epistemológicas sobre a física e o "mundo real", de forma que Einstein se refere então, não a uma questão epistemológica, mas a uma questão metodológica, onde é preciso distinguir entre o que a teoria afirma serem fatos objetivos e fatos fenomênicos, cumprindo apenas uma exigência metodológica, que somente fatos objetivos entrem nas leis fundamentais da física. Essa exigência foi chamada por Lehner (2011, p. 192) de realismo metodológico de Einstein.

$\mathrm{O}$ fato pelo qual isso isenta Einstein de um realismo ingênuo é que ele não pretendia fazer da física uma "imagem da realidade", "mas sim uma teoria de invariantes cujo objetivo é construir uma estrutura simples e coerente por trás da multidão vertiginosa de fenômenos" (Lehner 2011, p. 193).

Em seu livro Como Vejo o Mundo é possível identificar no pensamento de Einstein um pouco mais sobre como as leis e princípios da teoria física devem ser buscados pelos físicos. Para Einstein, a forma de representar a realidade física deveria consistir das leis elementares mais gerais, e o papel do físico seria então procurar tais leis. No entanto, para ele essas leis não poderiam surgir de um mero caminho lógico, seria necessário que uma ideia brilhante surgisse da intuição humana, despertada pela observação, isto é, em paralelo com a experiência. Dessa forma, Einstein descreve em seu discurso, na ocasião do sexagésimo aniversário de Max Planck (1918), o papel do físico dentro da ciência.

A suprema tarefa do físico consiste, então, em procurar as leis elementares mais gerais, a partir das quais, por pura dedução, se adquire a imagem do mundo. Nenhum caminho lógico leva a tais leis elementares. Seria antes exclusivamente uma intuição a se desenvolver paralelamente à experiência. (Einstein 2017, p. 103)

Obviamente, após a descoberta de determinado princípio, se seguiria a tarefa de deduzir suas consequências lógicas, que deveriam posteriormente ser postas à prova experimental. Ele exprime o método do físico teórico da seguinte maneira:

Sua atividade portanto se divide principalmente em duas partes. Em primeiro lugar, tem de procurar esses princípios, e em seguida desenvolver as consequências inerentes a eles. (Einstein 2017, p. 104) 
É possível encontrar um exemplo dessas leis fundamentais que derivam de uma intuição brilhante nas notas autobiográficas de Einstein, quando ele se refere à combinação feita por Bohr em 1913 da teoria quântica com o modelo atômico de Rutherford, que colocou a teoria quântica no caminho da pesquisa em Fundamentos da Física. Einstein escreve:

Que esse fundamento inseguro e contraditório [da velha teoria quântica] fosse suficiente para permitir a um homem, com o instinto e a sensibilidade únicos de Bohr, descobrir as leis principais das linhas espectrais [...] pareceu para mim como um milagre. (Einstein 1949, p. 45-47, apud Lehner 2011, p. 184).

Conforme aponta Lehner (2011, p. 183), Einstein diferencia dois tipos de teorias, as "teorias de princípios" e as "teorias construtivas". As teorias de princípios seriam fundadas em princípios gerais bem confirmados empiricamente, como a termodinâmica, cujas primeira e segunda leis seriam os tais princípios, porém baseados em dados da experiência. ${ }^{19}$ Por outro lado, as teorias construtivas seriam aquelas que constroem uma descrição da realidade física a partir de constructos simples, como os átomos da mecânica estatística de Boltzmann ou o campo eletromagnético do eletromagnetismo de Maxwell, que provêm de uma intuição acertada. Para Einstein, a vantagem da teoria de princípios é estar fortemente baseada em conhecimentos empíricos, porém, ele defende que uma verdadeira teoria física deve ser construtiva.

Segundo Lehner, o sucesso da teoria da relatividade geral, que é uma teoria construtiva, reafirmou a convicção de Einstein de que a teoria quântica deveria desenvolver-se por meio de um programa construtivo que a direcionasse para uma teoria de campo. Na década de 1920, Albert Einstein investiu na modificação da relatividade geral a fim de derivar elétrons das equações de campo e começou a trabalhar no programa, que se estenderia pelo resto de sua vida e sem sucesso, de uma teoria de campo unificado.

\footnotetext{
${ }^{19}$ Curiosamente, Einstein, em seu livro Como Vejo o Mundo, defende que uma teoria física deva ser construída partindo-se de "princípios" oriundos da intuição, conforme apresentado no início da seção. No entanto, Lehner, ao abordar os dois tipos de teorias distinguidos por Einstein, denomina "teoria construtiva" a forma de teoria defendida por Einstein, e de "teoria de princípios" aquela que ele critica.
} 


\section{Capítulo II \\ Os Testes da Teoria Quântica de Polarização para de Explorar o Argumento de EPR}

\section{A Proposta de Furry e Schrödinger}

O paradoxo de EPR repousa na natureza do estado quântico puro entrelaçado, que sofre uma redução de estado global após uma medição. No entanto, que evidências diretas haveria para supor que esta é a descrição correta do estado do sistema? Não seria possível obter correlações com estados em que cada partícula já sai com um estado de spin bem definido? Se eles se distribuíssem simetricamente em todas as orientações, tais estados seriam descritos por uma "mistura", ao invés de um estado puro.

Faz-se necessário esclarecer os conceitos de estado puro e mistura. "Se a preparação de um conjunto de indivíduos for tal que cada um deles puder ser representado pelo mesmo vetor de estado em um espaço de Hilbert $\boldsymbol{H}$, então o coletivo está em um estado puro. Porém, se diferentes indivíduos estiverem em diferentes estados em $\boldsymbol{H}$, então o coletivo se encontra em uma mistura estatística" (Pessoa, 2006, v. 1, p. 139).

Para uma partícula de spin 1/2, há uma maneira experimental de verificar se o estado é puro ou é uma mistura. De fato, Blum (1981, p. 2) propõe uma definição preliminar de estado puro da seguinte maneira: "Se for possível encontrar uma orientação do aparelho de Stern-Gerlach para o qual um dado feixe é completamente transmitido, então dizemos que o feixe está em um estado puro de spin".

Tal critério operacional, porém, não se estende para pares de partículas correlacionadas. Como então distinguir um estado puro entrelaçado de uma mistura de pares de partículas? Esta foi a tarefa que Furry e Schrödinger empreenderam, de maneira independente, após o artigo de EPR.

Um estado puro de EPR, na versão de Bohm para spins, no estado de singleto, é dado por:

$$
|\psi\rangle=\frac{1}{\sqrt{2}}\left(|+z\rangle_{1}|-z\rangle_{2}-|-z\rangle_{1}|+z\rangle_{2}\right)
$$

Para duas partículas correlacionadas descritas pela Eq. 9, os termos referentes a cada uma das partículas não são fatoráveis, portanto não é possível atribuir um estado puro para cada partícula individualmente. Suponha que se faça uma medição em uma 
das partículas, por exemplo, a partícula 1, e se obtenha spin + z. Pelo postulado da projeção o estado do sistema após a medição será:

$$
\left|\psi^{\prime}\right\rangle=|+\mathrm{z}\rangle_{1}|-\mathrm{z}\rangle_{2}
$$

Vemos que com a medição da partícula 1 é possível inferir o estado da partícula 2. Como o estado da Eq. 10 é fatorável, cada partícula está agora em um estado puro.

Wendell Furry, um físico estadunidense, investigou se seria possível distinguir experimentalmente o estado puro entrelaçado de diferentes misturas de estados fatorados na base $\left\{\left|\varphi_{\mathrm{i}}\right\rangle_{1}\left|\xi_{\mathrm{j}}\right\rangle_{2}\right\}$. Em $1^{\circ}$ de março de 1936, seu artigo "Note on the Quantum-Mechanical Theory of Measurement" foi publicado no Physical Review ${ }^{20}$. As hipóteses de Furry no artigo surgem no contexto posterior à discussão entre EPR e Bohr. Furry descreve a posição de Bohr da seguinte maneira:

Recentemente Bohr defendeu a visão de que a descrição quântica da natureza pode ser considerada completa, demonstrando como as restrições em medições simultâneas que ela impõe são inerentes ao caráter e uso dos instrumentos de medição. Esses instrumentos de medição devem sempre ser incluídos como parte da situação física da qual nossa experiência é obtida, e ao fazer isso vê-se que a mecânica quântica fornece uma interpretação completa e peculiarmente apta da experiência (Furry 1936a, p. 393a-b).

Assim, a discussão sobre a teoria de medições emerge após o apontamento de Bohr sobre o cuidado que devemos ter ao falar de atributos reais de um sistema que aparenta ser independente de outros sistemas apenas porque a interação dinâmica cessou.

Furry (1936a, p. 394a) discorre sobre a "informação estatística" presente nas equações da teoria quântica utilizando uma descrição geral por meio de uma "mistura estatística" de funções de onda (cada função de onda descreve um "estado puro"). Tal mistura estatística é chamada por ele de ensemble, o que pode ser traduzido por "coletivo",21, onde cada estado $\varphi_{\mathrm{i}}$ pode ocorrer com probabilidade $\omega_{\mathrm{i}}$. Afirma assim que dado um observável arbitrário $\mathrm{F}$ e as probabilidades $\omega_{\mathrm{i}}$ para cada estado quântico $\varphi_{\mathrm{i}}$ da

\footnotetext{
${ }^{20}$ Como veremos nas próximas seções, na década de cinquenta, David Bohm e Yakir Aharonov consideraram as hipóteses e modelos de mistura e de estado puro contidas no artigo de Furry para verificar se a teoria quântica de correlações distantes era adequada experimentalmente.

${ }^{21}$ No original Furry utiliza o termo "ensemble" e cita esse conceito como sendo aquele utilizado por Kemble (1935, p. 973).
} 
mistura, o valor esperado $\overline{\mathrm{F}}$ do observável $\mathrm{F}$ será a média ponderada dos valores esperados para cada estado $\varphi_{\mathrm{i}}$.

Um conjunto de sistemas quânticos distintos pode ser descrito por um estado puro apenas se cada estado individual estiver no mesmo estado puro que o das outras partículas (Pessoa, 2006, v. 1, p. 139). Blum (1981, p. 2) utiliza um procedimento experimental para fazer a diferenciação entre um estado puro e um estado misto (que não seja puro) de partículas de spin $1 / 2$.

Furry (1936a, p. 394a) mostra como diferenciar matematicamente o estado puro do estado de mistura por meio das probabilidades dos resultados por eles fornecidas. $\mathrm{O}$ procedimento é o seguinte. Quando o sistema está em um estado puro, a probabilidade para o estado $\varphi$ é $\left|\left(\varphi, \chi_{\delta}\right)\right|^{2}$, onde $\chi_{\delta}$ é a autofunção de $F$ correspondente ao autovalor $\delta$. Quando o sistema está em um estado de mistura, a probabilidade para o estado $\varphi_{\mathrm{i}}$ é $\sum_{\mathrm{i}} \omega_{\mathrm{i}}\left|\left(\varphi_{\mathrm{i}}, \chi_{\delta}\right)\right|^{2}$, onde $\omega_{\mathrm{i}}$ são as probabilidades para cada estado $\varphi_{\mathrm{i}}$. Furry salienta que o tipo mais geral de informação estatística sobre um sistema é representado por uma mistura, pois um estado puro é um caso particular onde há apenas uma probabilidade $\omega_{\mathrm{i}} \cdot$

Furry (1936a, p. 394b) se utiliza de uma função de onda a única para dois sistemas, I e II, cuja interação prévia cessou, estabelecendo um estado entrelaçado:

$$
\psi\left(\mathrm{x}_{1}, \mathrm{x}_{2}\right)=\sum_{\kappa}\left(\omega_{\kappa}\right)^{\frac{1}{2}} \varphi_{\lambda_{\kappa}}\left(\mathrm{x}_{1}\right) \xi_{\rho_{\kappa}}\left(\mathrm{x}_{2}\right)
$$

As $\varphi_{\lambda_{\kappa}}$ são autofunções de um observável $L$ com autovalores $\lambda_{\kappa}$ e $\xi_{\rho_{\kappa}}$ são autofunções de um observável $\mathrm{R}$ com autovalores $\rho_{\kappa}$. Dado qualquer estado puro entrelaçado, o teorema de decomposição de Schmidt (derivado em 1907) garante que há funções $\varphi_{\lambda_{\kappa}}$ e $\xi_{\rho_{\kappa}}$ de maneira que o estado entrelaçado pode ser escrito de modo "bilinear", como a Eq.11. Geralmente tal decomposição é única, mas o estado de EPR permite pelo menos duas decomposições equivalentes (Furry 1936a, p. 395a).

Nessas condições, Furry salienta que para o sistema II sozinho, quando a Eq. 11 é a função de onda do sistema combinado, a informação estatística acessível é uma mistura de estados $\xi_{\rho_{\kappa}}$ com a ponderação $\omega_{\kappa}$, e não um estado puro (envolvendo as variáveis do sistema II). D’Espagnat chama este estado do sistema II (que ignora o entrelaçamento com a partícula I) de "mistura imprópria" (ver Pessoa 2006, p. 309).

Por outro lado, levando em conta o entrelaçamento entre as partículas, uma medição do observável L sobre o sistema I é suficiente para prever o valor de R e o 
estado do sistema II. Assim, após uma medição em L, que fornece o autovalor $\lambda_{\mathrm{n}}$, o sistema II estaria no estado puro $\xi_{\rho_{\mathrm{n}}}$.

O problema que agora Furry se coloca é o seguinte:

Estamos agora prontos para discutir em detalhe os graus de concordância e discordância entre os resultados dos cálculos quânticos e aqueles a serem esperados sob a suposição de que o sistema, uma vez livre da interferência dinâmica, pode ser considerado como possuindo propriedades reais independentes. (Furry 1936a, p. 395b)

Para isso, Furry estabelece duas assunções e métodos, que denominou A e B. A assunção B é a suposição usual de que o estado permanece entrelaçado (segundo a Eq. 11) até que uma medição seja feita. Já a assunção A afirma que após a interação cada partícula entra em um estado quântico puro individual. Nas palavras de Furry, a assunção A:

assume que durante a interação dos dois sistemas, cada sistema fez uma transição para um estado definido, no qual agora está, o sistema I estando em um dos estados $\varphi_{\lambda_{\kappa}}$, e o sistema II em um dos estados $\xi_{\rho_{\kappa}}$. Essas transições não são causalmente determinadas e não há maneira de encontrar quais transições ocorreram, exceto fazendo uma medição adequada. Na ausência de medição nós conhecemos apenas que as probabilidades das diferentes transações são respectivamente $\omega_{\mathrm{k}}$, e que se o sistema I está no estado $\varphi_{\lambda_{i}}$, então o sistema II está no estado $\xi_{\rho_{\mathrm{i}}}$. (Furry 1936, p. 395-6)

Furry analisa então quatro situações de medição do sistema de duas partículas cuja interação prévia cessou. Os observáveis medidos são L (na partícula I) e R (na partícula II), cujos autoestados correspondem à base que aparece na Eq. 11, e também observáveis arbitrários M (na partícula I) e S (na partícula I e II), que não comutam respectivamente com L e R. As quatro situações são as seguintes. (a) Mede-se um observável arbitrário S tanto em I quanto em II. (b) Mede-se L em I e uma medição arbitrária S em II. (c) Mede-se um observável arbitrário M em I e R em II. (d) medemse observáveis arbitrários $\mathrm{M}$ em I e S em II.

Os resultados da assunção A para as três primeiras situações, utilizando arranjos de observáveis que mesclam os observáveis da base de autoestados da Eq. 11, L e R, com os observáveis $\mathrm{M}$ e S que não estão nesta base, fornecem probabilidades iguais aos resultados previstos pela assunção B (ou seja, pela mecânica quântica, supondo estado entrelaçado e postulado da projeção). 
A quarta situação, em que Furry considera apenas medições dos observáveis que não estão na base de autoestados da Eq. 11, fornece probabilidades diferentes para as assunções A e B.

Dessa forma, Furry conclui que o método A é inconsistente com a mecânica quântica. Com isso ele também verifica que é possível distinguir experimentalmente o estado puro entrelaçado (assunção B) de diferentes misturas de estados fatorados na base $\left\{\left|\varphi_{\mathrm{i}}\right\rangle_{1}\left|\xi_{\mathrm{j}}\right\rangle_{2}\right\}$ (assunção A), desde que as medições na partícula 1 sejam feitas com observáveis cuja base de autoestados seja diferente de $\left|\varphi_{i}\right\rangle_{1}$, e que as medições na partícula 2 sejam feitas com observáveis cuja base de autoestados seja diferente de $\left|\xi_{\mathrm{j}}\right\rangle_{2}$.

Schrödinger (1935a,b) também analisou esta questão, mas com finalidades diferentes, como aponta Furry (1936b). A chamada "hipótese de Schrödinger-Furry" é justamente que o estado quântico não é o estado puro entrelaçado, mas uma mistura (a assunção A de Furry). Tal sistema satisfaz a condição de localidade e é um exemplo de teoria realista local. Apesar do nome "hipótese de Schrödinger-Furry" dado a essa conjectura, os dois autores não a defenderam.

A análise teórica de Furry e Schrödinger passaria a ser comparada com resultados experimentais no final da década de 1950, com dois artigos de David Bohm \& Yakir Aharonov (1957, 1960). Estes autores se basearam em um experimento realizado na Universidade de Columbia C. S. Wu \& I. Shaknov (1950), que envolvia medições relacionadas à polarização de fótons emitidos do aniquilamento de um par pósitron-elétron. Bohm \& Aharonov basicamente compararam as previsões nas quais esse sistema é descrito por um estado entrelaçado puro com outros dois modelos de misturas locais, que satisfazem a hipótese de Furry-Schrödinger. Os aspectos experimentais e testes referentes a esta questão envolviam a teoria quântica de polarização, formulada inicialmente por Maurice Pryce \& John Clive Ward, como veremos a seguir.

\section{A Teoria Quântica de Polarização}

Em sua publicação de 1947, M. Pryce \& J.C. Ward estabeleceram a teoria quântica da polarização de dois fótons de raio gama gerados a partir da aniquilação de um par pósitron-elétron, teoria detalhada na tese de doutorado de Ward (1949). Segundo a teoria, esses fótons emitidos em direções opostas possuem momento angular total 
igual a zero e são polarizados perpendicularmente entre si. Esta ideia foi estabelecida por John A. Wheeler em 1946, que propôs o experimento de correlação de pares de raios gama correlacionados, inspirado em trabalho anterior de Dirac (1930). Independentemente de Pryce \& Ward, a análise do experimento de correlação de raios gama foi feita por Snyder, Pasternack \& Hornbostel (1948) (ver Duarte, 2012; Jammer, 1974, pp. 330-32).

Esse fenômeno corresponde ao entrelaçamento quântico de duas partículas e o estado desse sistema é descrito por um estado correlacionado semelhante ao da Eq. 9 para spins, só que neste caso envolvendo estados ortogonais de polarização linear $|x\rangle$ e $|y\rangle$, conforme a Eq. 13. Os índices 1 e 2 indicam cada um dos fótons do par.

$$
|\psi\rangle=\frac{1}{\sqrt{2}}\left(|x\rangle_{1}|y\rangle_{2}-|y\rangle_{1}|x\rangle_{2}\right)
$$

Além de estabelecer a teoria, Pryce e Ward foram os primeiros a apresentar diagramas experimentais explícitos para sua verificação (Duarte 2012, p. 315). A Fig. 11 representa o diagrama experimental proposto por Pryce e Ward no artigo de 1947.

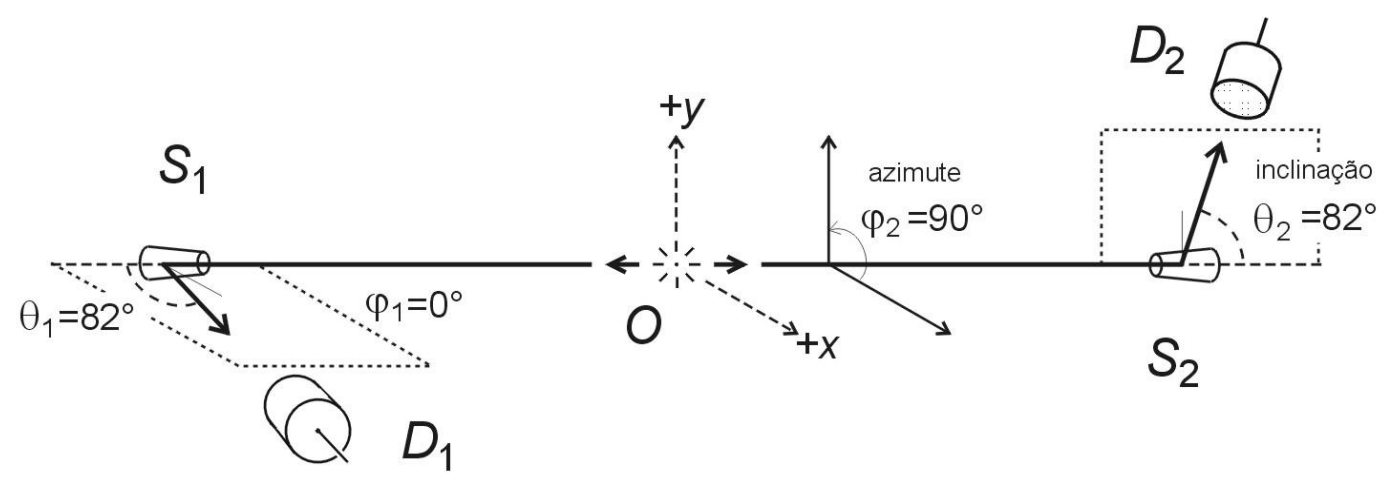

Figura 11: Diagrama experimental para verificar a teoria quântica de polarização, no caso em que os planos azimutais (indicados por linhas pontilhadas) em que são colocados os detectores são ortogonais (situação 1 de Bohm \& Aharonov, 1957).

Os fótons gerados a partir da aniquilação de um par pósitron-elétron são espalhados por efeito Compton nos espalhadores $S_{1}$ e $S_{2}$. Dois ângulos são relevantes. Os ângulos de inclinação $\theta_{1}$ e $\theta_{2}$ são medidos em relação à direção original de propagação dos fótons (a estipulação apenas de um ângulo de inclinação $\theta_{1}$ define um cone de espalhamento em torno do eixo original de propagação). Os ângulos $\varphi_{1}$ e $\varphi_{2}$ são os ângulos azimutais deste espalhamento; cada um destes ângulos fixa um semiplano 
azimutal (representado na Fig. 11 como pontilhado), que é definido como o semiplano que contém a reta de movimento original do fóton e a reta do fóton espalhado.

O que define quais são os ângulos de inclinação e azimutais são as posições dos detectores $\mathrm{D}_{1}$ e $\mathrm{D}_{2}$, que medem os fótons espalhados. $\mathrm{O}$ ângulo azimutal $0^{\circ}$ é definido por um referencial escolhido no laboratório, tipicamente onde se localiza $\mathrm{D}_{1}$.

Conforme analisado e apresentado por Bohm \& Aharonov (1957, p. 1074 b), o experimento consiste em medir a "taxa relativa de coincidência", $R$, no espalhamento dos dois fótons sob o mesmo ângulo de inclinação $\theta$ em dois casos:

1) Quando os semiplanos azimutais são perpendiculares (situação da Fig. 11):

$$
\varphi_{1}-\varphi_{2}=90^{\circ} .
$$

2) Quando os semiplanos azimutais são paralelos:

$$
\varphi_{1}-\varphi_{2}=0
$$

A taxa de coincidência, que corresponde ao número de contagens coincidentes nos dois detectores, em função dos ângulos de espalhamento, é calculada teoricamente pela expressão (14):

$$
\frac{1}{16} r_{0}^{4} \mathrm{~d} \Omega_{1} \mathrm{~d} \Omega_{2}\left[\frac{\left\{\left(1-\cos \theta_{1}\right)^{3}+2\right\}\left\{\left(1-\cos \theta_{2}\right)^{3}+2\right\}}{\left(2-\cos \theta_{1}\right)^{3}\left(2-\cos \theta_{2}\right)}-\frac{\operatorname{sen}^{2} \theta_{1} \operatorname{sen}^{2} \theta_{2}}{\left(2-\cos \theta_{1}\right)^{2}\left(2-\cos \theta_{2}\right)^{2}} \cos 2\left(\varphi_{1}-\varphi_{2}\right)\right] .
$$

Aqui $r_{\mathrm{o}}$ é o raio clássico do elétron, e $\mathrm{d} \Omega_{1}, \mathrm{~d} \Omega_{2}$ são elementos do ângulo sólido para os fótons 1 e 2 respectivamente (ou seja, que estipulam os ângulos de inclinação e azimutal de cada partícula) (Pryce \& Ward 1947, p. 435 b; Snyder et al., 1948, p. 446).

O cálculo da taxa relativa de coincidência $R$ no espalhamento de dois fótons sob o mesmo ângulo de inclinação $\left(\theta_{1}=\theta_{2}\right)$ obtém-se dividindo a taxa de coincidência perpendicular $\left(\varphi_{1}-\varphi_{2}=90^{\circ}\right) R_{\perp}$ pela taxa de coincidência paralela $\left(\varphi_{1}-\varphi_{2}=0\right) R_{\|}$:

$$
R=\frac{R_{\perp}}{R_{\|}}
$$

No artigo histórico do físico americano F.J. Duarte (2012) sobre o entrelaçamento quântico e medições de polarização, o autor se refere a essa grandeza apenas como "taxa de polarização".

A Fig. 12 apresenta a taxa relativa de coincidência prevista pela teoria em função do ângulo de espalhamento. 


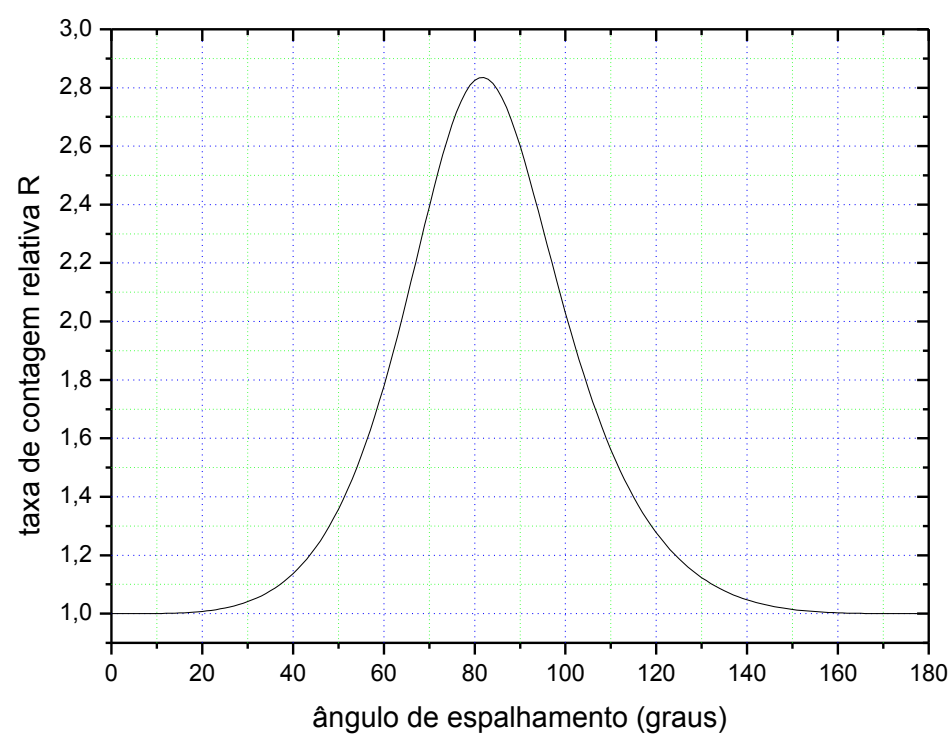

Figura 12: Taxa relativa de coincidência $R$ prevista pela teoria em função do ângulo de espalhamento (inclinação) $\theta_{1}=\theta_{2}$. Vê-se que o ângulo em que a taxa de coincidência relativa é máxima é em torno de $82^{\circ}$, com valor de $R$ de 2,85 (gerado pela autora com programa gráfico, a partir das Eqs. 14 e 15).

Teoricamente, o valor máximo de $R$ é de 2,85 , ocorrendo para o ângulo de espalhamento (inclinação) $82^{\circ}$. Isso significa que, para um ângulo de espalhamento de $82^{\circ}$, a cada contagem coincidente na medição em planos paralelos ocorre 2,85 contagens coincidentes em planos perpendiculares.

A comparação das previsões teóricas com os experimentos requer ajustes que dependem da geometria do aparato experimental utilizado, em especial uma integração da Eq. 14 para levar em conta ângulos sólidos finitos. Conforme aponta Duarte (2012, p. 314-15), três experimentos foram feitos para testar a teoria quântica de polarização que levou à fórmula derivada por Pryce \& Ward e por Snyder et al. Em 1948, Richard C. Hanna realizou o experimento com contadores Geiger e suas medições forneceram taxas de polarização em torno de $20 \%$ menores que as previstas. Também Bleuler \& Bradt (1948) fizeram medições com contadores Geiger, mas obtiveram uma taxa 12\% maior que a prevista. Finalmente, em 1949, Chien-Shiung Wu e Irving Shaknov usaram detectores de cintilação e apresentaram resultados condizentes com as previsões teóricas, obtendo uma taxa de polarização experimental de 2,04 $\pm 0,08$, que corresponde a $2 \%$ do valor teórico aplicável à geometria de seu aparato experimental. 
No experimento realizado por Wu e Shaknov (1950, p. 136) foi usada como fonte de pósitrons uma fonte de $\mathrm{Cu}^{64}$, ativado pelo bombardeamento de dêuterons, envolto por uma pequena cápsula de alumínio. A radiação de aniquilação dos pósitrons com elétrons do meio foi colimada por um bloco de chumbo com um canal no centro do chumbo, de maneira que o desvio angular dos fótons não superasse $3^{\circ}$.

O espalhador de alumínio foi preparado para absorver $40 \%$ da radiação de aniquilação e para limitar o espalhamento múltiplo da radiação espalhada a $90^{\circ}$ a $15 \%$. Um espalhador desse tipo encontra-se ao final de cada canal do colimador de chumbo e a radiação espalhada é detectada por dois contadores de cintilação, no caso, duas fotomultiplicadoras compostas por um cristal de antraceno.

O cristal do contador forma um ângulo de $43^{\circ}$ com o ponto no espalhador onde $20 \%$ da radiação incidente é absorvida, isto é, com o ponto de absorção média do espalhador. Um dos detectores foi fixado em uma posição e o outro foi girado em diferentes ângulos, proporcionando uma diferença angular dos planos de medição de $0^{\circ}$, $90^{\circ}, 180^{\circ}$ e $270^{\circ}$. O tempo total de medição foi de cerca de 30 horas contínuas.

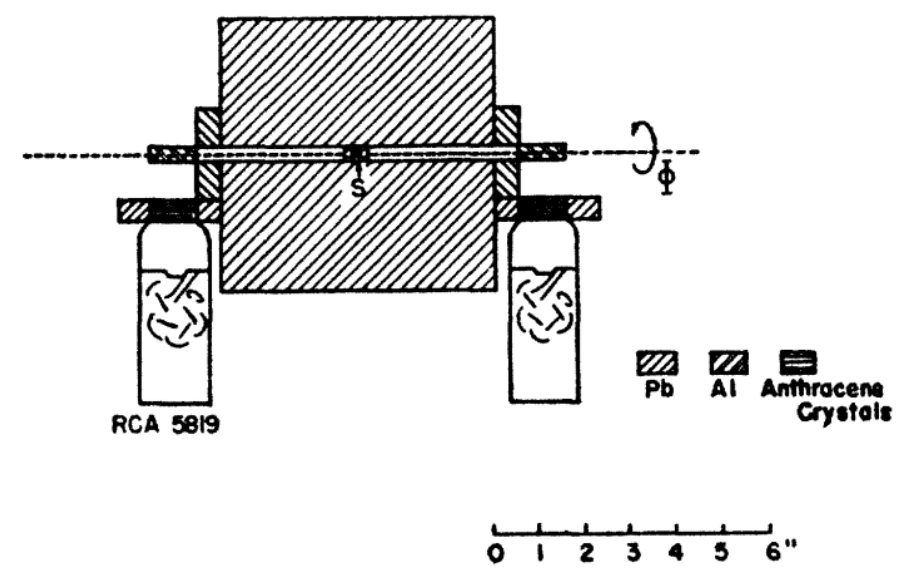

Figura 13: Diagrama esquemático do experimento de Wu \& Shaknov (1950).

\section{Como Testar o Argumento de EPR}

A discussão do experimento de Wu \& Shaknov é feita de maneira aprofundada em um artigo de Bohm \& Aharonov, de 1957. Eles partem de um experimento tipoEPR para partículas com spin $1 / 2$, e depois adaptam sua análise para a emissão de pares de fótons polarizados ortogonalmente, em estado entrelaçado, a partir da aniquilação de uma partícula e uma antipartícula, no caso, um pósitron e um elétron. 
O experimento hipotético que abre o artigo considera uma molécula composta por dois átomos sendo o spin total igual a zero. Os dois átomos são separados por um método que não influencia no spin total, em seguida faz-se a medição do spin da partícula 1, e imediatamente conclui-se que o spin da partícula 2 é o oposto.

Bohm \& Aharonov retomam o argumento de EPR, ressaltando a dificuldade que surge a partir do princípio de incerteza da mecânica quântica, segundo o qual "apenas um componente do spin de cada partícula pode ter um valor definido em um dado instante. Assim se o componente $x$ é definido, então os componentes $y$ e $z$ são indeterminados" (1957, p. 1070 b). Eles recordam que originalmente esse princípio fora interpretado como envolvendo um efeito da perturbação do sistema devido a uma interferência externa, no caso o aparato de medição. Contudo, essa interpretação do princípio de incerteza, associada à doutrina perturbativa, não é satisfatória quando aplicada ao experimento de EPR, porque "não explica porque a partícula 2 (que não interage com 1 ou com o aparato de medição) realiza sua potencialidade para um spin definido precisamente na mesma direção que ocorre em 1" (1957, p. 1071 a). ${ }^{22}$ Além disso, também não explica as flutuações dos outros componentes do spin da partícula $2 .^{23}$

No artigo, Bohm \& Aharonov observam que poder-se-ia supor a existência de interações ocultas instantâneas entre os átomos 1 e 2 e o aparato de medição, e que estas estariam fora do arcabouço da teoria quântica. Porém, eles evidenciam que interações instantâneas entre sistemas distantes são inconsistentes com a teoria da relatividade. $\mathrm{Na}$ visão deles, esta situação - que podemos traduzir como fruto da suposta não-localidade dos sistemas quânticos correlacionados - é justamente a essência do paradoxo do EPR.

Eles revelaram no artigo (1957, p. 1071 b) que Einstein propôs, em conversa particular com Bohm, que a formulação da mecânica quântica do problema de muitos corpos pode ser desmembrada quando as partículas estão suficientemente afastadas. Isso corresponde à “assunção A" de Furry (1936a), ou seja, a uma mistura de estados fatoráveis. Bohm \& Aharonov consideram a proposta de Einstein e supõem que após a separação dos átomos a função de onda não seja mais a Eq. 9, $\frac{1}{\sqrt{2}}\left(|+z\rangle_{1}|-z\rangle_{2}-\right.$

\footnotetext{
${ }^{22}$ Bohm \& Aharonov (1957, p. 1070 a) chamam as partículas 1 e 2 de "A" e "B", mas preferimos não usar esses nomes para não confundir com as suposições A e B de Furry, que curiosamente Bohm \& Aharonov (p. 1074 b) chamam respectivamente de "B" e "A" (invertendo a convenção de Furry, que adotamos). Na presente citação, trocamos "A" e "B" por "1" e "2".

${ }^{23}$ Discorremos sobre a doutrina da perturbação na seção I.5, e sobre as potencialidades em Bohm na seção III.2.
} 
$|-z\rangle_{1}|+z\rangle_{2}$ ), de um estado entrelaçado puro, mas sim o produto fatorável como o da Eq. 10, que para um ângulo genérico $\theta$ pode ser escrito como: $\left|\psi^{\prime}\right\rangle=|+\theta\rangle_{1}|-\theta\rangle_{2}$. Notamos que a Eq. 10 foi obtida após uma medição, pela aplicação do postulado da projeção, ao passo que aqui a hipótese é de que tal estado fatorável é gerado quando as partículas se separam (antes de qualquer medição).

Cada partícula entraria num estado de componente de spin bem definido, e os outros componentes de spin não poderiam ser medidos com correlação. Dessa maneira, o momento angular total de um par poderia não ser conservado, se os componentes de spin medidos fossem diferentes dos autoestados do par em questão (ou seja, se a direção do componente de spin medido fosse diferente da direção em que o componente de spin do par é bem definido). Neste ponto, Bohm \& Aharonov salientam que não havia até então uma prova experimental da conservação para cada componente do momento angular para partículas distantes não-interagentes.

Supondo que a mistura fosse preparada com simetria rotacional, de maneira que todas as direções dos componentes de spin tivessem igual probabilidade, mesmo assim, nesse modelo, a conservação do momento angular se daria apenas de maneira estatística, como uma média dos vários pares de partículas. Bohm \& Aharonov apontam que cada uma das teorias (correspondentes ao estado puro de entrelaçamento, Eq. 9, e aos estados com equação fatorável, Eq. 10, que compõem a mistura) são igualmente consistentes com os experimentos até então, porém, alegam que esta última teria a vantagem de evitar o paradoxo do EPR.

Bohm \& Aharonov (1957) apontaram a existência de dois tipos de solução para o paradoxo de EPR que vinham sendo oferecidos. A primeira era proposta por Bohr e entendia que cada tipo particular de aparato experimental, por exemplo, aquele que mediria o spin em $x$ e aquele que mediria o spin em $y$, formaria uma totalidade com o objeto da medição, um sistema combinado único incapaz de ser corretamente analisado em partes num nível quântico. Desse ponto de vista, a mecânica quântica apenas calcularia as probabilidades dos possíveis valores para cada observável que resultariam da operação de todos os possíveis sistemas combinados, de modo que "nós apenas podemos aceitar o resultado total que surge da medição e calcular sua probabilidade" (Bohm \& Aharonov 1957, p. 1072 a). Eles identificam que, nesse contexto, não haveria paradoxo, pois o sistema de dois átomos mais o aparato de observação seria um sistema inseparável e a questão de como ocorre a correlação não teria mais significado. 
A segunda maneira de interpretar o paradoxo de EPR é através de teorias de variáveis ocultas, que respeitariam a "totalidade" salientada por Bohr, mas permitiriam uma "análise conceitual" dos subsistemas. Eles mencionam duas formas possíveis de fazer isso. A primeira delas é por meio da interpretação causal de Bohm (1952), envolvendo um "potencial quântico", que admite a interação instantânea entre partículas distantes mesmo quando o potencial de interação clássico é zero. Esta proposta, porém, é aparentemente inconsistente com a teoria da relatividade. A segunda forma consiste em explorar um nível subquântico, cujas leis seriam diferentes da mecânica quântica, mas que teriam as leis da teoria quântica como aproximações. Como exemplo de tal abordagem, os autores citam Bohm (1957, caps. III e IV).

Bohm \& Aharonov mostram então que o estado quântico para o par de fótons entrelaçados, Eq. 13, produzidos pela aniquilação de um par pósitron-elétron, tem a mesma forma geral que a Eq. 9, obtida para spins. A ortogonalidade entre a polarização dos fótons com esse estado quântico se mantém em qualquer sistema de coordenadas gerado por uma rotação em torno do eixo de propagação dos fótons, incluindo para polarização circular. Em outras palavras, o estado $|\psi\rangle=\frac{1}{\sqrt{2}}\left(|\mathrm{x}\rangle_{1}|\mathrm{y}\rangle_{2}-|\mathrm{y}\rangle_{1}|\mathrm{x}\rangle_{2}\right)$ se manteria o mesmo se $\{|\mathrm{x}\rangle,|\mathrm{y}\rangle\}$ (polarizações lineares a $0^{\circ}$ e $90^{\circ}$ ) fosse substituído por $\left\{\frac{1}{\sqrt{2}}(|x\rangle+|y\rangle), \frac{1}{\sqrt{2}}(|x\rangle-|y\rangle)\right\}$ (polarizações lineares a $45^{\circ}$ e a $-45^{\circ}$ ), ou pela base de polarizações circularmente polarizada (em sentido horário e antihorário).

Bohm \& Aharonov mencionam então o experimento de Wu \& Shaknov (1950), em que se media a taxa relativa de coincidência, $R$, no espalhamento de dois fótons, conforme visto na seção anterior. Adotam então os dois casos considerados por Furry (1936a), as suposições A e B (lembrando que eles invertem as siglas "A" e "B"). Mantendo a convenção original de Furry, temos (Bohm \& Aharonov, 1957, p. 1074 b):

(A) A teoria quântica atual é correta somente quando a função de onda dos dois fótons se sobrepõe. Mas quando eles estão suficientemente distantes a função de onda se torna fatorável. Supõe-se que cada fóton está em um estado de polarização definido, sendo ortogonal ao do outro fóton. Por simetria, supõese também que a distribuição estatística dos estados da mistura tem simetria rotacional.

(B) A teoria quântica atual é correta e a função de onda para o sistema de dois fótons é dada pela combinação antissimétrica (Eq. 13). 
Considerando a primeira hipótese (A), eles estabelecem suas consequências para o experimento em questão em dois casos extremos:

(1) Cada fóton torna-se polarizado circularmente em torno da sua direção de propagação, com polarizações opostas.

(2) Cada fóton entra em um estado de polarização linear em alguma direção, enquanto que o outro entra em um estado de polarização perpendicular ao primeiro.

Para realizar os cálculos necessários à comparação das teorias sugeridas com os experimentos, Bohm \& Aharonov seguem o livro de Walter Heitler, Quantum Theory of Radiation (1954), e usam a fórmula de Klein-Nishina da secção transversal de espalhamento de um único fóton com um elétron em duas situações: quando a direção de polarização inicial do fóton é paralela ao semiplano azimutal e quando sua direção de polarização é perpendicular ao semiplano azimutal. A fórmula de Klein-Nishina se aplica bem para o caso sem entrelaçamento, próprio dos casos (A).

Ao calcular a taxa de coincidência relativa $R$ no caso de mistura de polarização circular (caso A1), obtêm o valor 1, que é bem menor do que o valor 2,85 previsto teoricamente, e menor do que o valor de Wu \& Shaknov de 2,04 \pm 0,08 para o caso com integração para ângulo sólido finito (o que não altera a previsão de $\mathrm{R}=1$ para o caso A1).

Ao calcular $R$ no caso de mistura de polarização linear (caso A2), obtêm uma desigualdade $R<2$, que é menor do que o valor teórico 2,85. Neste caso, para o ângulo sólido finito de Wu \& Shaknov, o valor calculado é em torno de 1,5, bem menor do que $2,04 \pm 0,08$.

Assim, o experimento de Wu \& Shaknov não pode ser explicado supondo-se que os fótons de raios gama estejam em uma mistura de estados fatoráveis! Nas palavras de Bohm \& Aharonov (1957, p. 1075a,b):

Os resultados da Tabela 1 mostram que este experimento é explicado adequadamente pela atual teoria quântica que implica correlações distantes, do tipo levando ao paradoxo de ERP [sic], mas não por qualquer hipótese razoável implicando a quebra da teoria quântica que poderia evitar o paradoxo de ERP. (Bohm \& Aharonov 1957, p. 1075)

Em suma, Bohm \& Aharonov consideraram as duas suposições de Furry, um estado de mistura fatorável (caso A) e um estado puro entrelaçado (caso B). O que os 
físicos do Technion (em Haifa, Israel) fizeram de novidade foi calcular as previsões quânticas supondo que o estado quântico é uma mistura fatorável. Mostraram que esses estados, que satisfazem a localidade, fornecem um resultado tal que $\mathrm{R}<2$ (ao passo que o estado entrelaçado fornece 2,85), ou experimentalmente, integrando para o ângulo sólido, $\mathrm{R}<1,5$ (em comparação com 2,00 do estado entrelaçado). Como vimos, o experimento de $\mathrm{Wu} \&$ Shaknov forneceu para $\mathrm{R}$ o valor 2,04 $\pm 0,08$, confirmando as previsões quânticas.

Este resultado é bastante significativo, e pode ser considerado uma antecipação da desigualdade de Bell. As teorias consideradas na suposição (A) são um caso particular de teorias realistas locais, como aquelas proibidas pelo teorema de Bell. Chama atenção também a desigualdade $R<2$ obtida por Bohm \& Aharonov para o caso da mistura de estados linearmente polarizados. Será que esse resultado, em termos de desigualdade, tem alguma relação com a desigualdade de Bell? Em outras palavras, será que o resultado de Bohm \& Aharonov de fato é uma instância do teorema de Bell? 


\section{Capítulo 3}

\section{O Teorema de Bell}

\section{Teorias de Variáveis Ocultas e Provas de Impossibilidade}

Uma vez que a teoria quântica fosse considerada incompleta, poder-se-ia admitir a necessidade de se considerar variáveis adicionais ocultas que, juntamente com uma função de onda, forneceriam um único resultado para uma medição.

Dentre as motivações para o desenvolvimento das Teorias de Variáveis Ocultas (TVOs), iremos destacar a manutenção do determinismo, do determinismo nas medições e do princípio de localidade (Belinfante 1973, pp. 8-19; Pessoa 2006, p. 226).

É importante notar que o determinismo nas medições difere do conceito usual de determinismo, sendo este último relacionado a uma influência causal presente durante todo o procedimento experimental, uma vez que considera que as leis da natureza sejam deterministas - as TVOs que satisfazem a este princípio são teorias “criptodeterministas" (TVO-crip). Já o determinismo nas medições não se compromete com o determinismo das leis da natureza; neste caso, o determinismo se dá apenas no instante da medição, isto é, quando o sistema físico interage com o detector. Dessa forma, o resultado seria determinado por variáveis ocultas no instante da medição. As TVOs que abarcam este princípio são conhecidas como TVOs "com determinismo na medição" (TVO-det). Ressaltamos ainda a existência de TVOs cujos parâmetros ocultos determinam apenas as probabilidades dos resultados, estas são conhecidas como TVOs “estocásticas” (TVO-estoc).

Outro fator discutido com relação às TVOs é a localidade. Belinfante (1973, pp. 11-13) distinguiu entre TVOs de $1^{\circ}$ e $2^{\circ}$ tipo, sendo que esta segunda procura uma descrição local, como a que foi feita com a hipótese A de Furry, que utiliza misturas para descrever o experimento de EPR. Com o teorema de Bell, esta classe de TVOs foi, em larga medida, descartada, restando só as de $1^{\circ}$ tipo, que reproduzem as previsões da mecânica quântica, como a teoria causal de Bohm (1952).

As variáveis ocultas entraram em cena muito antes do artigo de EPR. Segundo Jammer (1974, p. 263-64), já em 1926 Max Born comentou sobre a possibilidade de processos individuais serem determinados por "coordenadas microscópicas”, de 
maneira que uma média sobre estas variáveis forneceriam as previsões quânticas. Tal ideia foi explorada por seu aluno Jakov Frenkel.

Dado um estado quântico $|\psi\rangle$, uma TVO supõe que qualquer observável $Q$ tenha um valor bem definido $[\widehat{Q}]^{|\psi\rangle}(\lambda)$ para cada valor da variável oculta $\lambda$. Segundo qualquer TVO, o valor médio $\langle\psi|\widehat{Q}| \psi\rangle$ de qualquer observável quântico teria que ser expresso pela média dos valores possuídos deste observável sobre todas as variáveis ocultas $\lambda$ possíveis, ponderada por uma função de distribuição estatística $\rho_{\psi}(\lambda)$ :

$$
\langle\psi|\widehat{Q}| \psi\rangle=\int[\hat{Q}]^{|\psi\rangle}(\lambda) \cdot \rho_{\psi}(\lambda) \cdot d \lambda
$$

No entanto, John von Neumann em 1932 concluiu pela impossibilidade de uma TVO, tratando o problema de forma matemática. O teorema que sustenta essa conclusão está articulado sobre cinco hipóteses baseadas no formalismo matemático quântico. A quinta hipótese, a da aditividade dos valores médios, é de que o valor médio da soma de operadores é a soma dos valores médios dos mesmos operadores:

$$
\langle\widehat{Q}+\widehat{R}\rangle=\langle\widehat{Q}\rangle+\langle\widehat{R}\rangle
$$

Esta relação é válida para operadores da mecânica quântica, como pode ser ilustrado para os operadores de spin 1/2, descritos pelas matrizes de Pauli. Von Neumann foi além e supôs que tal relação é válida também para quaisquer valores possuídos $[\widehat{Q}]^{|\psi\rangle}(\lambda)$ e $[\widehat{R}]^{|\psi\rangle}(\lambda)$, dado um certo estado quântico $|\psi\rangle$ e variável oculta $\lambda$. Com isso, conseguiu provar que, para qualquer de variável oculta, há algum observável quântico que assume mais de um valor único, ou seja, tem dispersão estatística. Von Neumann chegou neste resultado provando que há sempre algum operador $\widehat{Q}$ tal que:

$$
\left\langle\widehat{Q}^{2}\right\rangle \neq\langle\widehat{Q}\rangle^{2}
$$

Esta desigualdade afirma a existência de um operador autoadjunto $\widehat{Q}$, no espaço de Hilbert $\boldsymbol{H}$, que tem dispersão não nula; ou seja, para qualquer estado descrito por uma TVO (fixado por $|\psi\rangle$ e $\lambda$ ), existe um observável cuja medição pode fornecer mais do que um resultado.

A prova de von Neumann foi bem recebida pelos físicos. Ao longo dos 20 anos seguintes surgiram apenas poucas críticas à sua prova. Destaca-se a crítica da filósofa Grete Hermann, em 1935, em relação ao uso da hipótese de aditividade dos valores médios (Jammer 1974, pp. 272-75). No início dos anos 50, na União Soviética, Dimitrii Blokhintsev considerou a possibilidade de que uma TVO, que não satisfizesse o 
formalismo da mecânica quântica, escapasse da prova de impossibilidade de von Neumann. Provavelmente, David Bohm, na elaboração de sua TVO, tenha se inspirado não apenas nas conversas com Einstein, mas também em algum artigo russo, escrito por Blokhintsev ou Terletzkii (Jammer 1974, p. 279).

\section{A TVO Contextual de David Bohm}

Na seção 9 do Capítulo I vimos que David Bohm, em seu livro de 1951, ao propor uma nova versão do argumento de EPR utilizando os componentes do spin dos átomos, apresenta a sua visão de que a teoria quântica implica uma concepção de mundo microscópica bastante diferente do nível macroscópico. Ele estabelece o conceito de potencialidade, no qual os observáveis quânticos de um elétron, por exemplo, não são propriedades bem definidas, mas potencialidades, as quais são realizadas mais definidamente após a interação com um sistema clássico apropriado, no caso, o aparelho de medição (Ver seção 9, Cap. I). Além disso, Bohm (1951, p. 622) descarta a possibilidade de suplementar a descrição quântica com variáveis ocultas.

Curiosamente, um ano depois Bohm publicou um artigo, cujo título pode ser traduzido por "Uma interpretação sugerida da mecânica quântica em termos de variáveis ocultas", artigo publicado no Physical Review em duas partes, I e II.

Na parte I de seu artigo, Bohm apresenta sua interpretação da teoria quântica em termos de variáveis ocultas, indicando que ela conduz aos mesmos resultados da interpretação usual (ortodoxa) da teoria quântica, mas que fornece uma estrutura conceitual que torna possível uma descrição contínua e precisa de todos os processos a nível quântico ${ }^{24}$. Na parte II do artigo, Bohm discute como a teoria de medição é entendida do ponto de vista de sua interpretação da teoria quântica por meio de variáveis ocultas.

O primeiro ponto abordado por Bohm na parte I é o caráter probabilístico da mecânica quântica, no qual a descrição mais completa possível sobre o estado físico de um sistema individual, especificado pela função de onda, fornece apenas as probabilidades dos resultados de uma medição. Ele aponta que um dos motivos pelos

\footnotetext{
${ }^{24}$ Bohm (1952, p.166) argumenta também que a teoria quântica atual poderia não ser adequada para dimensões menores ou da ordem de $10^{-13} \mathrm{~cm}$, e que as modificações propostas por sua teoria em termos de variáveis ocultas, além de não afetarem o domínio quântico gerando os mesmos resultados da interpretação usual, poderia ser mais adequada para eliminar as complicações que a teoria quântica da época enfrentava para essas dimensões menores que $10^{-13} \mathrm{~cm}$.
} 
quais a crítica de Einstein quanto à incompletude da teoria quântica foi considerada irrelevante reside no fato de que a mecânica quântica estava em acordo com os resultados experimentais e que não havia uma interpretação alternativa consistente. Seu artigo viria então propor essa interpretação alternativa, que, segundo Bohm (1952, p. 166b) "permite-nos conceber que cada sistema individual esteja em um estado precisamente definível, cujas mudanças com o tempo são determinadas por leis definidas". Fazendo uma analogia com a mecânica estatística clássica, Bohm (ibid.) explica que as probabilidades quânticas seriam consideradas "apenas como uma necessidade prática e não como uma manifestação de uma falta de determinação completa inerente às propriedades da matéria no nível quântico".

Após abordar essa questão probabilística, David Bohm (1952, p. 167) parte para a análise do princípio de incerteza, afirmando que este pode ser derivado da teoria de duas formas. Primeiro, por meio da assunção de que a função de onda fornece probabilidades para o sistema quântico individual unido às relações de de Broglie, e, nesse caso, o princípio de incerteza seria uma limitação inerente e irredutível. Em segundo lugar, o princípio envolve a interferência de um distúrbio incontrolável no processo de medição, devido à interação do aparelho de medição com o sistema observado. Nesse segundo caso, Bohm sublinha que, se fosse possível controlar precisamente os efeitos desse distúrbio, poder-se-ia em princípio obter medições simultâneas de observáveis incompatíveis com ilimitada precisão, violando o princípio de incerteza proveniente da interpretação probabilística. Para evitar isso, a interpretação usual considera a assunção adicional de que esse distúrbio é inerentemente incontrolável, imprevisível e não sujeito à análise ou descrição racional detalhada, e com isso justifica-se que há "um conjunto de assunções que permitem uma formulação autoconsistente da interpretação usual da Mecânica Quântica” (Bohm 1952, p. 167b). O autor argumenta então que a consistência da interpretação usual não exclui a possibilidade de outra interpretação consistente.

Nesse sentido, Bohm coloca que é necessário verificar os motivos pelos quais a interpretação usual seria correta, porém, suas assunções (a interpretação probabilística da função de onda e o distúrbio incontrolável da medição) não limitam as formas da teoria matemática suficientemente para tornar possível um único conjunto de previsões que possa ser testado experimentalmente. Bohm (1952, p. 169a) explica que isso ocorre porque é possível introduzir operadores não-locais, campos não lineares e matrizes $S$, de maneira que seja possível "fazer a teoria concordar com os experimentos pela adição 
de alguma mudança na formulação matemática ainda não conhecida, sem requerer qualquer mudança fundamental na interpretação física". Segundo Bohm, isso deixa a teoria vulnerável à armadilha de hipóteses circulares que não podem ser testadas.

Nesse contexto, Bohm (1952, p. 169b) introduz a necessidade de assumir a hipótese de que "o resultado preciso de cada processo de medição individual é em princípio determinado por alguns elementos ou variáveis atualmente 'ocultas', e poderíamos então tentar encontrar experimentos que dependam de uma maneira única e reproduzível dos estados assumidos desses elementos ou variáveis ocultas”. Se as variáveis ocultas forem verificadas, teremos evidências a favor das TVOs, se não, não necessariamente a correção da interpretação usual será provada, mas talvez o caráter das variáveis ocultas deverá ser alterado.

Bohm (1952, p. 170-71) propõe então sua nova interpretação física da teoria quântica a partir da equação dinâmica de Schrödinger para uma partícula cujo estado é representado pela função de onda na forma polar, $\psi=\mathrm{R} \mathrm{e}^{\mathrm{iS} / \hbar}$, dependente das funções $R(\mathbf{x}, t)$ e $S(\mathbf{x}, t)$, que são funções reais. A densidade de probabilidade é dada pelo quadrado de $\mathrm{R}, \mathrm{P}(\mathbf{x})=\mathrm{R}^{2}(\mathbf{x})$. Ele considera o caso não clássico, $\hbar \neq 0$, para um coletivo de partículas de forma que sobre cada partícula atue não apenas um potencial clássico, $\mathrm{V}(\mathbf{x})$, mas também um "potencial quântico", U(x).

$$
\mathrm{U}(\mathbf{x})=\frac{-\hbar^{2}}{2 \mathrm{~m}} \frac{\nabla^{2} \mathrm{R}(\mathbf{x})}{\mathrm{R}(\mathbf{x})}
$$

A Eq. 19, definida por Bohm para o potencial quântico, $\mathrm{U}(\mathbf{x})$, permite que as equações de Hamilton-Jacobi possam também ser consideradas para esse coletivo de partículas, bem como a equação para a velocidade, $\nabla \mathrm{S}(\mathbf{x}) / \mathrm{m}$, e a equação de conservação da probabilidade. Nesse sentido, Bohm afirma por diversas vezes ao longo do artigo que sua interpretação em termos de variáveis ocultas da equação de Schrödinger reproduz os mesmos resultados probabilísticos da interpretação usual (ortodoxa) da teoria quântica.

Em sua interpretação, cada elétron é considerado uma partícula com valores de posição e momento variando continuamente. A solução para a equação de HamiltonJacobi, $\mathbf{S}(\mathbf{x})$, representa o conjunto de possíveis trajetórias para esta partícula. Dessa forma, a função de onda $\psi$ de um elétron individual permite calcular a força sobre uma partícula; assim, se também conhecêssemos a posição inicial e o momento da partícula, 
poderíamos calcular sua trajetória completa (Bohm 1952, p. 170b), o que dá lugar a uma descrição contínua e precisa de todos os processos em nível quântico.

Bohm (1952, p. 171a) apresenta também diversas propriedades do campo $\psi$ e da equação de Schrödinger, fazendo uma comparação com o campo eletromagnético e as equações de Maxwell. Ele deixa claro que, em sua interpretação, a posição e o momento das partículas devem ser considerados como variáveis "ocultas" e que "o uso do coletivo estatístico é (como no caso da mecânica estatística clássica) apenas uma necessidade prática e não o reflexo de uma limitação inerente", esclarecendo que a necessidade de uma descrição probabilística surge por causa do distúrbio incontrolável introduzido pelo aparelho de medição.

Como conclusão, Bohm afirma que sua interpretação da teoria quântica fornece uma estrutura conceitual mais ampla do que a fornecida pela interpretação usual, pois os mesmos resultados são obtidos se forem assumidas as seguintes suposições:

(1) Que o campo $\psi$ satisfaça a equação de Schrödinger.

(2) Que o momento da partícula seja restringido a $\mathbf{p}=\nabla \mathrm{S}(\mathbf{x})$.

(3) Que nós não prevemos ou controlamos a localização precisa da partícula, mas temos, na prática, um coletivo estatístico com densidade de probabilidade $\mathrm{P}(\mathbf{x})=|\psi(\mathbf{x})|^{2}$. O uso de estatística não é, contudo, inerente à estrutura conceitual, mas meramente uma consequência da nossa ignorância das condições iniciais precisas da partícula. (Bohm 1952, p. 171b)

A segunda parte do artigo de 1952 se dedica a aplicar a interpretação em termos de variáveis ocultas ao desenvolvimento de uma teoria de medição, ressaltando que, nessa interpretação, medições que violam o princípio de incerteza são em princípio concebíveis (Bohm 1952, p. 180b). Por outro lado, uma medição depende de uma interação com o aparelho de medição de maneira que um tal estado do sistema observado conduza a uma certa gama de estados do aparelho. Portanto, a interação introduz correlações entre o estado do sistema observado e o aparelho de medição.

Bohm descreve matematicamente a interação que ocorre na medição, que estabelece uma função de onda correlacionada, que envolve as funções $R(\boldsymbol{x}, \boldsymbol{y}, t)$ e $S(\boldsymbol{x}$, $\boldsymbol{y}, t)$, onde $\mathbf{x}$ é a variável do objeto quântico e $\mathbf{y}$ a do aparelho. Segundo a teoria de Bohm, $R$ e $S$ sofrem rápidas oscilações causadas por violentas flutuações do potencial quântico, sendo que o momento das partículas também fica sujeito a flutuações extremamente complicadas. Após um tempo suficientemente longo, a interferência entre as amplitudes de onda cessa, e o sistema torna-se descritível classicamente. 
As variáveis y do aparelho tendem a se fixar em um dos pacotes de onda e permanecem nele, determinando assim o resultado final da medição. Os outros pacotes seriam ignorados porque eles não afetam nem o potencial quântico atuando sobre as coordenadas das partículas nem o momento das partículas. Estes pacotes correspondem às "ondas vazias", na nomenclatura de L. de Broglie. "Assim, para todos os fins práticos podemos substituir a função de onda completa por uma nova função de onda renormalizada" (Bohm 1952, p. 182a). Bohm também salienta que essas ondas vazias não podem gerar interferência devido à perda de coerência, ou seja, "a variável y do aparelho se acoplará inevitavelmente a um grande número de graus de liberdade termodinâmicos internos resultantes de efeitos como o atrito e o movimento browniano" (ibid.).

Dessa forma, não só o potencial quântico e as variáveis ocultas posição e momento do sistema sob medição determinariam o resultado da medição, mas também as variáveis ocultas do aparelho de medição. No entanto, Bohm (1952 p. 182b) reconhece que tudo o que podemos prever na prática é que, em um coletivo no qual são feitos experimentos similares sob condições iniciais equivalentes, a densidade de probabilidade é $|\psi(x, y)|^{2}$.

Ao analisar o "experimento hipotético" de Einstein, Podolsky e Rosen (EPR), no qual em um sistema de duas partículas correlacionadas há a possibilidade de fazer medições de observáveis incompatíveis apenas na primeira partícula e inferir o resultado de uma medição na segunda partícula do mesmo observável, Bohm (1952, p. 186b) explica que, na perspectiva de sua interpretação em termos de variáveis ocultas, uma medição da posição da primeira partícula introduz flutuações incontroláveis na função de onda do sistema global, as quais, devido às "forças quânticas" (que surgem do potencial quântico), trazem flutuações incontroláveis no momento de cada partícula e similarmente para a medição do momento. Então, as forças mecânico-quânticas podem transmitir distúrbios incontroláveis instantâneos de uma partícula para a outra por meio do campo $\psi$. Dessa forma a teoria de Bohm é claramente não-local.

Bohm faz ainda referência à demonstração de von Neumann, de 1932, de que a teoria quântica é inconsistente com variáveis ocultas. Ele afirma que a prova de von Neumann contém uma restrição quanto à classe de parâmetros ocultos e que tal classe não é a que é proposta na teoria de Bohm, pois a prova de von Neumann não considera variáveis ocultas do aparelho de medição. Na teoria de Bohm, os observáveis são potencialidades que dependem do aparelho de observação para se desenvolverem 
precisamente e a distribuição de parâmetros ocultos varia de acordo com os diferentes arranjos de medição. Em linhas gerais, a teoria de variáveis ocultas de Bohm escapa da prova de impossibilidade de von Neumann por seu aspecto contextual, que postula também variáveis ocultas do aparelho de medição.

\section{O Teorema de Bell}

Em 1964 John Stuart Bell escreveu uma resenha sobre as diferentes provas de impossibilidade de teoria de variáveis ocultas, no entanto, esse artigo só foi publicado em 1966. Nele, Bell mostra que a prova de impossibilidade de von Neumann continha uma hipótese muito restritiva, a aditividade dos valores médios, além de salientar que a teria de Bohm é contextual (como Bohm sublinhara), ou seja, envolve variáveis ocultas pertencentes ao aparelho de medição. Além disso, Bell (1987, p. 11) mencionou que a contextualidade da TVO de Bohm a tornava imune a outras provas de impossibilidade, como a prova de Gleason, o que pode ser estendido para o teorema de Kochen-Specker.

Ainda em 1964, Bell derivou um teorema, expresso por uma desigualdade, que seria satisfeito por qualquer TVO local, cuja localidade fosse expressa por uma fatorabilidade na descrição matemática. A derivação da desigualdade foi apresentada em seu artigo de 1964, intitulado "On the Einstein-Podolsky-Rosen paradox" $" 25$. Neste artigo Bell (1987, p. 15) inicia sua exposição apresentando a situação do argumento de EPR (que envolve um sistema entrelaçado de duas partículas, 1 e 2) evidenciando, por meio da analise com spins, que, se "podemos prever antecipadamente o resultado da medição de qualquer componente escolhida de $\boldsymbol{\sigma}_{2}$, pela medição prévia da mesma componente de $\boldsymbol{\sigma}_{1}$, segue que o resultado de qualquer medição, deve, na realidade, estar predeterminado". A partir daí, surge a possibilidade de uma especificação mais completa, por parte da teoria quântica, integrado a variáveis ocultas.

Antes de analisar o desenvolvimento da derivação original do teorema de Bell, se faz necessário compreender o conceito matemático e físico de coeficiente de correlação para um sistema de duas partículas correlacionadas, que é o sistema utilizado na derivação do teorema.

\footnotetext{
${ }^{25} \mathrm{O}$ artigo foi publicado originalmente em $1964 \mathrm{em}$ Physics 1, p. 195-200, porém, referenciaremos aqui a publicação na coletânea de artigos de Bell sobre Filosofia da Física, Speakable and Unspeakable in Quantum Mechanics.
} 
O experimento envolvido, que segue esquematizado na Fig. 13, corresponde ao mesmo sistema utilizado por Bohm, duas partículas de spin $1 / 2$ que, tendo uma origem comum, após se separarem por um processo que conserva o momento angular total, mantêm uma correlação entre os spins.

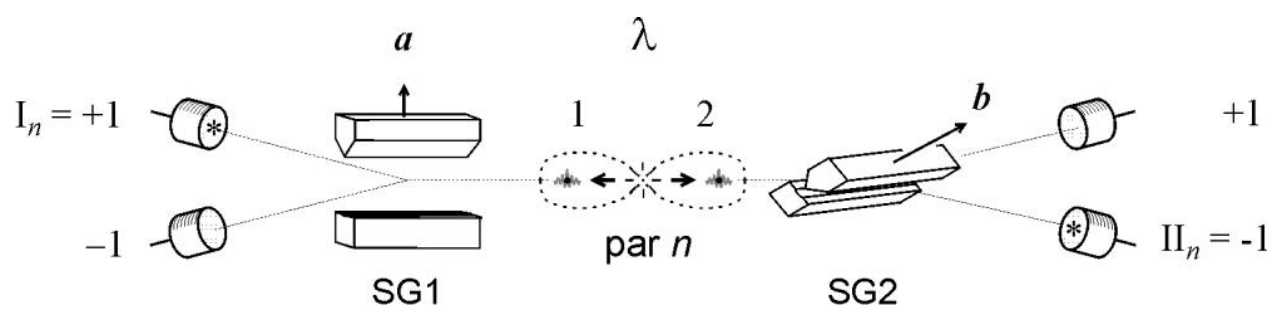

Figura 14: Montagem para a verificação do teorema de Bell (Pessoa 2006, p. 258).

Para um certo estado quântico das duas partículas, a correlação entre as medições obtidas para os pares de partículas depende dos ângulos escolhidos para a medição dos spins, via as orientações dos dois aparatos de Stern-Gerlach utilizados. Na Fig. 14, os aparatos estão orientados em direções arbitrárias $\boldsymbol{a}$ e $\boldsymbol{b}$, sendo que quando o componente de spin tem valor $+\frac{\hbar}{2}$, utiliza-se para simplificar unidades tal que este valor seja +1 , e quando for $-\frac{\hbar}{2}$ ele é denotado por -1 . O resultado obtido para a partícula 1 , no par $n$, é denotado por $\mathrm{I}_{n}$, e o resultado obtido para a partícula 2 é denotado por $\mathrm{II}_{n}$.

Para partículas de spin 1/2, a correlação é a média dos produtos $\mathrm{I}_{n} \cdot \mathrm{II}_{n}$. A chamada correlação perfeita ocorre quando o produto $\mathrm{I}_{n} \cdot \mathrm{II}_{n}$ tem sempre o valor +1 , de forma que a média também tem este valor +1 . A anticorrelação perfeita ocorre quando este produto tem valor -1 . Em geral, o coeficiente de correlação é dado por:

$$
\mathrm{c}(\boldsymbol{a}, \boldsymbol{b})=\sum_{\mathrm{n}=1}^{\mathrm{N}} \frac{\mathrm{I}_{n}(\boldsymbol{a}) \cdot \mathrm{II}_{n}(\boldsymbol{b})}{\mathrm{N}}
$$

Um exemplo de anticorrelação perfeita pode ser obtido para o estado de singleto (Eq. 9), quando os aparatos estão orientados na mesma direção $\boldsymbol{a}$ (como na Fig. 10, p.38). Neste caso, ao serem realizadas $\mathrm{N}$ medições simultâneas, todas elas fornecerão valores de spin opostos entre as partículas. A situação de correlação perfeita, no mesmo caso do estado singleto, aconteceria no caso de medições cuja diferença entre os ângulos de medição de cada partícula fosse de $180^{\circ}$, por exemplo, direcionando o aparato de Stern-Gerlach da primeira partícula em $\boldsymbol{a}$ e o aparato da segunda partícula em $-\boldsymbol{a}$. Dessa forma, os resultados $\mathrm{I}_{n}(\boldsymbol{a})$ e $\mathrm{II}_{n}(-\boldsymbol{a})$ seriam sempre +1 , e, portanto, o coeficiente de 
correlação seria 1. Para ângulos intermediários, o coeficiente de correlação estaria entre $-1 \mathrm{e}+1$.

Bell supõe que, dado um sistema correlacionado de duas partículas distantes (partículas identificadas como 1 e 2), haja parâmetros ocultos $\lambda$, variáveis contínuas, que determinam o resultado da medição de um observável, no caso o spin das partículas em diferentes direções. As possibilidades para esses resultados, $\mathrm{I}_{n}$ e $\mathrm{II}_{n}{ }^{26}{ }^{26}$ conforme explicitado anteriormente, são sempre $+1 \mathrm{ou}-1$. Como agora o resultado da medição é determinado, não apenas pela direção de medição, mas também por parâmetros ocultos, os resultados das medições são denotados por Bell da seguinte forma:

$$
\mathrm{I}(\boldsymbol{a}, \lambda)= \pm 1, \mathrm{II}(\boldsymbol{b}, \lambda)= \pm 1
$$

É importante notar que, conforme apontado por Bell e de acordo com a notação das equações acima, o resultado $\mathrm{I}_{n}$, da medição a ser feita na partícula 1 (que segundo a TVO, com determinismo na medição, é o valor possuído antes da medição), não depende da direção $\boldsymbol{b}$ do arranjo experimental na partícula 2, e vice-versa. Esta é a hipótese da localidade, introduzida por Bell.

Sendo $\rho(\lambda)$ a densidade de distribuição de probabilidades de $\lambda$ normalizada, Bell indica que o valor esperado do produto dos resultados do experimento nas duas partículas, ou seja, o coeficiente ou função de correlação é dado pela equação a seguir:

$$
\mathrm{c}(\boldsymbol{a}, \boldsymbol{b})=\int \mathrm{d} \lambda \rho(\lambda) \mathrm{I}(\boldsymbol{a}, \lambda) \mathrm{II}(\boldsymbol{b}, \lambda)
$$

Dessa forma, segundo Bell, esse valor deveria ser o mesmo que o valor esperado segundo a mecânica quântica, indicado na equação a seguir:

$$
\left\langle\boldsymbol{\sigma}_{\mathbf{1}} \cdot \mathbf{a} \boldsymbol{\sigma}_{\mathbf{2}} \cdot \mathbf{b}\right\rangle=-\mathbf{a} \cdot \mathbf{b}=-\cos \theta_{a b}
$$

Aqui $\theta_{a b}$ é o ângulo formado pelas direções $\boldsymbol{a}$ e $\boldsymbol{b}$ de medição. Bell, no entanto, mostrará ser impossível reproduzir os resultados da Eq. 23 com a Eq. 22.

Bell analisa então o caso de duas partículas, em um estado entrelaçado de singleto, que possuem a propriedade de anticorrelação perfeita quanto aos spins. Essa propriedade garante que os resultados de uma medição do spin, na mesma direção (e sentido) para as duas partículas, forneçam valores opostos entre si. Dessa forma, seguese que:

\footnotetext{
${ }^{26}$ Bell utiliza a notação "A" e "B" para os resultados das medições $\mathrm{I}_{n}$ e $\mathrm{II}_{n}$.
} 


$$
\mathrm{I}(\boldsymbol{a}, \lambda)=-\mathrm{II}(\boldsymbol{a}, \lambda) \quad \text { e } \quad \mathrm{II}(\boldsymbol{b}, \lambda)=-\mathrm{I}(\boldsymbol{b}, \lambda) .
$$

É possível, portanto, reescrever a função de correlação da Eq. 22 da seguinte forma:

$$
\mathrm{c}(\boldsymbol{a}, \boldsymbol{b})=-\int \mathrm{d} \lambda \rho(\lambda) \mathrm{I}(\boldsymbol{a}, \lambda) \mathrm{I}(\boldsymbol{b}, \lambda)
$$

Bell utiliza então uma subtração entre duas funções de correlação, uma para duas direções de medição $\boldsymbol{a}$ e $\boldsymbol{b}$, e outra para as direções $\boldsymbol{a}$ e $\boldsymbol{c}$, obtendo:

$$
\mathrm{c}(\boldsymbol{a}, \boldsymbol{b})-\mathrm{c}(\boldsymbol{a}, \boldsymbol{c})=-\int d \lambda \rho(\lambda)[\mathrm{I}(\boldsymbol{a}, \lambda) \mathrm{I}(\boldsymbol{b}, \lambda)-\mathrm{I}(\boldsymbol{a}, \lambda) \mathrm{I}(\boldsymbol{c}, \lambda)]
$$

Inserindo como artifício $\mathrm{I}(\boldsymbol{b}, \lambda) \mathrm{I}(\boldsymbol{b}, \lambda)$, que é igual à unidade, no segundo termo da integral, temos:

$$
\mathrm{c}(\boldsymbol{a}, \boldsymbol{b})-\mathrm{c}(\boldsymbol{a}, \boldsymbol{c})=-\int d \lambda \rho(\lambda)[\mathrm{I}(\boldsymbol{a}, \lambda) \mathrm{I}(\boldsymbol{b}, \lambda)-\mathrm{I}(\boldsymbol{a}, \lambda) \mathrm{I}(\boldsymbol{b}, \lambda) \mathrm{I}(\boldsymbol{b}, \lambda) \mathrm{I}(\boldsymbol{c}, \lambda)] .
$$

Fatorando o termo $\mathrm{I}(\boldsymbol{a}, \lambda) \mathrm{I}(\boldsymbol{b}, \lambda)$, presente nos dois termos da integral, e eliminando o sinal negativo diante da integral, temos:

$$
\mathrm{c}(\boldsymbol{a}, \boldsymbol{b})-\mathrm{c}(\boldsymbol{a}, \boldsymbol{c})=\int d \lambda \rho(\lambda) \mathrm{I}(\boldsymbol{a}, \lambda) \mathrm{I}(\boldsymbol{b}, \lambda) \cdot[\mathrm{I}(\boldsymbol{b}, \lambda) \mathrm{I}(\boldsymbol{c}, \lambda)-1] .
$$

Sabendo que $\mathrm{I}(\boldsymbol{a}, \lambda) \mathrm{I}(\boldsymbol{b}, \lambda)= \pm 1$ (pois os valores dos fatores são \pm 1 ), temos dois valores limites. O primeiro é quando $\mathrm{I}(\boldsymbol{a}, \lambda) \mathrm{I}(\boldsymbol{b}, \lambda)=1$ para todo valor de $\lambda$, situação em que $\mathrm{c}(\boldsymbol{a}, \boldsymbol{b})-\mathrm{c}(\boldsymbol{a}, \boldsymbol{c})=\int d \lambda \rho(\lambda)[\mathrm{I}(\boldsymbol{b}, \lambda) \mathrm{I}(\boldsymbol{c}, \lambda)-1] ;$ o segundo é quando $\mathrm{I}(\boldsymbol{a}, \lambda) \mathrm{I}(\boldsymbol{b}, \lambda)=-1$ para todo valor de $\lambda$, situação em que $\mathrm{c}(\boldsymbol{a}, \boldsymbol{b})-\mathrm{c}(\boldsymbol{a}, \boldsymbol{c})=-\int d \lambda \rho(\lambda)[\mathrm{I}(\boldsymbol{b}, \lambda) \mathrm{I}(\boldsymbol{c}, \lambda)-1]$. Porém, como os valores possuídos variam entre \pm 1 , o valor de $\mathrm{c}(\boldsymbol{a}, \boldsymbol{b})-\mathrm{c}(\boldsymbol{a}, \boldsymbol{c})$ está entre esses dois limites. Bell exprimiu isso de maneira elegante tomando o módulo de $\mathrm{c}(\boldsymbol{a}, \boldsymbol{b})-\mathrm{c}(\boldsymbol{a}, \boldsymbol{c})$ :

$$
|\mathrm{c}(\boldsymbol{a}, \boldsymbol{b})-\mathrm{c}(\boldsymbol{a}, \boldsymbol{c})| \leq \int d \lambda \rho(\lambda) \cdot[1-\mathrm{I}(\boldsymbol{b}, \lambda) \mathrm{I}(\boldsymbol{c}, \lambda)] .
$$

O segundo termo é $1+\mathrm{c}(\boldsymbol{b}, \boldsymbol{c})$, então:

$$
|\mathrm{c}(\boldsymbol{a}, \boldsymbol{b})-\mathrm{c}(\boldsymbol{a}, \boldsymbol{c})| \leq 1+\mathrm{c}(\boldsymbol{b}, \boldsymbol{c})
$$

Esta é a desigualdade de Bell, derivada em 1964. 
A intenção de autor, a partir deste ponto, é mostrar que c $(\boldsymbol{a}, \boldsymbol{b})$ não é equivalente ao valor esperado para o produto dos dois observáveis $\sigma_{1} \cdot \boldsymbol{a} \mathbf{e} \boldsymbol{\sigma}_{2} \cdot \boldsymbol{b}$ fornecido pela Eq. 23: $\mathrm{c}(\boldsymbol{a}, \boldsymbol{b})=-\cos \theta_{a b}$. Ele o faz por meio de um teorema que não demonstraremos. No entanto, é fácil verificar essa divergência, considerando valores específicos para as direções $\boldsymbol{a}, \boldsymbol{b}$ e $\boldsymbol{c}$. Por exemplo, para os ângulos com $\theta_{a b}=\theta_{b c}=30^{\circ}$ e para $\theta_{a c}=60^{\circ}$, temos:

$$
\begin{gathered}
c(\boldsymbol{a}, \boldsymbol{b})=-\cos 30^{\circ}=-\frac{\sqrt{3}}{2} \\
c(\boldsymbol{a}, \boldsymbol{c})=-\cos 60^{\circ}=-\frac{1}{2} \\
c(\boldsymbol{b}, \boldsymbol{c})=-\cos 30^{\circ}=-\frac{\sqrt{3}}{2}
\end{gathered}
$$

Substituindo esses valores na desigualdade de Bell (Eq. 30) chegamos a uma inconsistência:

$$
\begin{gathered}
\left|-\frac{\sqrt{3}}{2}+\frac{1}{2}\right| \leq 1-\frac{\sqrt{3}}{2} \quad, \\
\sim 0,37 \leq \sim 0,13 .
\end{gathered}
$$

Ao provar o teorema (na derivação original de Bell), segundo o qual os coeficientes de correlação fornecidos por uma TVO e pela teoria quântica não são equivalentes, indicando que o coeficiente de correlação fornecido por uma teoria de variáveis ocultas local gera uma desigualdade que é violada pela mecânica quântica (conforme apresentado acima), Bell demonstrou que TVOs locais são incompatíveis com a teoria quântica, e portanto que a quântica não pode ser "completada" com variáveis ocultas adicionais que atuem de maneira local.

É importante notar que no artigo de 1964, Bell assume variáveis ocultas que, juntamente com o estado quântico, determinariam de maneira unívoca o resultado das medições "em um instante". Isso porque ele aponta - como alternativa à proposta de teoria física completa do tipo previsto por Einstein, onde as variáveis ocultas deveriam ter significado dinâmico, segundo leis de movimento - que suas variáveis " $\lambda$ podem então ser pensadas como valores iniciais dessas variáveis num instante adequado" (Bell, 1987, p. 15). Dessa forma ele assume uma versão do realismo com determinismo apenas num instante adequado, o instante da medição. Denotaremos essa versão da 
hipótese do realismo como "realismo de TVOs com determinismo na medição" $\left(\mathbf{R}_{\text {TVO-det }}\right)$.

Vimos que a hipótese da localidade é suposta ao assumir que os resultados $\mathrm{I}(\boldsymbol{a}, \lambda)$ e II $(\boldsymbol{b}, \lambda)$ dependem apenas das variáveis ocultas locais e da direção de medição local $\boldsymbol{a}$ e $\boldsymbol{b}$, respectivamente. Bell (1987, p. 15) afirma que "a assunção vital é que o resultado B [II] para a partícula 2 não depende da direção $\boldsymbol{a}$ do imã para a partícula 1, e nem A [I] [depende] de $\boldsymbol{b}$ ". Em nota ele cita Einstein (1949), que escreveu: "uma suposição a qual nós devemos, em minha opinião, nos agarrar: a situação factual real do sistema $\mathrm{S}_{2}$ é independente do que é feito no sistema $S_{1}$, o qual está separado espacialmente do anterior" (Bell 1987, p. 20).

\section{O Dilema de Bell}

Uma vez que a teoria quântica prevê a violação da desigualdade de Bell, conforme foi exemplificado na seção anterior, é possível fazer testes experimentais a fim de verificar se a natureza física das partículas subatômicas respeita tal desigualdade ou a viola. De fato, até o teorema de Bell, a única maneira de explorar experimentalmente o argumento de incompletude de EPR e a tentativa de completar a teoria quântica por meio de variáveis ocultas locais, foi o experimento de $\mathrm{Wu}$ \& Shaknov (1950), examinado na seção II.2, e analisado por Bohm \& Aharonov (seção II.3). Com o teorema de Bell, uma nova era de testes experimentais se abriu.

Em 1979, o físico francês Bernard d'Espagnat publicou um artigo que discutia de forma bastante didática as consequências filosóficas dos testes experimentais da desigualdade de Bell. Em seu artigo ele apresenta sete experimentos realizados no decorrer da década de 70 , sendo que em apenas dois deles os resultados permaneceram dentro do limite imposto pela desigualdade de Bell, ao passo que os outros cinco verificaram a violação prevista pela quântica. A conclusão que se tira desses resultados é a impossibilidade de teorias de variáveis ocultas locais.

D’Espagnat (1979, p. 158b) explica que as teorias realistas locais, excluídas pelo teorema de Bell, são compostas por três premissas básicas: (1) o realismo, doutrina de que regularidades em fenômenos observados são causadas por alguma realidade física cuja existência é independente dos observadores humanos; (2) inferência indutiva, que é um modo válido de raciocinar e pode ser aplicada livremente de modo que as conclusões podem ser extraídas de observações consistentes; e (3) a localidade de 
Einstein, que afirma que nenhuma influência de qualquer tipo pode se propagar mais rápido do que a luz (d'Espagnat 1979, p. 158b).

Nesse sentido, a pergunta que se coloca é, qual das premissas deve ser abandonada? D'Espagnat (1979, p. 177a) aponta o realismo como a premissa mais fundamental, afirmando que "o realismo pode ser enunciado formalmente como a crença de que uma mera descrição de dados não é tudo o que deve ser requerido de uma teoria [...]. O pensamento demanda algo mais: não necessariamente determinismo [...], mas pelo menos explicações objetivas para regularidades observadas, ou em outras palavras, causas". Além disso, ele alega que é o realismo que sustenta a justificativa para postular o livre uso da inferência indutiva, "é a indução que permitiu ao físico extraplorar de uma série de correlações negativas observadas para a conclusão de que quaisquer dois prótons no estado de singleto têm valores opostos para qualquer componente do spin, mesmo se nenhuma componente for medida" (d'Espagnat 1979, p. 177c). Esta última oração subordinada talvez devesse ser substituída por "quando forem medidos", já que a indução só se refere a medições. ${ }^{27}$

Dessa forma, se o realismo e o uso da livre indução são mantidos, a localidade é questionada. Segundo d'Espagnat (1997, p. 180c), o princípio de localidade foi introduzido como uma premissa da teoria da relatividade, que não pode ser consistente sem ele. Nesse sentido, d'Espagnat adverte que o abandono da localidade não deve ser uma resposta imediata à violação do teorema de Bell, pois sinais que ultrapassam a velocidade da luz dão origem a paradoxos bizarros de causalidade, nos quais observadores em alguns referencias concluem que um evento é causado por um outro que ainda não aconteceu.

D’Espagnat (1997, p. 180c) afirma ainda que a resposta de Bohr ao argumento de Einstein introduz uma violação implícita da separabilidade e que isto é fundamentado em uma "estranha indivisibilidade do sistema de partículas e dos instrumentos de observação". No entanto, a interpretação convencional da mecânica quântica, estabelecida em grande medida por Bohr, não identifica a função de onda de um sistema com qualquer realidade, considerando a função de onda como uma mera ferramenta para fazer cálculos.

Assim, aceitando-se que a inferência indutiva é uma premissa fundamental derivada do realismo, seguir-se-ia da violação experimental da desigualdade de Bell um

\footnotetext{
${ }^{27}$ Deixaremos o exame do conceito de "indução" ou de "amostragem justa" para um trabalho posterior
} 
dilema entre o realismo e a localidade, isto é, as duas grandes premissas evolvidas no estabelecimento de teorias realistas locais.

Uma forma mais precisa de estabelecer tal dilema seria especificando a teoria realista local a ser rechaçada pelas provas experimentais, como uma teoria de variáveis ocultas com determinismo na medição, conforme especificado na derivação do teorema de Bell da seção anterior. Seguir-se-ia então um dilema entre duas hipóteses, o realismo de TVO com determinismo na medição e a localidade de Einstein, relacionada a dois eventos separados espacialmente. Esse dilema ficou conhecido como dilema de Bell, e afirma que, no escopo da mecânica quântica, deve-se abandonar um dos seguintes conceitos filosóficos: o realismo $\left(\mathbf{R}_{\text {TVO-det }}\right)$ ou a localidade (LOC), ou ambos.

$$
\neg \mathbf{R}_{\text {TVO-det }} \text { ou } \neg \text { LOC }
$$

É importante salientar que, posteriormente, em 1971, Bell estendeu o teorema para TVOs estocásticas, que determinam apenas as probabilidades dos resultados das medições. Assim, o teorema de Bell seria escrito da seguinte forma:

$$
\neg \mathbf{R}_{\text {TVO-estoc }} \quad \text { ou } \quad \neg \text { LOC }
$$

\section{Argumento da Não-Localidade e o Dilema do Instrumentalista}

Retomando o Capítulo I, no qual foi desenvolvido o argumento de EPR para a incompletude da mecânica quântica, poderíamos nos perguntar, à luz do teorema de Bell, se Einstein não teria errado em sua argumentação a favor da incompletude da quântica, uma vez que ele assume o postulado da localidade e uma versão do realismo.

Como a hipótese da localidade usada por Bell é equivalente à localidade de Einstein, o ponto a ser analisado é se as versões do realismo usadas por Einstein, no artigo de 1935, e por Bell são equivalentes.

Em 1964, Bell utiliza, na derivação de seu teorema, a tese do realismo de TVOs com determinismo na medição $\left(\mathbf{R}_{\mathbf{T V O} \text {-det }}\right)$. O teorema foi, posteriormente, estendido (por Bell, 1971; Clauser \& Horne, 1974) para TVOs estocásticas, generalizando então a tese do realismo para um realismo de TVO estocásticas $\left(\mathbf{R}_{\text {TVO-estoc }}\right)$. Ambos os realismos afirmam a existência de variáveis ocultas que determinariam as probabilidades dos resultados - no caso das TVOs-det essa probabilidade é 1. No entanto, essa 
probabilidade não é acessível aos seres humanos, só a um hipotético demônio de Laplace.

Por outro lado, o critério de realidade física, $\mathbf{R}$ utilizado por EPR afirma a existência de elementos de realidade quando for possível prever com probabilidade $1 \mathrm{o}$ resultado de uma medição, sem se referir à existência de variáveis ocultas. Aqui, esta probabilidade se refere a previsões humanas.

Dessa forma, a aceitação de $\mathbf{R}$ não implica logicamente a aceitação de $\mathbf{R}_{\text {TVO-estoc }}$, e, portanto, é aceitável supor $\mathbf{R}$ e LOC simultaneamente como hipóteses de um argumento, de forma que o argumento de EPR não repousa sobre premissas contraditórias. Nesse sentido, podemos dizer que Einstein não errou, ou seja, ele não utilizou hipóteses que violam o dilema de Bell.

Porém, notemos que incompletude da mecânica quântica, defendida por EPR, que denotaremos por INC, implica uma forma de realismo, pois afirma que há uma realidade, não descrita pela mecânica quântica, que seriam justamente as variáveis ocultas. Denotaremos essa forma de realismo por $\mathbf{R}_{\mathbf{E P R}}$, apesar de EPR não afirmarem isso. A afirmação "INC $\rightarrow \mathbf{R}_{\mathbf{E P R}}$ " é uma tese nossa. Tais variáveis ocultas, no sistema não medido, determinariam univocamente o resultado das medições dos observáveis envolvidos no argumento de EPR. Assim, para todos os observáveis envolvidos em um argumento tipo EPR, haveria variáveis ocultas com "determinismo na medição". Assim, a tese do $\mathbf{R}_{\text {TVO-det }}$ se seguiria do argumento de EPR, ao afirmarem a incompletude em sua conclusão.

Aceitando-se então que esta tese, $\mathbf{R}_{\text {Tvo-det }}$, se segue do argumento de EPR, podemos nos perguntar: o que aconteceria se juntássemos este resultado com o dilema de Bell?

O realismo presente nas versões posteriores do teorema de Bell, $\mathbf{R}_{\text {TVO-estoc }}$, é uma extensão do realismo de TVOs com determinismo na medição ( $\mathbf{R}_{\text {TVo-det }}$ ). Nas TVOs estocásticas, as variáveis ocultas determinam apenas as probabilidades dos resultados, que podem ser menores ou iguais a 1. Assim, um mundo possuindo a propriedade do $\mathbf{R}_{\text {TVO-det }}$ também possuiria a propriedade do $\mathbf{R}_{\text {TVO-estoc }}$ :

$$
\mathbf{R}_{\text {TVO-det }} \rightarrow \mathbf{R}_{\text {TVO-estoc }}
$$


Retomando a seção I.9, o dilema de Einstein afirma que devemos abandonar a tese de completude ou a tese da localidade (INC ou $\neg$ LOC). Da seção III.3, o dilema de Bell afirma que devemos abandonar o realismo ou a localidade $\left(\neg \mathbf{R}_{\text {TVO-estoc }}\right.$ ou $\neg$ LOC). Unindo os dilemas de Einstein e de Bell, é possível derivar a tese da não-localidade independentemente do valor de verdade da tese do realismo, conforme apresenta o seguinte cálculo proposicional:

$$
\begin{aligned}
& \neg \mathbf{R}_{\text {TVO-estoc }} \vee \neg \mathbf{L O C} \quad \text { (Hip) (Dilema de Bell) } \\
& \text { INC } \vee \neg \text { LOC } \quad \text { (Hip) (Dilema de EPR) } \\
& \text { INC } \rightarrow \mathbf{R}_{\mathbf{E P R}} \quad \text { (Definição de Incompletude) } \\
& \mathbf{R}_{\text {EPR }} \vee \neg \mathbf{L O C} \\
& \mathbf{R}_{\text {EPR }} \rightarrow \mathbf{R}_{\text {TVO-estoc. }} \quad \text { (Teorema a ser provado) } \\
& \mathbf{R}_{\text {TVO-estoc }} \vee \neg \mathbf{R}_{\text {TVO-estoc. }} \quad \text { (Tautologia) } \\
& \mathbf{R}_{\text {TVO-estoc }} \rightarrow \neg \text { LOC } \\
& \neg \mathbf{R}_{\text {TVO-estoc }} \rightarrow \neg \mathbf{R}_{\mathbf{E P R}} \quad(5, \text { modus tollens }) \\
& \neg \mathbf{R}_{\text {TVO-estoc }} \rightarrow \neg \text { LOC } \quad(8,4) \\
& \neg \mathbf{L O C} \quad(9,7)
\end{aligned}
$$

Outro dilema pode ser derivado a partir da postura adotada pelo instrumentalista. No dilema de Bell, o instrumentalista abandona o realismo e mantém a localidade. Uma vez que aceitar os dilemas de EPR e Bell implica aceitar a não-localidade, para manter a defesa da localidade, nesse cenário, ele pode não aceitar o argumento de EPR, rejeitando o uso do princípio de incerteza forte. Mas e para os argumentos que não se utilizam do princípio de incerteza, como o argumento de Einstein apresentado na seção I.10? A única saída seria rejeitar uso do raciocínio contrafactual, ou se abandona a localidade, LOC (como fazem os realistas), ou se rejeita o raciocínio contrafactual $\mathbf{C F}$ (como sugeriu Bohr e como farão os instrumentalistas), ou os dois:

$$
\neg \mathrm{LOC} \text { ou } \neg \mathrm{CF} \text {. }
$$




\section{Conclusão}

Nas primeiras décadas do século XX o surgimento da teoria quântica colocou em questão diversos princípios fundamentais da física clássica. Após a publicação do artigo de Einstein, Podolsky \& Rosen (EPR) em 1935, o qual apresentou um argumento que conduz à tese de incompletude da teoria quântica, o princípio de localidade segundo o qual um processo físico ocorrido em uma determinada região do espaço não pode afetar instantaneamente elementos de realidade física localizados em outra região do espaço - passou a ser um dos principais alvos do debate que se estenderia ao longo do século XX.

O capítulo I da presente dissertação dedicou-se, primeiramente, à exposição mais fiel possível da estrutura original do argumento. Seguiram-se então algumas análises de sua estrutura lógica e conceitual a fim de identificar as premissas e assunções, explicitas ou implícitas, envolvidas. Além disso, foram consideradas três possibilidades de interpretação do princípio de incerteza, concluindo-se que apenas sua versão realista forte viabilizaria o objetivo de derivar a incompletude.

Ainda nesse contexto de análise lógica e conceitual do argumento, foram selecionadas algumas propostas de estruturação por meio do cálculo proposicional que consideramos relevantes para possibilitar uma compreensão clara e detalhada dos princípios assumidos. A análise de Chibeni $(1997,2005)$ apresentou com clareza e objetividade a pretensa contradição a ser estabelecida por EPR, bem como a exposição de uma complicação desnecessária envolvendo o uso de um condicional lógico (em “C $\rightarrow$ RS") e da doutrina da perturbação vinculada ao princípio de incerteza. Ao retomarmos uma estruturação lógica mais antiga e detalhada feita por McGrath (1978), também por meio do cálculo proposicional e modal, verificou-se uma concordância interessante com a tese de Chibeni de que a assunção de completude $\mathrm{C}$, que aparece acima no antecedente do condicional lógico, não foi, de fato, usada na finalização do argumento, concordância esta que aparece de forma sutil no complicado cálculo proposicional de McGrath.

Uma análise ainda mais detalhada, porém com o diferencial de incluir as diversas possibilidades de interpretação epistemológica das premissas evolvidas no argumento, bem como de identificar qual dessas interpretações foi pensada e estabelecida implicitamente por EPR, foi publicada por Linda Wessels (1981) e gerou 
um significante trilema, no qual uma das três premissas, determinismo fraco (WD), propriedades possuídas na ausência de medições $\left(I^{*}\right)$ ou a sentença de Heisenberg $(\mathrm{H})$, deveria ser negada para que qualquer interpretação do argumento fosse adequada.

Seguindo o capítulo I, retomamos uma das primeiras respostas ao argumento de EPR, a resposta de Bohr, publicada apenas dois meses após o artigo de EPR também no Physical Review, que remonta às discussões entre Bohr e Einstein no famoso Congresso de Solvay de 1927. Além disso, vimos que Bohr, ao se deparar com a ausência de perturbação mecânica evidente no argumento de EPR, parece desviar seu discurso sobre o fenômeno perturbativo para a arena linguística, na qual ele identifica no argumento de EPR uma ambiguidade no critério de elemento de realidade física, afirmando que apesar de não haver perturbação mecânica, haveria uma influência sobre as próprias condições que definem o sistema e as possibilidades de previsões associadas às suas propriedades.

Abordamos então duas versões alternativas do argumento. Primeiramente a versão de Bohm (1951), análoga à versão original com a diferença de utilizar o spin das partículas correlacionadas em vez da posição e momento, e cujo desenvolvimento foi fundamental para possibilitar os testes experimentais da década de 1970. E em seguida apresentamos a versão original de Einstein, que foi por ele exposta em uma carta destinada a Schrödinger, a qual continha uma versão mais simples, além de sua crítica em relação à erudição da redação de Podolsky, que teria obscurecido a essência da incompletude pensada por Einstein. Essa versão deriva um interessante dilema entre incompletude e não-localidade $(\neg \mathbf{C}(\mathrm{MQ})$ ou $\neg$ LOC $)$.

As últimas seções do capítulo I trazem ao debate lógico-conceitual do argumento a postura filosófica realista de Einstein quanto ao procedimento científico, identificando-a antes de tudo como uma tese metodológica extremamente pertinente, cuja preocupação está centrada na produção de um conhecimento que estabeleça suas leis fundamentais sobre objetos invariantes, isto é, objetos independentes da escolha de um sistema descritivo de referência e que, dessa forma, tais leis sejam definidas objetivamente e independente do observador.

O argumento de EPR perpassa vários aspectos do conhecimento científico e de seu desenvolvimento teórico, conceitual e filosófico. No capítulo I foi notável a presença de uma análise lógica sistemática que define critérios e princípios utilizados no argumento, que analisa ambiguidades, que identifica diferentes versões e estabelece dilemas. Esta forma de proceder ao analisar um argumento permite identificar sua consistência e validade lógica dentro de um ou outro determinado conjunto de conceitos 
aceitos que, por sua vez, estão permeados de interpretações. Esse conjunto de conceitos aceitos, unidos a determinadas interpretações teóricas e resultados experimentais, determinará os dilemas e consequências lógicas e filosóficas a serem extraídos do debate em questão.

Nesse sentido, o argumento de EPR e as insistentes críticas de Einstein à teoria quântica são bastante pertinentes e importantes no campo da interpretação das teorias físicas, isto é, no campo da epistemologia e ontologia, podendo inclusive influenciar o desenvolvimento científico. Essa influência dá lugar a uma importante questão digna de estudos futuros: qual a contribuição dos debates filosóficos no desenvolvimento eficiente de novas teorias científicas. A princípio, poderíamos estabelecer duas funções importantes do debate filosófico. Em primeiro lugar, estudar as interpretações das teorias físicas no sentido de saciar-nos a vontade de compreender a natureza, tanto em seu sentido instrumental, quanto no sentido ontológico e existencial. Em segundo lugar, promover uma ampla visão epistemológica do processo científico, colaborando para a sua eficiência. Essas preocupações parecem ter alguma aproximação com as preocupações de Einstein, que identificamos em seu realismo metodológico.

Explorando um pouco mais profundamente os aspectos experimentais envolvidos nas primeiras tentativas de se obter evidências empíricas sobre a problemática levantada pelo argumento de EPR quanto à incompletude da teoria quântica, o capítulo II remonta a alguns testes experimentais da teoria quântica de polarização de Price \& Ward (1947), vinculados às propostas formuladas independentemente por Wendell Furry (1936) e Erwin Schrödinger (1935) sobre modelos de estado puro entrelaçado e misturas de pares de partículas.

A teoria quântica de polarização foi testada experimentalmente ao longo da década de 1940 por diversos físicos experimentais, porém os resultados mais satisfatórios e precisos foram obtidos apenas no final da década pelo experimento de Wu \& Shaknov (1950). Nesse contexto, a discussão mais significativa a ser notada se encontra na análise realizada por David Bohm \& Yakir Aharonov (1957). Eles consideram as duas suposições de Furry, um estado de mistura fatorável (caso A) e um estado puro entrelaçado (caso B), e percebem que, ao calcular a taxa de polarização $\mathrm{R}$ para o caso $\mathrm{A}$, obtêm a desigualdade $\mathrm{R}<2$, que é inconsistente com o valor teórico previsto pela teoria do espalhamento de pares de raios gama, usado por $\mathrm{Wu} \&$ Shaknov, de 2,85. Para calcular o resultado experimental, os cientistas da Universidade de Columbia tiveram que integrar os resultados sobre um ângulo sólido finito, de maneira 
que o resultado teórico tornou-se 2,00, considerando o estado quântico entrelaçado (caso B). Seu experimento forneceu 2,04 $\pm 0,08$, confirmando as previsões quânticas.

Conforme visto nas seções II.2 e II.3, o experimento de Wu \& Shaknov, pautado na teoria quântica de polarização que envolve dois fótons correlacionados, não pode ser explicado por um estado de mistura fatorável. Nota-se uma semelhança entre a análise de Bohm \& Aharonov, envolvendo uma desigualdade que é violada experimentalmente, e a desigualdade derivada por Bell em 1964. Com efeito, as teorias consideradas na suposição A são um caso particular das teorias realistas locais envolvidas no teorema de Bell. Seria interessante investigar se o resultado de Bohm \& Aharonov de fato é uma instância do teorema de Bell. Esse é um resultado interessante, digno de maiores explorações em trabalhos futuros.

O capítulo III proporcionou, em seguida, uma básica exploração teórica do teorema de Bell em sua versão original; seus precedentes, que são permeados pelas teorias de variáveis ocultas e provas de impossibilidade; e seus desdobramentos, que se direcionam também para testes experimentais e resultados de caráter filosófico, como o dilema de Bell.

Uma interessante e viável interpretação da teoria quântica em termos de variáveis ocultas foi proposta por David Bohm (1952) com o objetivo de tornar possível uma descrição contínua e precisa de todos os processos físicos, mesmo no nível quântico. Segundo essa proposta, a mecânica quântica probabilística descreveria os efeitos da manifestação das variáveis ocultas do sistema composto, isto é, composto pelo objeto de medição e aparelho de medição. Este é um dos pontos fundamentais da TVO de Bohm: dado que ela considera também as variáveis ocultas do aparelho de medição, ela escapa da prova de impossibilidade de von Neumann (1932). A isso se dá o nome de teoria de variáveis ocultas "contextual". Além disso, a teoria de Bohm é claramente uma teoria não-local, o que se manifesta em variações do potencial quântico. A TVO de Bohm produz os mesmos resultados probabilísticos da mecânica quântica usual, mas para o autor permite uma estrutura conceitual mais palatável do que a interpretação ortodoxa da teoria quântica.

Depois apresentamos o desenvolvimento feito por John Stuart Bell (1964), que produziu uma desigualdade matemática envolvendo coeficientes de correlação de um sistema de duas partículas do tipo utilizado no argumento de EPR, e que foi derivada por meio de uma teoria de variável oculta local e determinista, isto é, que determina o resultado no instante da medição. Utilizamos alguns ângulos hipotéticos de medição 
para aclarar a situação em que a teoria quântica prevê a violação da desigualdade de Bell, o que evidencia a incompatibilidade entre as teorias realistas locais e a teoria quântica, e que, portanto, teorias realistas locais não podem completar a mecânica quântica.

Salientamos a extensão do teorema feita por Bell (1971) para teoria de variáveis ocultas estocásticas. Apresentamos a importante discussão sobre as consequências filosóficas e conceituais decorrentes dos testes experimentais da desigualdade de Bell da década de 1970, que terminaram por corroborar a correção da teoria quântica, confirmando a violação experimental da desigualdade de Bell. Utilizamos as explorações de Bernard d'Espagnat quanto às três assunções envolvidas na derivação do teorema: o realismo, a indução e a localidade. Com isso, desembocamos no dilema de Bell, que envolve uma escolha entre uma tese filosófica e um princípio físico, respectivamente, o realismo de teoria de variáveis ocultas estocásticas e o princípio de localidade ( $\neg \mathbf{R}_{\text {TVO-estoc }}$ ou $\neg$ LOC). Consideramos esta análise filosófica plausível, apesar de haver críticos a ela (ver Berkowitz 1998, e Chibeni 2014).

No campo científico, há uma tendência à adoção de uma postura antirrealista e instrumentalista. $\mathrm{O}$ sucesso experimental da teoria quântica sustentou esta atitude ao longo das décadas, mesmo com as propostas realistas de Einstein, de Broglie, Schrödinger e Bohm. Curiosamente, foi a partir do teorema de Bell que as discussões sobre os fundamentos da mecânica quântica ganharam força, apesar de sua desigualdade não afetar nenhuma das interpretações vigentes, como a interpretação ortodoxa (que adota $\neg \mathbf{R}_{\text {TVO-estoc }}$ ) e a interpretação causal de Bohm (que adota $\neg$ LOC). A classe de teorias realistas locais nunca havia sido defendida explicitamente (isso só seria feito por Marshall, Santos \& Selleri, 1983, que de certa forma abandonam a indução), apesar de talvez fazer parte das intuições dos físicos, em certos momentos. A compreensão de porque o teorema de Bell teve tanto impacto, mesmo não afetando nenhuma interpretação vigente da teoria quântica, é objeto de estudos históricos, como o de Freire (2006) (ver também Pessoa 2014).

Ao final do capítulo III, explorou-se o dilema resultante do argumento de incompletude original de Einstein, apresentado na seção I.10, e fazendo uma análise lógica e conceitual por meio do cálculo proposicional, pudemos verificar que, estabelecendo um tipo de realismo derivado da tese de incompletude de Einstein, é possível fornecer um argumento a favor da não-localidade, independente das teses 
filosóficas realistas ou antirrealistas. Este é um resultado original, que deverá agora ser publicado na forma de um artigo. 


\section{Referências Bibliográficas}

BELL, J. S. (1964). On the Einstein Podolsky Rosen Paradox. Physics 1:195-200.

(1971) On the Problem of Hidden Variables in Quantum Mechanics. Review of Modern Physics 38: 447-52.

(1987). Speakable and Unspeakable in Quantum Mechanics. Cambridge: Cambridge University Press.

BELINFANTE, F.J. (1973). A Survey of Hidden-Variables Theories. Oxford: Pergamon.

BERKOVITZ, J. (1998). Aspects of quantum non-locality I: superluminal signaling, action-at-a-distance, non-separability and holism. Studies in the History and Philosophy of Modern Physics 29: 183-222.

BLEULER, E. \& BRADT, H.L. (1948). Correlation between the States of Polarization of the Two Quanta of Annihilation Radiation. Physical Review 73: 1398.

BLUM, K. (1981). Density Matrix: Theory and Applications. New York: Plenum.

BOHM, D. (1951). Quantum Theory. Englewood Cliffs (NJ): Prentice-Hall.

(1952). A Suggested Interpretation of the Quantum Theory in Terms of "Hidden" Variables. I. II. Physical Review 85: 166-79, 180-93.

(1957) Causality and Chance in Modern Physics. Londres: Routledge and Kegan-Paul.

BOHM, D. \& AHARONOV, Y. (1957). Discussion of Experimental Proof for the Paradox of Einstein, Rosen and Podolsky. Physical Review 108: 1070-76.

(1960). Further Discussion of Possible Experimental Tests for the Paradox of Einstein, Podolsky and Rosen. Nuovo Cimento 17: 964-76.

BOHR, N. (1935). Can Quantum-Mechanical Description of Physical Reality be Considered Complete? Physical Review 48: 693-702. (Recebido em 13/07/1935, e publicado em 15/08/1935.) Em português: (1981). A Descrição da Realidade Física Fornecida pela Mecânica Quântica pode ser Considerada Completa? Trad. C.W. Abramo. Cadernos de História e Filosofia da Ciência 2: 97-106.

(1949). Discussion with Einstein on Epistemological Problems in Atomic Physics. In: Schilpp, P.A. (org.). Albert Einstein: Philosopher-Scientist. Evanston (IL): Library of Living Philosophers, pp. 201-41. Em português: in Bohr (1995), Física Atômica e Conhecimento Humano. Rio de Janeiro: Contraponto, pp. 41-83.

BORN, M. (1971). The Born-Einstein Letters. New York: Macmillan. 
CHIBENI, S. S. (1997). Aspectos da Descrição Física da Realidade. Coleção CLE, vol. 21. Campinas: Centro de Lógica, Epistemologia e História da Ciência, Unicamp.

(2005). A Logico-Conceptual Analysis of the Einstein-Podolsky-Rosen Argument. In: Piettrocola, M. e Freire Jr., O. (orgs.), Filosofia, Ciência e História: Michel Paty e o Brasil, uma homenagem aos 40 anos de colaboração. São Paulo: Discurso Editorial, pp. 115-35.

(2014). At what points of the history of quantum mechanics has scientific realism faced a real threat (and for what reason)? Preprint fornecido pelo autor. A sair em español: ¿En qué puntos de la historia de la mecánica cuántica el realismo científico ha enfrentado amenazas reales (y por qué razones)? In Borge, B. \& Gentile, N. (orgs.). La ciencia y el mundo inobservable: discusiones contemporáneas en torno al realismo científico. Buenos Aires: Eudeba, 2018.

CLAUSER, J. F. \& HORNE, M. A. (1974) Experimental consequences of objective local theories. Physical Review Letters 23: 880-84.

DEUTETE, R \& GUY, R. (1991). Einstein and EPR. Philosophy of Science 58: 377397.

D'ESPAGNAT, B. (1979). The Quantum Theory and Reality. Scientific American 241 (nov.), pp. 158-181.

DIRAC, P.A.M. (1930). On the annihilation of electrons and protons. Proceedings Cambridge Philosophical Society 26: 361-375.

DUARTE, F.J. (2012). The Origin of Quantum Entanglement Experiments Based on Polarization Measurements. European Physical Journal H 37: 311-18.

EINSTEIN, A. (1949) Autobiographical Notes. In: SCHILPP, Paul A. (org.) Albert Einstein: Philosopher-Scientist. Evanston, IL: Library of Living Philosophers, p. 2-94. Em português: (1982) Notas Autobiográficas. Trad. A. S. Rodrigues. Rio de Janeiro: Nova Fronteira.

(2017) Como Vejo o Mundo. 23 ${ }^{\mathrm{a}}$ ed. Rio de Janeiro: Nova Fronteira.

EINSTEIN, A.; PODOLSKY, B. \& ROSEN, N. (1935). Can Quantum-Mechanical Description of Physical Reality be Considered Complete? Physical Review 47: 777-80. (Recebido em 25/03/1935, e publicado em 15/05/1935.) Em português: (1981). A Descrição da Realidade Física Fornecida pela Mecânica Quântica pode ser Considerada Completa? Trad. C.W. Abramo. Cadernos de História e Filosofia da Ciência 2: 90-96. Citado como EPR 1935.

FINE, A. (1996). The Shaky Game: Einstein, Realism and the Quantum Theory. $2^{\mathrm{a}}$ ed. Chicago: University of Chicago Press. 
FREIRE Jr., O. (2006). Philosophy enters the optics laboratory: Bell's theorem and its first experimental tests (1965-1982). Studies in the History and Philosophy of Modern Physics 37: 577-616.

FURRY, W.H. (1936a). Note on the Quantum-Mechanical Theory of Measuraments. Physical Review 49: 393-399.

(1936b). Remarks on Measurements in Quantum Theory. Physical Review 49: 476.

HANNA, R.C. (1948). Polarization of Annihilation Radiation. Nature 162: 332.

HEITLER, W. (1954). Quantum Theory of Radiation. Oxford: Oxford University Press.

KEMBLE, E. (1935). The Correlation of Wave Functions with the States of Physical Systems. Physical Review 47: 973.

McGRATH, J. H. (1978). A Formal Statement of the Einstein-Podolsky-Rosen Argument. International Journal of Theoretical Physics 17: 557-571.

JAMMER, M. (1974). The Philosophy of Quantum Mechanics. New York: Wiley.

LEHNER, C. (2011). O Realismo de Einstein e sua Crítica da Mecânica Quântica. In: O. Freire; O. Pessoa Jr.; J. L. Bromberg. (orgs.). Teoria Quântica. Estudos históricos e implicações culturais. Campina Grande-PB: Eduepb; São Paulo: Livraria da Física, pp. 181-228.

MARSHALL, T.W.; Santos, E. \& Selleri, F. (1983). Local realism has not been refuted by atomic cascade experiments. Physics Letters 98 A: 5-9.

PESSOA Jr., O. (2003). Conceitos de Física Quântica. Vol. 1. São Paulo: Livraria da Física.

— (2006). Conceitos de Física Quântica. Vol. 2. São Paulo: Livraria da Física.

(2014). O dilema de Bell: abandonar o realismo ou a localidade? Ciência Hoje 54 (n. 320, nov.): 60-61.

PRYCE, M.H.L. \& WARD, J.C. (1947). Angular Correlation Effects with Annihilation Radiation. Nature 4065: 435.

PRZIBRAM, K. (org.) (1967). Letters on Wave Mechanics. New York: Philosophical Library. Tradução de Martin J. Klein. Original: (1963). Briefe zur Wellenmechanik. Vienna: Springer.

REDHEAD, M. (1987). Incompleteness, Nonlocality, and Realism. New York: Oxford University Press.

SCHILPP, P. A. (org.) (1949). Albert Einstein: Philosopher-Scientist. Evanston (IL): Library of Living Philosophers. 
SCHRÖDINGER, E. (1935a). Discussion of Probability Relations between Separated Systems. Proceedings of the Cambridge Philosophical Society 31: 555-63.

(1935b). Die gegenwärtige Situation in der Quantenmechanik. Die Naturwissenschaften 23:807-812, 823-828, 844-849. Tradução em inglês: The Present Situation in Quantum Mechanics. A translation of Schrödinger's 'Cat Paradox Paper". In WHEELER \& ZUREK (1983), op.cit., pp. 152-67.

SNYDER, H.S.; PASTERNACK, S. \& HORNBOSTEL, J. (1948) Angular Correlation of Scattered Annihilation Radiation. Physical Review 73: 440-48.

WARD, J.C. (1949). Some Properties of the Elementary Particles. Ph.D. Thesis. Oxford: Oxford Univertiy.

WESSELS, L. (1981). The 'EPR' Argument: A Post-Mortem. Philosophical Studies 40: 3-30.

WHEELER, J.A. (1946). Polyelectrons. Annals of the New York Academy of Sciences 48: 219-238.

WHEELER, J.A. \& ZUREK, W.H. (orgs.) (1983). Quantum Theory and Measurement. Princeton: Princeton University Press.

WU, C.S. \& SHAKNOV, I. (1950). The Angular Correlation of Scattered Annihilation Radiation. Physical Review 77: 136. 